Florida International University FIU Digital Commons

2014

\title{
Predictors of Independent Living Outcomes Among Older Women Receiving Informal Care
}

Julie Grochowski

Florida International University, jgroc001@fiu.edu

DOI: $10.25148 /$ etd.FI14110765

Follow this and additional works at: https://digitalcommons.fiu.edu/etd

Part of the Social Work Commons

\section{Recommended Citation}

Grochowski, Julie, "Predictors of Independent Living Outcomes Among Older Women Receiving Informal Care" (2014). FIU Electronic Theses and Dissertations. 1685.

https://digitalcommons.fiu.edu/etd/1685 


\section{FLORIDA INTERNATIONAL UNIVERSITY}

Miami, Florida

\section{PREDICTORS OF INDEPENDENT LIVING OUTCOMES AMONG OLDER WOMEN RECEIVING INFORMAL CARE}

A dissertation submitted in partial fulfillment of the

requirements for the degree of

DOCTOR OF PHILOSOPHY

in

SOCIAL WELFARE

by

Julie Ann Grochowski 
To: Dean Michelle Ciccazzo

R. Stempel School of Public Health

This dissertation written by Julie Ann Grochowski, and entitled Predictors of Independent Living Outcomes Among Older Women Receiving Informal Care, having been approved in respect to style and intellectual content, is referred to you for judgment.

We have read this dissertation and recommend that it be approved.

Mark Macgowan

$\begin{array}{r}\text { Miriam Potocky } \\ \hline \text { Ellen Brown }\end{array}$

Barbara Thomlison, Major Professor

Date of Defense: November 13, 2014

The dissertation of Julie Ann Grochowski is approved.

Dean Michelle Ciccazzo

R. Stempel College of Public Health and Social Work

Dean Lakshmi N. Reddi

University Graduate School

Florida International University, 2014 
(C) Copyright 2014 by Julie Ann Grochowski

All rights reserved. 


\section{DEDICATION}

To my Babcia, as her independence and resilience inspired this dissertation study. 


\section{ACKNOWLEDGMENTS}

The completion of this dissertation would not have been possible without the support and guidance of several individuals. I am especially thankful to my advisor and chair, Dr. Barbara Thomlison for her mentorship and guidance throughout this experience in the doctoral program. I am also grateful to my supportive committee members, Dr. Miriam Potocky, Dr. Mark Macgowan and Dr. Ellen Brown, who have all shared their expertise with me, while providing ongoing encouragement. I would like to thank Dr. Mary Helen Hayden for her diligence to the School of Social Work as well as her confidence in my abilities and strengths.

I am appreciative of the time that I spent with Dr. Jiabin Zhu and Angeline Low of the statistical consulting department at FIU, especially for their patience and commitment in helping me with my data analysis. In addition, the expertise of my Spanish speaking research assistant, Yamely Gonzalez, was vital to the data collection and analysis of the qualitative findings for this study. The translations for the instruments and consent forms into Spanish from Michael Reimer and Erica Lara were fundamental to the Spanish data collection portion of this dissertation study.

I am thankful to the older women and informal caregivers who participated in this community-based research as they opened their homes, sharing their stories and lives with me. This experience has impacted me in a way that words cannot describe. I would also like to acknowledge the directors and case managers at the community agency sites who were invaluable to this dissertation as they were patient and understanding throughout the data collection process. 
This dissertation would not have been possible without the gracious financial support from FIU and the University Graduate School through the Dissertation Evidence Acquisition Fellowship. In addition, I would like to thank the School of Social Work at Rutgers University for providing me with a solid educational foundation in social work. I would especially like to recognize those at RU who encouraged me to continue my education with the doctoral degree: Jean Mahoney, Dr. DuWayne Battle and Sharea Farmer.

I would like to thank those who have inspired and challenged me to be the best that I can be, including, my peers in the Social Welfare doctoral program: Adi, Antoinette, Chrissy, Dr. Julieta, John, Natalia, and Sherry; my support network of doctoral students outside the school of social work: Carmen, Chaundra, Dr. Christi, Dr. Julia, Dr. Karl, Kimiko, Dr. LaToya, and Dr. Nicole; and my friends outside of academia: Jan \& Joe, Jennifer, John, Katie, Katura, Nikki and Sandra. Lastly, I would like to thank my mother who continues to demonstrate the importance of a strong work ethic through professional ambition and dedication. 


\section{ABSTRACT OF THE DISSERTATION \\ PREDICTORS OF INDEPENDENT LIVING OUTCOMES AMONG OLDER WOMEN RECEIVING INFORMAL CARE}

by

Julie Ann Grochowski

Florida International University, 2014

Miami, Florida

Professor Barbara Thomlison, Major Professor

This study examined the predictors of independent living outcomes among communityliving older women who received informal care. The central hypothesis was that older women's level of functioning is influenced by their relationship with their informal caregiver. The study attempted to understand the independence of older women through the perspective of both informal caregivers and the older women themselves. The following eight variables were measured: 1) the older women's independence (dependent variable); 2) the relationship between older women and their informal caregivers (independent variable); 3) roles of both the informal caregiver and older women (independent variable); 4) the older women's attitudes toward aging (independent variable); 5) the older women's age identity (independent variable); 6) the older women's health (control variable); 7) the older women's level of social support (control variable); and 8) the older women's level of depression (control variable). The variables were measured from the perspective of the older woman herself and her informal caregiver. This study used an ecological and developmental framework along with role theory to understand the interaction among the aforementioned variables through a cross-sectional design. The recruited older women participants of this study were receiving ongoing care 
and personal assistance from two large home care agencies located in Miami, FL. An analysis was conducted through a mixed-methods incorporated into the study design. The present study aimed to contribute to the understanding of how the relationship between older women and their informal caregivers influences older women's ability to maintain independent outcomes. The primary finding of this study was that there were both positive and negative experiences within the relationship dynamic of older women and their informal caregivers and that this relationship was either unidirectional or bidirectional. 


\section{TABLE OF CONTENTS}

CHAPTER

PAGE

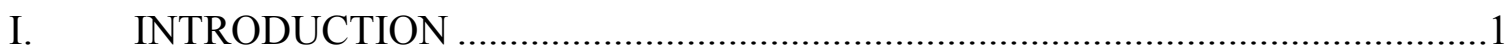

The Present Study …………………………………………………..5

Research Questions .............................................................................

Rationale for the Present Study.............................................................

Theoretical Foundation ...........................................................................

Ecological and Developmental Frameworks ................................10

Strengths Perspective .................................................................11

Role Theory …………………………………………….....11

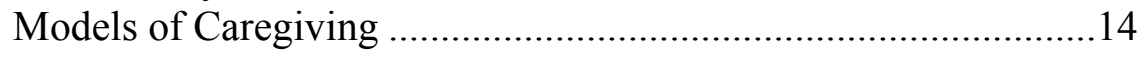

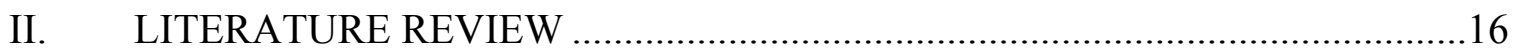

History of Systems of Care ....................................................................16

Home and Community-Based Services (HCBS) …………………….......18

Population Statistics..........................................................................19

Characteristics and Barriers for Older Women........................................22

Independence and Healthy Aging...........................................................24

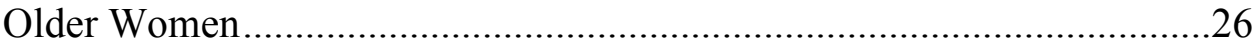

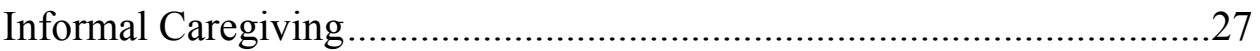

Age Identity and Attitudes Toward Aging...............................................29

Review of Relevant Definitions and Constructs .............................30

Older Women ................................................................ 31

Informal Caregivers .........................................................31

Independence (Dependent Variable)....................................32

Relationship between Older Women and their Informal

Caregivers (Independent Variable) ......................................33

Roles of Older Women and their Informal Caregivers

(Independent Variable) .........................................................35

Attitudes Toward Aging (Independent Variable) ................36

Age Identity (Independent Variable) ...................................36

Health (Control Variable) ....................................................38

Social Support (Control Variable) .......................................38

Depression (Control Variable) ..............................................39

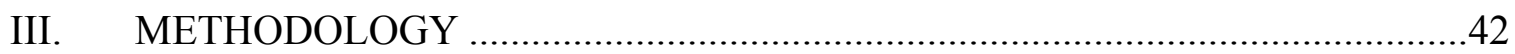

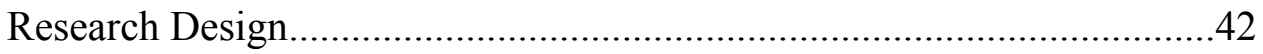

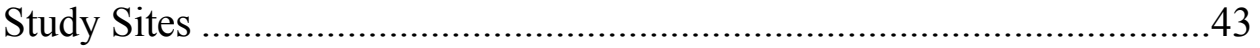

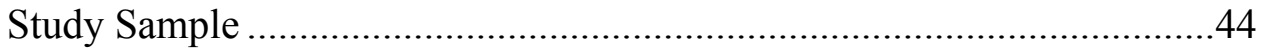

Rationale for a Smaller Study than Originally Intended.............................45

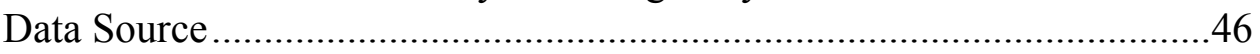

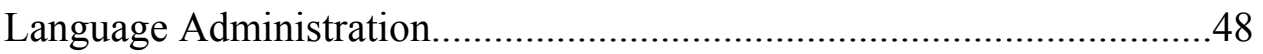

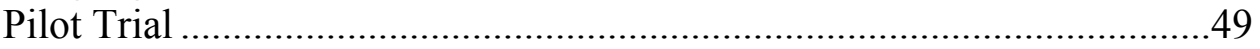




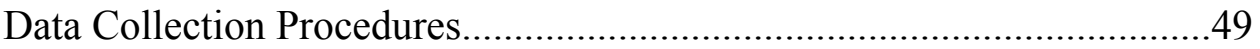

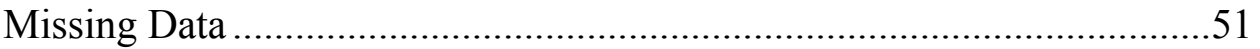

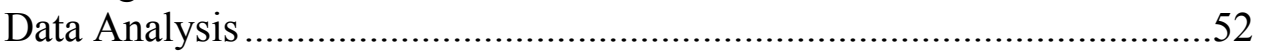

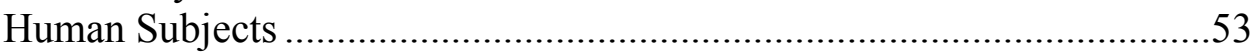

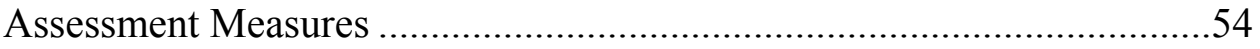

Quantitative Measures ................................................................54

Katz Index of Independence in Activities of Daily

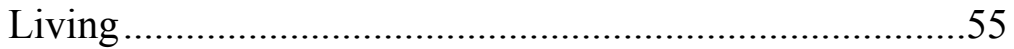

Lawton Instrumental Activities of Daily Living.................56

Attitude Toward Own Aging ..............................................57

Age Identity ...................................................................5

Dyadic Relationship Scale ................................................58

Short-Form 12 Version 2 Health Survey …………….........59

Abbreviated Duke Social Support Index .............................60

Patient Health Questionnaire .............................................61

Demographic Characteristics .............................................62

Qualitative Measures ...................................................................63

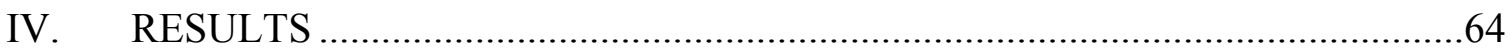

Demographic Characteristics ...................................................................64

Age

Educational Attainment ...............................................................64

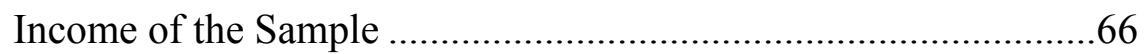

Ethnic/ Racial Characteristics and Place of Birth ...........................66

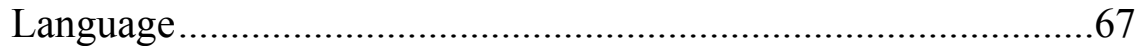

Religious Affiliation of the Sample ..............................................67

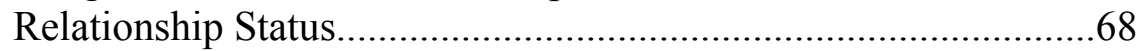

Caregiving Relationships ..............................................................68

Descriptive Findings for the Major Study Variables .................................69

Katz Index of Independence in Activities of Daily Living............69

Lawton Instrumental Activities of Daily Living.............................69

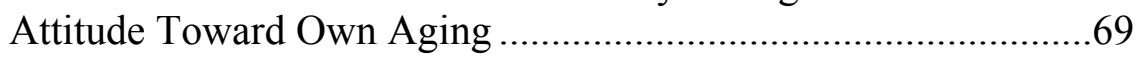

Age Identity ..............................................................................

Dyadic Relationship Scale .......................................................... 70

Short-form 12 Version 2 Health Survey ……………………..........71

Abbreviated Duke Social Support Index .....................................71

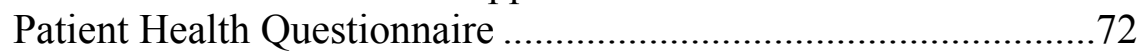

Research Questions and Hypothesis Testing ………………....................72

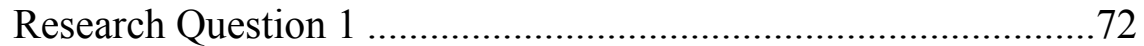

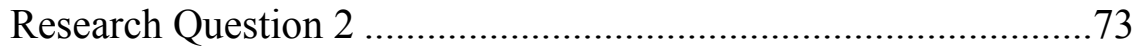

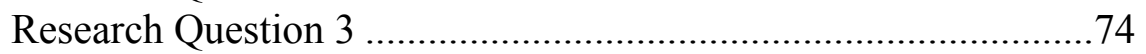

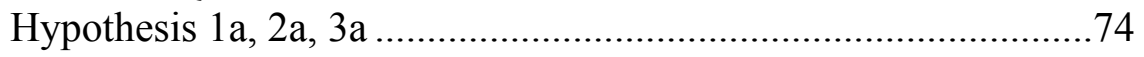

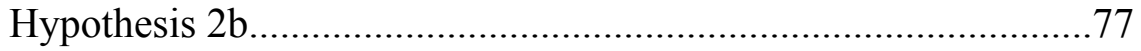

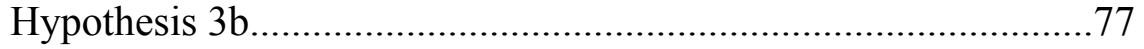


Qualitative Findings..............................................................................78

Theme I: Attitudes Towards Aging ..............................................78

Sub-Theme A: Does not feel old in comparison to others

Sub-Theme B: Accepted aging as a normal process in life .80

Sub-Theme C: Fears associated with getting older.............80

Sub-Theme D: Inspired by other adults with active lifestyles .82

Theme II: Opinions on Independence.............................................. 82

Sub-Theme E: Independence is being able to do tasks without assistance

Sub-Theme F: Perseverance .....

Theme III: The Caregiving Relationship ......................................83

Sub-Theme G: Responsibilities within the caregiving relationship.

Sub-Theme H: Roles within the caregiving relationship ...84

Sub-Theme I: Positive interactions within the caregiving relationship

Sub-Theme J: Negative interactions within the caregiving relationship

Theme IV: Family System .88

Sub-Theme K: Supportive Family System ……………......88

Sub-Theme L: Non-supportive Family System

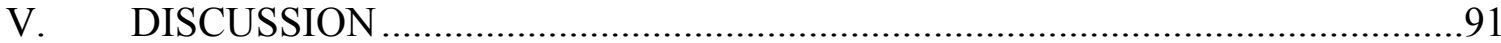

Dynamics within the Caregiving Relationship ......................................92

Implications for Social Work ...............................................................95

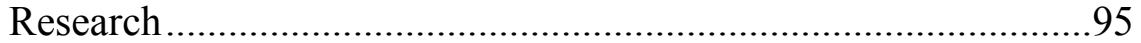

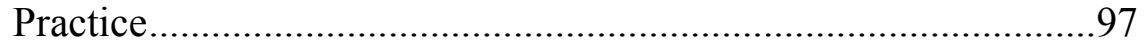

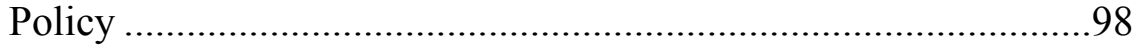

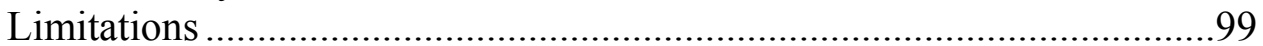

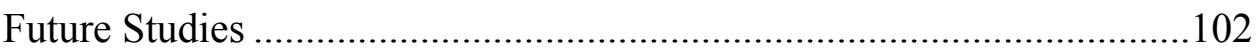

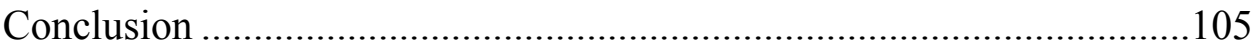

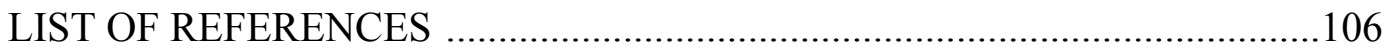

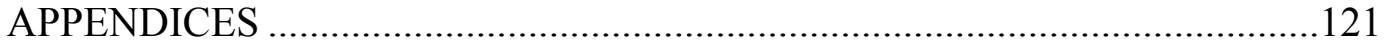

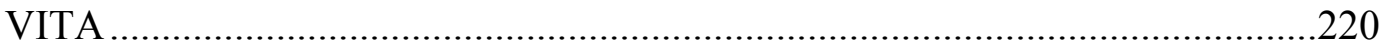




\section{CHAPTER I: INTRODUCTION}

As the U.S. baby boomer generation ages, it is expected that older women will continue to outnumber older men. Women have higher rates of survival at every age compared to men and are living longer. The 2010 census revealed that the proportion of men to women was 86 men for every 100 women between the ages of 65 and 74 , and for those aged 85 and over the ratio was 49 men to 100 women (Pirkl, 2009). Projections of the population suggest rapid increases in the number of older women in the United States. Currently there are 23 million older women (65+), and this is expected to increase to 48.6 million by 2050 (Population Division, U. S. Census Bureau, 2008). The population of the oldest-old is also expecting significant increases as there were an estimated 3.9 million women over the age of 85 in 2010 and by 2050 it is expected that there will be over 11.5 million (Population Division, U.S. Census Bureau, 2008). Furthermore, although the mortality gap between men and women has narrowed, there were almost twice as many women as men at age 89 according to the 2010 Census (Pirkl, 2009).

Greater longevity among women means that aging is disproportionately a female experience and may be especially difficult as "older women must often make psychological adjustments toward greater independence at a time when they are increasingly physically dependent and in need of support" (Gaylord, 2001, p. 52). According to the Department of Health and Human Services, women who live to age 65 can anticipate, on average, living to age 84 , while women who reach age 85 can expect to live, on average, 8 additional years (DHHS, 1999). Although women have an advantage in life expectancy compared to men, women are more susceptible to living with 
disabilities and chronic conditions for the remaining years of their life after age 65 (Tabloski, 2004). Longer life expectancy and lower mortality rates among women place them at greater risk than men for experiencing disability throughout older age. The duration of disability may be longer or more severe, not only because men tend to die earlier than women, but because they are not necessarily exposed to prolonged decreases in functioning (Leveille, Penninx, Melzer, Izmirlian, \& Guralnik, 2000). This phenomenon is called the "morbidity paradox" since women live longer than men, but tend to report poorer health than men (Verbrugge, 1989). However, there is not conclusive research to identify why there is a disparity between men and women.

Gender differences in function have been well documented in the literature (Crimmins, Kim, \& Sole-Auro, 2010; Gorman \& Read, 2006; Leveille et al., 2000; Merrill, Seeman, Kasl, \& Berkman, 1997; Salive \& Guralink, 1997; Verbrugge, 1989), as the prevalence of functional problems are greater in older women than older men (Newman \& Brach, 2001). Female disadvantage in health is considerable as women report $57 \%$ more functional limitations than men and this disadvantage increases in severity as women become older (Gorman \& Read, 2006). The World Health Organization defines a functional limitation as "any health problem that prevents a person from completing a range of tasks, whether simple or complex" (Farlex, 2011). Longitudinal data from the Established Populations for the Epidemiologic Studies of the Elderly (EPESE) revealed that prevalence of mobility disability (the inability to walk up/down stairs and walk a half mile without help) among individuals ages 65 to 95 was higher among women, as prevalence increased from $60 \%$ at age 65 to $90 \%$ at age 95 
compared to a rate of $14-74 \%$ for the same age range in men (Leveille et al., 2000).

Gorman \& Read (2006) found that an average of 4.07 functional limitations were reported among older women age 75 and older, compared to 2.90 among men of the same age. Furthermore, in a gender comparison of physical disability among age cohorts, women were found to be more likely to report functional limitations than men in eight categories (dressing/grooming, arising, eating, walking, hygiene, reaching, gripping and doing errands/chores) at an overall rate of $52 \%$ for women and $37 \%$ for men (Murtagh \& Hubert, 2004).

Chronic conditions, frailty, functional limitations and cognitive losses contribute to dependency in older women (Beeber, 2008). Chronic conditions increase as women get older and become a greater health risk compared to acute conditions (Nathanson \& Tirrito, 1998). Eighty percent of women 65 and older have at least one of the following chronic conditions: hypertension, diabetes, arthritis, heart disease or cancer (Collins \& Strumpf, 2000). Women are at a higher risk of experiencing degenerative and inflammatory arthritis compared to men, as women report these arthritic conditions more than twice as much (Young \& Cochrane, 2004). The presence of chronic conditions in older women does not necessarily indicate dependence or significant impairments in their level of functioning, but it can affect how individuals perform their activities of daily living (ADL) and instrumental activities of daily living (IADLs). ADLs refer to self-care activities, or the types of activities that people normally do for themselves every day including: personal hygiene, dressing, feeding oneself, transferring, ambulation, and voluntary bowel and bladder control (McDowell \& Newell, 1996). IADL's allow 
individuals to remain living independently within the community, such as housework, meal preparation, shopping, using the telephone, managing money, taking medications, transportation and using technology (Bookman, Harrington, Pass \& Reisner, 2007). Performing these types of daily activities is important for older women as routines and meaningful activities can increase levels of independence and well-being at their current stage, as well as at a later time in life (Oswald et al., 2007)

Significant changes in attitudes towards long term care supportive services have occurred within the last three decades. Service delivery for older women has shifted from traditional views of care in nursing facilities and institutions to the more consumerdriven approaches of home and community-based services. The shift in services for older women focuses on home care which provides individuals with the freedom and ability to make their own decisions on a daily basis (Kropf, Schneider, \& Stahlman, 1993). There is a great need to provide care to older women through both informal and formal caregiving; however, the current direct care (paid and unpaid) workforce is expected to be insufficient to meet the demands of the rapidly increasing aging population (SimonRusinowitz, Loughlin, Ruben \& Mahoney, 2010).

The ability to remain self-sufficient, rather than be a burden is an important aspect in the identity of older women, influencing their feelings of worth and purpose. It can be argued that all individuals are interdependent to some extent, as relationships and the ability to rely on others is crucial for survival (Thomas, 2007). Biddle (2008) defines interdependence as "a shared dependence or the action of being joined together with a common bond; an individual's offering and receiving love, admiration, and value" (p. 
21). Informal caregivers may believe that they know what is best for older women, making assumptions regarding their capacities based on their age, without understanding that they are individuals, and not necessarily fitting into aging stereotypes. For informal caregivers who provide assistance to older women, there is a fine line between having concern for their loved one and being overprotective by not letting them do things for themselves. Providing assistance and care to an aging adult can be overwhelming, daunting and challenging. When older women experience declines in their functioning, informal caregivers may feel pity towards them, and may become fearful of the possibility that more significant declines will occur in the future. As a result, the informal caregivers may feel that it is their responsibility to protect and prevent older women from further decline. Allowing older women to perform daily activities to the extent of their abilities is critical as routines and meaningful activities increase levels of independence and well-being at their current stage, as well as at later times in their life (Oswald et al., 2007).

\section{The Present Study}

The present study examined the predictors of independent living outcomes among older women living within the community and receiving informal care. The central hypothesis was that older women's level of functioning is influenced by their relationship with informal caregivers. The present study aimed to understand the independence of older women through the perspective of both informal caregivers and the older women themselves by using a cross-sectional design, incorporating both quantitative and qualitative methods. A mixed-methods approach allowed the variables in the study to be 
examined from different design standpoints. A key purpose of this study was to explore the relationship between older women and their informal caregivers to examine how these relationships inform us about independence, rather than dependency among older women living in the community. The primary aims of this study were (a) to examine the relationship between older women and their informal caregivers and (b) to examine whether this relationship is a predictor of an older women's ability to maintain independent outcomes.

\section{Research Questions}

The research questions used for this study were intended to evaluate whether and in what ways informal caregivers influence older women's ability to live independently. This study examined independence through the following independent variables: 1) relationship between older women and their informal caregivers, 2) the roles of both the informal caregiver and older women, 3) attitudes toward aging, and 4) age identity. Health, social support and depression were measured as control variables in this study. The following research questions were proposed:

Question 1: How do older women experience the relationship with their informal caregivers and what is the quality of this relationship?

Question 2: How does age identity influence independence among older women and what factors in the caregiving relationship influence an older women's age identity?

Question 3: What are the attitudes towards aging among older women and what are 
informal caregivers attitudes towards the older women's aging?

Hypothesis 1a, 2a, 3a: Controlling for health status, social support, depression, and all other independent variables in the model, older women who experience lower levels of dyadic strain and greater levels of positive dyadic interaction, who have age identities lower than their chronological age, and who have greater positive attitudes toward aging have higher levels of independence.

Hypothesis $2 \mathrm{~b}$ : Informal caregivers' perspective of older women's age identity has a larger disparity than the older women's own age identity.

Hypothesis $3 \mathrm{~b}$ : Older women have more positive attitudes towards aging compared to the perspective of their informal caregivers.

\section{Rationale for the Present Study}

There are few studies that aim to understand the interaction in the relationship between older women and their informal caregivers, so this study serves as a much needed body of research on this topic. A key reason that older women are an understudied population is because of their dispersive nature within the community, making them difficult to access and interview (Li \& Conwell, 2007). Researchers studying older women in a non-institutionalized setting face barriers in identifying, locating and connecting with potential participants in the community. In addition, the caregiving relationship involves two people, the caregiver and the care recipient, yet the 
literature on caregiving generally views the exchange between the caregiver and care recipient as unidirectional, rather than bidirectional or reciprocal (Lingler, Sherwood, Crighton, Song \& Happ, 2008). Gerontology research has focused on the burdens and stresses associated with caregiving, with less emphasis on the experience of caregiving from the viewpoint of older women as the care recipients. Understanding the perspectives of both the caregiver and care recipient allows the relationship to be seen holistically, as a dynamic and interactive process (Lyons \& Sayer, 2005). Moreover, conducting this research study in Miami-Dade County Florida contributes to the gerontology literature because the Latino populations residing in this metro area have not been extensively studied in the United States. Research has focused more on Latinos from Mexico and Puerto Rico, with less attention on the Latino populations that are more prevalent in Miami-Dade County, which are primarily Latinos from South and Central America and Cuban-Americans. Older women are racially diverse, as one in every six women over age 65 is a minority, identifying as African American, Hispanic, Native American or Asian American/Pacific Islander (Elderly women, 2011). Women from various ethnic, racial and economic backgrounds may have fewer opportunities to access resources and information for long-term care services due to factors including discrimination, level of education, geographic location or type of insurance coverage (Konetzka \& Werner, 2009).

\section{Theoretical Foundation}

For this study, living at home in a familiar environment is best conceptualized utilizing ecological and developmental frameworks, strengths perspective, role theory as 
well as models of caregiving. Studying ecological and developmental constructs aids in identifying long and short-term risk factors, as late life development processes play a role in living independently and safely in the community while maintaining a sense of wellbeing and healthy aging. The present study incorporates the strengths-perspective to examine the relationship between older women and their informal caregivers, focusing on positive, rather than negative aspects (Chapin, Nelson-Becker, \& MacMillan, 2006). Applying role theory to study the relationship between older women and their informal caregivers allowed the researcher to 1) address gaps in knowledge about this relationship; 2) contribute to understanding the varying levels of interdependency; and 3) gauge the influence caregiver-care recipient relationships have on the independence of older women. The interaction between caregivers and care-recipients is complex, involving both positive and negative effects. There are varying conceptual models to understand caregiving dynamics between older women and their informal caregivers in this study.

Caregiving can be studied as either a unidimensional/unidirectional or bidimensional/bidirectional process, specifically with static caregiving outcome models and dynamic caregiving outcome models (Kahana \& Young, 1990). This study examined the theoretical constructs associated with independent living, aging, and relationships to offer guidance for program and policy planners seeking to reduce risk factors while promoting protective factors for community-dwelling older women. Developing an understanding of older women's ability to live independently in light of these theories can augment the knowledge base in social work and gerontological literature while also 
facilitating the development of policy initiatives, interventions, and societal changes at the micro and macro levels.

\section{Ecological and Developmental Frameworks}

There are complex theoretical relationships involved that can be attributed to ageing and independence. This study utilized both ecological and developmental frameworks as a basis for examining the research questions. Ecological and developmental frameworks illustrate the dynamic interplay of environment, life situations and social conditions on development (Coady \& Lehmann, 2001). This perspective focuses on concepts such as: the needs of the individual, biology and people's physical bodies; individuals capacities for creativity and choice; individual beliefs (sustaining and constraining); one's values, spirituality, strengths and competencies; as well as the needs, demands and availability of resources within the environment (Rothery, 2008). Establishing a "goodness of fit" between individuals and their environments allows for reciprocity, interdependence and adaptation of the biological, psychological, social and cultural aspects of the relationship (Robbins, Chatterjee \& Canda, 2006). Maintaining a good fit between living systems and the environment occurs when there is adaptability and limited stress from life transitions, environmental pressures or interpersonal processes (Germain \& Gitterman, 1980). Life transitions include developmental changes, changes in status or role and the restructuring of life space (Payne, 1997). Furthermore, promoting the well-being of older women living independently within the community is influenced by planned social change and economic development. 


\section{Strengths Perspective}

The strengths perspective views individuals as unique, where each person has their own set of characteristics, skills, motivation and capacities that enable them to effectively help themselves and overcome challenges (Sheafor \& Horejsi, 2003). This paradigm shift in thinking encourages individuals to be seen positively and as possessing strengths, rather than being viewed negatively based on their limitations, problems or diagnoses (Schriver, 2001; Sheafor \& Horejsi, 2003). This perspective presumes that all people have the capacity to change and improve their lives if they receive positive support and are optimistic about their situation (Greene, 2000). In addition, the strengths perspective focuses on what an individual has done or knows, the resources they have access to, as well as their own dreams and inspirations. This perspective focuses on promoting individual strengths, rather than placing emphasis on diseases, pathology, problems, weaknesses and deficits. Empowerment strategies and strengths-based perspectives can improve an individual's well-being by focusing on creating positive changes and addressing problems in their lives. The present study incorporated the strengths-perspective to examine the relationship between older women and their informal caregivers by focusing on positive, rather than negative aspects (Chapin, Nelson-Becker, \& MacMillan, 2006)

\section{Role Theory}

Role theory proposes that interactions with others are influenced by one's expectations and reactions, and that these expectations and reactions cause others to respond in certain ways (Payne, 1997). Role is defined by Thomas \& Biddle (1966) as "a 
set of standards, descriptions, norms, or concepts held (by anyone) for the behaviors of a person or a position" (p. 11-12). Kimberley \& Osmond (2011) state that the concept of role "implies a societally determined set of social expectations, associated with the boundaries of status and identity and patterns of conduct internalized in social interaction, and undertaken or placed on, the person by himself or herself, by significant others, and/or by the community or society" (p. 415). Roles within the context of a relationship are important to consider as Payne (1997) describes, "roles create our identity as others see it. Because of the way others react to us, roles as others see them build up our own concept of our identity" (p. 160). Ecological and developmental frameworks guide role theory, as roles change throughout the life course and are influenced by social determinates of human behavior and human interactions (Davis, 1996; Germain \& Gitterman, 1980). Roles are also influenced by social status (prestige, wealth and authority), ascribed dispositions (characteristics present at birth), and achieved positions (attained through skill or work) (Davis, 1996). Behavior and personality are influenced by the type of roles an individual assumes (ie. work, family and parental), as well as the social structures and relationships that they interact in.

Issues associated with role theory include: role conflict, role strain, role ambiguity and role entrance and exit (Robbins et al., 2006). According to role theory, psychological distress within relationships is caused by role conflict, where role expectations and role performance are incompatible with each other, causing interpersonal and intrapersonal stress (Davis, 1996). Role expectations are the set of standards held for the behaviors of a person (Davis, 1996; Thomas \& Biddle, 1966). Role expectations can be distinguished 
into three types: 1) individual versus shared expectations; 2) personal versus positional expectations; and 3) expectations for self versus expectations for others (Biddle,1979). Conflicts can develop between older women and their informal caregivers as emotional and physical demands influence the level of congruence within the relationship. Conflicts can be due to differences in perceptions, assessments or beliefs about the prioritization of needs and the feasibility of approaches to meet those needs (Horowitz, Goodman \& Reinhardt, 2004). Findings from Lyons et al. (2002) suggest that the level of strain on the caregiving relationship increases when there is more difficulty in providing care or greater discrepancy over the perceived needs of the care recipient.

Socialization and developmental aspects throughout the life span can influence an individual's role expectations of their self and others (Robbins et al., 2006). Roles are influenced by internalized societal values and cultural conformity. (Davis, 1996). The interplay of societal expectations and psychological adaptations throughout the life span influences an individual's role performance (Greene \& Cohen, 2008). Maintaining meaningful role performance enhances well-being in older age (Bowling, 2005). Since role theory is not pathology-oriented, problems within the caregiving relationship can be assessed by understanding the conditions that are affecting an individual's desired role behaviors and the role conflicts that contribute to intra- and inter-personal stress (Davis, 1996). Specific to this study, role theory can assist in exploring the types of roles that older women and their informal caregivers have within and across the relationship and can focus on conceptions, misunderstandings and incongruence between the respective 
role expectations and expressed experiences of older women and their caregiver in the relationship.

\section{Models of Caregiving}

The interaction between caregivers and care-recipients is complex, involving both positive and negative effects. There are varying conceptual models to understand caregiving dynamics between older women and their informal caregivers. The caregiving models discussed in this section are relevant to the present study and were used in the interpretation of the qualitative data from the interviews with older women and their informal caregivers. Caregiving can be studied as either a unidimensional/unidirectional or bidimensional/bidirectional process, specifically with static caregiving outcome models and dynamic caregiving outcome models (Kahana \& Young, 1990). The theoretical frameworks identified by Kahana \& Young (1990) include the following:

a) Caregiver-centered one-directional model. This model focuses on the adverse psychosocial outcomes and subjective burdens that result from the stress and commitments (time and energy) of caregiving.

b) Care-recipient-centered one-directional model. This model suggests that caregiving impacts the care-recipient's satisfaction as well as their physical and emotional well-being.

c) Caregiver-centered bidirectional model. This model provides a more comprehensive view of the caregiving relationship, revealing that there is the potential for positive uplifts as well as negative burdens within the dynamic. The focus of this model is on the care-recipient's needs. 
d) Care-recipient-centered bidirectional model. This model suggests that caregivers exert both positive (supportive) and negative (stressful) influences on carerecipients. Because of this interaction, the net benefit derived by care recipients is assumed to be minimal. The focus of this model is on the behaviors of the caregiver.

e) Symmetrical model of caregiver/care-recipient outcomes. This model considers the simultaneous outcomes for caregivers and care-recipients but does not specifically consider interactions and feedback within the relationship.

f) Contingency model of caregiver/care-recipient interactions and outcomes. This model views the caregiver's behavior as a stimulus, causing a reactionary behavior in the care-recipient. However, this model does not consider the impact that care-recipient dependency may have on the behavior of the caregiver.

g) Feedback model of caregiver/care-recipient interactions and outcomes. This model suggests that the needs of the care-recipient may activate the cycle of caregiving. Caregivers engage in dependency-inducing behaviors as they begin to do more for the care-recipient, which may reinforce learned helplessness in the care-recipient. The learned helplessness may reinforce the dependency inducing behaviors of the caregiver, thus causing the cycle of caregiving to continue.

h) Congruence model of caregiver/care-recipient interactions and outcomes. This model focuses on the match or mismatch between the needs of the care-recipient and the caregiver's responses to those needs. Positive outcomes are a result of a good-fit or match between care-recipient needs and caregiver responses to needs and negative outcomes are the result of an imbalance or mismatch. 


\section{CHAPTER II: LITERATURE REVIEW}

\section{History of Systems of Care}

The long-term care system in the United States is continually evolving with the aging of the population, as older women are experiencing more freedom and choice in deciding the types of care they want to receive. There are five major types of long-term care services: adult day services, assisted living facilities, residential care communities, home health agencies and hospice care. Long-term care is defined by the U. S. government as,

"a variety of services that includes medical and non-medical care to people who have a chronic illness or disability. Long-term care helps meet health or personal needs. Most long-term care is to assist people with support services such as activities of daily living like dressing, bathing, and using the bathroom. Longterm care can be provided at home, in the community, in assisted living or in nursing homes." (Long-Term Care, 2009)

Long-term care services have evolved throughout the past 100 years. Findings from the 1995 National Nursing Home Survey (NNHS) found that between 1985 and 1995 there was an 8.2 percent decline in nursing home residents age 65 and older. Models of assisted living began being developed and operated in the 1980's following a paradigm shift away from nursing home settings. This shift, which occurred from 1979 to 1985 , was influenced by dissatisfaction with nursing homes, as well as optimism regarding 
residential environments, level of service, and philosophies of consumer-directed care (Wilson, 2007).

The greater economic stability of older adults has increased the proportion of older adults living independently, while also providing more options in choosing where they desire to "age in place" (Himes \& Fang, 2007). Aging in place is defined as an individuals' ability to continue living where they have lived for many years, specifically in a non-healthcare environment, where adaptations and services can be utilize to ensure that the individual can remain at home (Senior Resource Center, 2010).

As admissions at nursing home and assisted living facilities have decreased, there has been a greater need for community and home-based services to provide long-term care for older adults. Support services for older women occur on a continuum of restrictiveness. Institutional care is the most restrictive and includes any facility that provides 24 hours residential services such as skilled nursing homes, intermediate care facilities, group homes and retirement villages that provide life care and services. Moderately restrictive support services are various sites around the community including hospice, respite care, adult day care, community mental health centers and senior citizen centers. In-home services are the least restrictive type of support services for older women, as visiting nurses, home health aides, chore services and meal delivery are provided within the home. Home care consists of formal (paid) and informal (unpaid) caregiving. 


\section{Home and Community-Based Services (HCBS)}

In 2012, approximately one-third of long-term care services were provided in home and community-based settings (Harris-Kojetin, Sengupta, Park-Lee \& Valverde, 2013). Home and community-based services include adult day services, home health agencies and hospice. Adult day services offer a variety of services to older adults in the community through a group setting which provides social activities, meals and snacks, personal care assistance, therapeutic activities, while also providing respite for caregivers (NADSA, 2014). Home health agencies provide health care services within the home of the individual, similar to the skilled nursing care that is provided within the hospital or in a nursing home (Department of Health and Human Services, 2014). Hospice provides pain management with medical care to individuals facing a terminal illness. In 2012, adult day services accounted for $8.2 \%$ of all long-term care services, while home health agencies accounted for $20.9 \%$ and hospices at $6.3 \%$ of total services (Harris-Kojetin et al., 2013). Long-term care services provided in institutions are generally more expensive than home and community-based services. Costs for home care in the community are about $\$ 22,000$ per year, a substantial decrease in expenditures per individual (SimonRusinowitz, Loughlin, Ruben, \& Mahoney, 2010) compared to the cost of living in a nursing home generally ranging from about $\$ 61,000$ to $\$ 70,000$ per year (Metlife, 2004). Costs of home care are greatly influenced by the role of informal and unpaid caregivers whose services are economically valued at over $\$ 300$ billion per year (AARP Public Policy Institute, 2008; Inglehart, 2010). 
Data from the 2013 Overview of Long-term Care Services in the United States found that skilled nursing care was provided in every home health agency, while $96.6 \%$ provided therapeutic services. Social work services was provided less often, only in $82.3 \%$ of the home health agencies (Harris-Kojetin et al, 2013). Furthermore, nearly all of the agencies (99.8\%) had some type of registered nurse as a full-time employee, while only $44.9 \%$ of home health agencies had employed a full-time social worker (HarrisKojetin et al., 2013). A large portion of the home health agencies in the United States are located in the Southern region of the country, encompassing nearly half of the agencies (48.3\%), while the Midwest had $27.3 \%$ of the total home health agencies, followed by the West at $16.4 \%$ and the Northeast at $8.0 \%$ (Harris-Kojetin et al., 2013).

\section{Population Statistics}

In the United States the total female population age 65 and older has been estimated to be $23,006,675$ or $7.4 \%$ of the total population (U.S. Census Bureau, 2010). According to the National Nursing Home Survey conducted in 2004, there were $1,061,700$ women nursing home residents in the nation's 16,100 facilities (National Nursing, 2004). The majority of residents (70.6\%) in nursing facilities/skilled nursing facilities are women, as there were 888,060 women over the age of 65 living in these facilities in 2010 (U.S. Census Bureau, 2010). Seventy-four percent of assisted living residents are older women (Stringfello, 2011).

A large portion (97.8\%) of the older female population (age 65 and older) does not reside in group quarters numbering 22,504,440 (U.S. Census Bureau, 2010). Group quarters are defined as "places where people live or stay, in a group living arrangement 
that is owned or managed by an entity or organization providing housing and/or services for the residents" (American Community Survey, 2010; p. 8). According to the 2013 Overview on Long-Term Care Services in the United States, there were over 12,200 home health agencies in the United States and in 2011, there was an estimated 4,742,500 individuals receiving services from home health agencies (Harris-Kojetin, 2013). Among those receiving services from home health agencies, the majority (62.7\% of all users) were women (Harris-Kojetin et al., 2013). Data collected from the National Home and Hospice Care Survey found that $68.7 \%$ of home health care patients are aged 65 or older, while women account for $64 \%$ of home health care patients (Caffrey, Sengupta, Moss, Harris-Kojetin \& Valverde, 2011). In 2010, there were 7,823,965 (34.0\%) women aged 65 or older living alone in their household (U.S. Census Bureau, 2010). "A household includes all the people who occupy a housing unit. People not living in households are classified as living in group quarters" (American Community Survey, 2010; p. 73).

The 2010 American Community Survey reported the levels of self-care difficulty and independent living difficulty among noninstitutionalized older women. Self- care difficulty is defined as having difficulty in the two specific activities of daily living (ADL) of dressing and bathing. Independent living difficulty refers to difficulties with instrumental activities of daily living (IADL), specifically, "doing errands alone such as visiting a doctor's office or shopping" (American Community Survey, 2010 p. 58). For women aged 65 to 75 years, 569,831 (4.9\%) have a self-care difficulty and 1,084,330 (9.3\%) have an independent living difficulty (U.S. Census Bureau, 2010). Self-care difficulties are prevalent in 1,655,677 (15.7\%) women who are 75 years of age and older, 
while 3,216,793 (30.5\%) of women in this age range have independent living difficulties (U.S. Census Bureau, 2010).

\section{Characteristics and Barriers for Older Women}

Women's experiences, needs and expectations regarding healthcare are different from men's as a result of their gender, society and culture. Older women experience aging differently than men, as women encounter barriers associated with gender discrimination in addition to age discrimination. Morris (1993) explains, "Women experience particular disadvantages and powerlessness as a result of the structures of oppression associated with both gender and disability" ( $\mathrm{p}$ 92). Gender stereotypes based on physical characteristics typically define men as being strong and powerful, while women are seen as being the softer, gentler sex. The difference in physicality, height and muscle generally attributes to the roles and expectations of men to be protectors, providers and to be concerned for the safety of women, who are seen as more fragile and less able to defend themselves against danger. This assumption suggests that women are physically weaker, dependent on the security of men and to some extent, helpless.

Research conducted by Bayliss, et al. (2003) found various barriers to self-care for older women with chronic conditions, including a need for social and emotional support, lack of knowledge about their conditions, low self-efficacy and physical limitations. Women experience five major gender-associated disadvantages, which are important predictors of health outcomes. The following were identified as gender disadvantages by): (a) women generally require more care in later life than men and have a greater need for health resources, (b) women have a higher rate of widowhood, (c) older 
women have lower material resources generally caused by gender inequality in employment compensation and pensions (d) women have a greater likelihood of selfdisclosing negative feelings and (e) women are less valued by society as they age, while men may gain social prestige as they get older (Pinquart \& Sorensen, 2001).

Furthermore, older women are often viewed as inferior and may be considered less intelligent and less rational as well as incapable of making their own decisions. Older women who have limitations in their functioning experience oppression, disadvantages and a loss of power, emphasized by Morris (1999): “A key part of being a woman in our society is dependency and passivity, yet this, too, is a key part of the social experience of physical impairment" (p. 88).

Older women with some degree of dependency are often viewed as a drain on society rather than being able to contribute to the greater good (Thomas, 2007). This is a misconception as the costs associated with assisted living and hospitalization eclipse the cost of informal caregiving and may also contribute to psychosocial problems for older women. Furthermore, nearly $40 \%$ of older women are financially vulnerable as they are more likely to be widowed or living alone and struggling in poverty compared to only 16\% of older men (Holland, 2008; Tabloski, 2004, Weitz \& Estes, 2001). Women account for nearly $75 \%$ of all older adults with incomes below the poverty level (ElderIssues, 2011). In addition, women age 65 and older who live alone are at a significantly higher risk of having a lower SES compared to men of the same age, with a poverty rate of $19.9 \%$ compared with $11.8 \%$ among men (Federal Interagency Forum on Aging-Related Statistics, 2010). Lower SES among older women is associated with a 
higher incidence of chronic diseases and disabilities, with this relationship increasing as older women age (Olson, 2003).

Women who live alone are vulnerable and could experience social isolation, unmet healthcare needs, poor nutrition and loneliness, and are more susceptible to being institutionalized and placed in nursing homes (Adams, 2006). Older women are three times more like than older men to be living alone or widowed and women are also twice as likely to reside in a nursing home (ElderIssues, 2011). Reports show that older women have more feelings of loneliness than men, with the risk of loneliness higher among women who are widowed or live alone (Pinquart \& Sorensen, 2001). Loneliness significantly contributes to the prediction of chronic conditions and perceived health among adults age 69 and older (Bailis \& Chipperfield, 2002). Furthermore, research found that social loneliness is associated with a lower satisfaction with the aging process, as well as an increase in the gap between individuals' actual age and their own age identity (Kleinspehn-Ammerlahn, Kotter-Gruhn, \& Smith, 2008). A social support system of family and friends who are reliable and supportive is beneficial to individuals who live alone as it moderates the effects of stressful situations and reduces feelings of loneliness (McInnis-Dittrich, 2005).

Older women who are at least 65 years of age and living alone are among the two poorest groups in the United States, along with single mothers (Doress-Worters \& Siegal, 1994). Race influences poverty levels among older women, with unmarried African American women are two times as likely to experience poverty compared to white women (Holland, 2008). For older women living alone, being a minority puts them at 
greater risk of experiencing financial hardship, as three out of five African-American women and two out of five Latinas live in poverty (ElderIssues, 2011). Higher poverty rates among women may be due to lower rates of employment throughout their lifetimes, lower wages and smaller pension incomes (Price \& Ginn, 2003) as well as cumulative disadvantages related to education levels and women's roles as wives and homemakers (Adams, 2006). In addition, marital disruptions leave older women vulnerable to financial difficulties, especially if they were dependent on their husbands for support. The death of a husband can be detrimental to the financial security of an older woman and can lead to poverty, as more than half of poor elderly widows were not living in poverty while their husbands were alive (ElderIssues, 2011). McInnis-Dittrich, (2005) explains, “... women often are forced to survive on more limited incomes than men. Chronic financial stress and its effect on adequate health care and living conditions are sources of constant and destructive stress" (p. 118). In addition, older women experience barriers in accessing preventive health care services as two thirds of older women are unable to access such services due to cost, believing they don't need the service, or are unable to be referred by their physician (ElderIssues, 2011).

\section{Independence and Healthy Aging}

The concept of independence, or the capacity for older women to live independently and safely in their community, is an important priority in maintaining a sense of well-being and healthy aging. Bowling (2005) describes independence as "acting for oneself" and having the "freedom from control in physical functioning and/or the ability to organize one's day-to-day life" $(p, 189)$. Factors that influence 
independence are different for each individual and relate to physical health status, the type of home environment the older women are currently living in, and level of supportive services received. The idea of health and wellness is an important factor for the aging population as it incorporates health behaviors, social contributions and access to health care (Putnam \& Stark, 2006). Healthy aging is defined as, "the development and maintenance of optimal mental, social and physical well-being and function in older adults. This is more likely to be achieved when communities are safe, promote health and well-being, and use health services and community programs to prevent or minimize disease" (Joint Rural Health, 2006, pg 1).

Healthy aging encompasses interrelated aspects of health to address the physical, emotional and social needs of older women and how these aspects directly influence their level of independence (Oswald et al., 2007). A main component of healthy aging is the ability for older women to continue to live the way they want and participate in the activities they enjoy, both within their homes and in the communities (Putnam \& Stark, 2006). Healthy aging consists of five determinants, or factors that contribute to an individual's current state of health including: biological and genetic, behavioral, social environment, physical environment, and health services (Social Determinants, 2011). This proposal aims to explore the social environment determinant of healthy aging by seeking to understand how the relationship between older women and their informal caregivers influences independence in older women.

The familiarity and comfort of home, as well as being integrated in the community are important environmental determinants of healthy aging and independent 
living. Remaining at home provides older women with a sense of freedom, independence, safety, and security as well as the ability to be integrated in their community while having close proximity to their established social supports (Senior Resource Center, 2010). The desire to remain living at home is a concept known as aging in place, which is defined by the Centers for Disease Control (CDC) as "the ability to live in one's own home and community safely, independently, and comfortable, regardless of age, income, or ability level" (Healthy Places, 2010). Research indicates that sentimental and emotional attachments to an individual's home environment encourage feelings of increased satisfaction and fulfillment, as women generally desire to continue to live at home rather than be placed in a nursing home (Aberg, Sidenvall, Hepworth, O'Reilly \& Lithell, 2004). The proximity of being close to family, friends and other social activities is also an important aspect of maintaining independence (Senior Resource Center, 2010). Age-friendly communities encourage social environments that are inclusive and engage individuals in a role where they can define their own needs (Lui, Everingham, Warburton, Cuthill \& Bartlett, 2009). Older women who are involved in social activities and engage outside their home environment are more likely to achieve health aging. For older women to maintain independence and healthy aging, this may entail having an informal caregiver to provide assistance with daily activities and tasks.

\section{Older Women}

Older women's ability to remain living independently at home is related to their health and wellness, functional abilities, their home environment and the level of assistance they have access to or are currently receiving. Examining the effect of social, 
cultural, gender, and aging stereotypes on older women is crucial to holistically understand how aging is influenced by context. Factors that have a significant influence on older women's functional status include physical and psychosocial health, social support and home environment (Pearson, 2000).

Allowing women the freedom to decide on the type of care they desire encourages independence and dignity, while also influencing perceptions of older women and their capacity to continue to live independently in their homes and communities, rather than assuming that nursing home care is the only option for the aging population (Rose et al., 2010). Older women who view themselves as dependent or helpless in their situation experience threats to their sense of self and this might be more worrisome than their fears of getting older or nearing death (Lustbader, 1993). Older women needing assistance may have differing responses to receiving help, either accepting or rejecting the support. Older women may be hesitant to accept help, as they do not want to become dependent upon another person. In addition, older women may find that asking for help is difficult, as their pride, dignity and self-esteem are susceptible when they are dependent upon informal caregivers for certain activities or tasks. Enabling older women to discover and build on their strengths creates a sense of hope, personal satisfaction and self reliance, while also acknowledging that they have the power to learn, grow and make their own decisions with their lives (Chapin et al., 2006).

\section{Informal Caregiving}

Research suggests that women prefer to remain living independently within their homes as long as possible, with institutionalization viewed as a last resort (Eckert, 
Morgan \& Swamy, 2004; Howes, 2007; Kelly, Knox \& Gekoski, 1998; Magasi \& Hammel, 2009). In addition, rising health care costs pose a financial hardship on older women, making reliance on informal caregivers' assistance vital to maintaining independence within their homes, as uncompensated care reduces the financial burden for older women. Informal caregivers are generally family members, friends and neighbors who provide assistance for various types of activities and tasks to help older women remain living as independently as possible within their homes. Informal caregivers are different than formal or paid caregivers because their motivation to help is based on feelings of affection, love, loyalty and obligation toward the women receiving care rather than being based on a trained knowledge or skill (Aberg et al., 2004).

Arno et al. (1999) estimates the prevalence of informal caregivers in the United States to be at least 25 million, with these caregivers providing an average of 17.9 hours per week of assistance to older adults. Informal caregivers can provide assistance to an older adult for varying lengths of time, as research estimates the duration of caregiving can range from under 1 year for $22 \%$ of caregivers to 10 years or more for $19 \%$ of caregivers (Harvard School of Public Health, 1998). Older women account for about two-thirds of informal caregivers, as these women often provide care and assistance to family members (Weitz \& Estes, 2001). The widespread societal perspective of women as more nurturing and caring explains why women are caregivers more often than men (Bader, 1985). In addition, women are assumed to be willing to provide uncompensated care to family members who are in need of assistance (Parks, 2003). Care recipients are often women family members, as the Caregiving in the U.S. study found that $28 \%$ of care 
recipients are mothers, $9 \%$ are grandmothers and $7 \%$ are mother-in-laws (National Alliance for Caregiving and AARP, 2004). Approximately eighty percent of older women have living children, some of whom may be their informal caregivers and may be influential in the lives of older women, adding meaning and contributing to their sense of self and independence (Roberto, 1999).

\section{Age Identity and Attitudes Toward Aging}

Socialization influences how people establish meaning in their lives and formulate their own identity, especially in the case of gender, as changes in culture, situations and history, as well as social inequalities related to race, ethnicity, class, age and sexual orientation can affect the ways in which women view and perceive themselves or others (Calasanti \& Slevin, 2001). Society and culture are also a significant influence in the development of identity, meaning and expectations among individuals, but they also are a potential cause for gender disadvantages in health (Gorman \& Read, 2006). In addition, the influence of culture is a significant factor in women's development of expectations, as it is partially responsible for the process in which women assign meaning to themselves as well as their ability to define their position within society (Schafer \& Shippee, 2010).

The internalization of stereotypes, attitudes and expectations associated with the aging process or with being old can become a part of a women's identity and self-concept early in life, while remaining relatively stable throughout the life course (Demo, 1992; Levy, Slade, \& Kasl, 2002). Older women are particularly vulnerable to negative stereotypes and discrimination as they have dual group membership, identifying as both "old" and "woman" (Clarke, 2011). Although men are devalued as they age, women 
experience a harsher reality as their worth is defined by their attractiveness, beauty and being young; as a result, they may feel pressure to use products and get surgical procedures to hide the signs of aging. Furthermore, youthfulness is ideally viewed and prized among contemporary societies and contributes to the prevalence of ageism and negative stereotypes of aging, especially among older women as they are no longer positively evaluated on traits such as physical beauty and sexual attraction (Schafer \& Shippee, 2010). As women get older, they are more vulnerable to being viewed as incapable, feeble, weak, and dependent as a result of age related changes, while men seem to retain their sense of vigor and strength that is associated with the male gender. Garner (1999), explains that "women lose their social value simply by growing old. Men are more likely to be evaluated and rewarded for what they do" (p. 4).

Research has found that social loneliness is associated with a lower satisfaction with the aging process, as well as an increase in the gap between individuals' actual age and their own age identity (Kleinspehn-Ammerlahn, Kotter-Gruhn, \& Smith, 2008).

\section{Review of Relevant Definitions and Constructs}

This section discusses the relevant constructs and variables that were relevant for the present study: independence (dependent variable); relationships between older women and their informal caregivers, roles of both the informal caregiver and older women, attitudes toward aging and age identity (independent variables); and health, social support and depression (control variables). 


\section{Older Women}

Developed countries have defined older women as including females who are age 65 and older (World Health Organization, 2010). Although this definition is subjective, it is associated with the age at which an individual can receive benefits from a pension, and presumably retire. Within this classification of old age, there are three sub-populations: the "young old "(age 65-74), the "old" (ages 74-84) and the "oldest-old (age 85 and older (Pirkl, 2009). In this study, the participants included women in the "old" and "oldestold" subpopulations (74 years and older), who were noninstitutionalized and living within the community.

\section{Informal Caregivers}

For older women, informal caregivers are often family members. Neighbors or friends can also serve as informal caregivers as they generally live closer to older women than family members and thus are able to respond quickly to daily needs and emergency situations (Schneider, 1989). In this study, informal caregivers included the primary person who provided uncompensated care to the older women. Informal caregivers in this study did not have to meet any specific requirements regarding how much care they provided or how often they assisted the older women. The nature of the informal caregivers' relationship and role from the perspective of both informal caregivers and older women was explored in this study. An important aspect in explaining the relationship lies in evaluating the impact of the relationship on older women's independence. 


\section{Independence (Dependent Variable)}

Independence and dependence are at two ends of a continuum, where independence is defined as "the ability to provide for oneself and not being burdensome to others" and dependence as "the state of being influenced, determined, subject to, or controlled by another" (Beeber, 2008, p. 21). Practitioners use functional assessments to measure levels of independence, specifically assessing an individual's ability to perform activities of daily living (ADLs) and instrumental activities of daily living (IADLs) as well as continuing to live within one's home and community (Gallo, Bogner, Fulmer \& Paveza, 2006). In addition, mobility and physical functioning are essential factors in maintaining independence among older women living at home and has been identified as a critical component to quality of life and self-efficacy (Parker, Baker, \& Allman, 2002, Gitlin et al., 2006).

In this study, independence referred to the older women's ability to provide selfcare. The World Health Organization (1998) defines self-care as "what people do for themselves to establish and maintain health, prevent and deal with illness" (p. 2). It is a broad concept encompassing: 1) hygiene (general and personal); 2) nutrition (type and quality of food eaten); 3) lifestyle (sporting activities, leisure etc.); 4) environmental factors (living conditions, social habits, etc.); 5) socioeconomic factors (income level, cultural beliefs, etc.); and 6) self-medication (WHO, 1998). Following the model of the National Survey of Self-Care and Aging (NSSCA), these broad categories of self-care behaviors were examined in this research study. 


\section{Relationship between Older Women and their Informal Caregivers (Independent Variable)}

Receiving care from informal caregivers is assumed to be a positive experience for older women because it is believed that they will benefit from the care they receive, however, care may not always be helpful for the recipient (Edwards, 2001). Informal caregivers who overestimate older women's problems, limitations or deficiencies may negatively influence how older women view their own capabilities (Sheafor \& Horejsi, 2003). Older women who describe themselves as independent may object to receiving assistance to avoid the feelings of inadequacy that may accompany their diminishing abilities (Minichiello, 2000). Informal caregivers may interpret a refusal of help as the older women's attempt to mitigate the perceived theft of their pride, confidence and selfimage (Aberg et al., 2004). Research by Vernon and Qureshi (2000) suggests that there are five major components that influence an individual's feelings about receiving care: respect, dignity, trust, reliability and being treated equally. Kahana, Kahana \& Wykle (2009) identified "care-getting" as a major developmental task essential to healthy aging, with a focus on maintaining comfort, psychological well-being, meaningfulness and a sense of being cared for during the later stages of life. In addition, attachment in the caregiving relationship influences a sense of well-being among older women, as secure and positive attachments are related to higher levels of social integration life satisfaction, physical health and an overall healthier state of well-being (Bradley \& Cafferty, 2001).

Maintaining a balanced and mutually beneficial relationship between informal caregivers and older women is important to providing the highest quality of help, while 
reducing the possibility of caregiver burden and elder abuse or mistreatment (Greene \& Adelman, 2001). Lustbader (1993) elaborates on this idea of reciprocation by stating, "giving help, eventually embitters us, unless we are compensated at least by appreciation: accepting help degrades us, unless we are convinced that our helpers are getting something in return" (p. 18). A reciprocal relationship between informal caregivers and older women requires empathy, or the ability to understand and appreciate the other person's attitudes, feelings and opinions (Nathanson \& Tirrito, 1998). A relationship that emphasizes dependency or passivity among the care recipient can be destructive, negatively affecting an individual's self-esteem and dignity (Vernon \& Qureshi, 2000). When older women are forced to rely on family members for care because of their diminished level of functioning, there can be negative consequences if there is not equal reciprocity. A lack of reciprocity between older women and her informal caregivers can lead to feelings of guilt and a sense of burden on the part of older women. This tension can result in resentment, shame and negative feelings of indebtedness or humiliation, causing an imbalance in the relationship (Lustbader, 1993). Furthermore, older women may have fears of becoming a burden to her informal caregiver and losing that person's support or compassion. Conversely, overly protective caregivers may encourage learned helplessness by failing to provide older women with the opportunity to maximize their own independence and abilities (Sherman, 2006).

In the relationship between informal caregivers and older women, it is crucial that a collaboration exists where older woman is viewed as the expert of her own situation and whose expertise is used as the foundation for creating effective interventions to 
improve their health and well-being (Harding,1997). In addition, in an equitable relationship, it is important for all involved to know their own capabilities, limitations and responsibilities to affectively establish appropriate levels of participation and involvement (Nathanson \& Tirrito, 1998). Finding a common ground within the caregiving relationship from which to address needs is influenced by multiple factors including: family conflicts, optimism and pessimism, mutuality, healthcare, developmental stage, chronic illness, support systems and the context of the relationship (Lyons \& Sayer, 2005). To understand the current functioning of a caregiving relationship, it may have been necessary to study the type of relationship that existed prior to the start of caregiving responsibilities (Lingler, Sherwood, Crighton, Song \& Happ, 2008) however the past experiences in the relationship were not evaluated for this study.

\section{Roles of Older Women and their Informal Caregivers (Independent Variable)}

Gannon (1999) describes roles as "expected, socially encouraged patterns of behaviors for individuals within a particular social context" (p. 24). According to Biddle (1979), role is defined by four elements: 1) roles are behavioral; 2) roles are performed by persons; 3 ) roles are normally limited in some way by context and do not represent total set of all behaviors and 4) roles consist of those behaviors that are characteristic of a set of persons and a context (p. 58). The McMaster Model of Family Functioning describes the types of tasks and functions required to maintain healthy and effective dynamics within families (Ryan, Epstein, Keitner, Miller \& Bishop, 2005). The role definition established in the McMaster Model of Family Functioning was applied to the 
current study to understand the nature of the roles of both informal caregivers and older women. Necessary role functions include: a) nurturing and support (comfort, warmth and reassurance); b) personal development (formation and pursuit of goals); c) maintaining and managing relationship (decision-making functions, boundaries and creating standards or rules); d) role allocation (assigning appropriate roles and distributing tasks fairly); e) role accountability (sense of responsibility); f) emotional responsiveness; and g) involvement (Ryan et. al., 2005).

\section{Attitudes Toward Aging (Independent Variable)}

Studies suggest that there is a correlation between age bias and life satisfaction, finding that older adults with positive attitudes towards aging have improved physical and psychological health later on in their lives (Collins, 2008; Davis \& Friedrich, 2010; Kleinspehn-Ammerlahn, Kotter-Gruhn \& Smith, 2008; Levy, Slade, Kunkel, \& Kasl, 2002). Moreover, older adults may compare their abilities and condition to their peers and conclude that they are worse or better off than their same age counterparts. Older women who think that they are aging better than others may view themselves more positively, suggesting that comparing oneself can contribute to improved well-being, ageidentity, quality of life and self-perceptions of aging (Pinquart, 2002). For women, their experience of aging is influenced by social and economic resources, as well as by their age, class, sexual preference, physical ability and race/ethnicity (Clark, 2011). In addition, the influence of culture is a significant factor in women's development of expectations, as it is partially responsible for the process by which women assign 
meaning to themselves as well as their ability to define their position within society (Schafer \& Shippee, 2010).

\section{Age Identity (Independent Variable)}

Individuals' beliefs about their own aging have been found to have a greater effect over time on their cognitive and physical functioning compared to factors like gender, race, economic status and self-rated health (Levy, Slade, \& Kasl, 2002). Age identity, or how old/young a person feels in comparison to their chronological age significantly shapes self-perceptions of aging, and specifically in women, "having as much or more of an impact than objective age" on health outcomes and well-being (Schafer \& Shippee, 2010, p. 95). Women also identify themselves as reaching "old age" earlier than men, as they experience declines in their physical attractiveness and reproductive ability while their role as mothers diminishes (Barrett \& von Rohr, 2008). In addition, it is important to recognize that women are at a greater risk of experiencing financial stress as they age. Research suggests that individuals with lower socioeconomic status have older age identities compared to their wealthier peers as a result of less optimistic views of their own health that arises from being disadvantaged (Barrett, 2003). Additionally, the hardships they experience throughout their lives are associated with an increase in the rate of their physiological aging (Rosow, 1967). Research suggests that individuals with younger age identities have a more optimistic view not only of their physical capabilities, but also their cognitive abilities, especially in regards to maintaining their memory (Schafer \& Shippee, 2010). The internalization of stereotypes, 
attitudes and expectations associated with the aging process or with being old can become a part of a women's identity (Demo, 1992; Levy, Slade, \& Kasl, 2002).

\section{Health (Control Variable)}

Health is defined by the World Health Organization as a "state of complete physical, mental and social well-being, and not merely the absence of disease or handicap" (World Health Organization, 2010). Similarly, the CDC defines health as "a state of complete physical, mental, and social well-being and not just the absence of sickness or frailty" (Social Determinants, 2011). In this study, health referred to the physical, psychosocial and social aspects of older women.

\section{Social Support (Control Variable)}

Social support may change throughout the life course of older women, as the varying roles, relationships and behaviors can influence the meaning and significance of her own viewpoint on social support (Cohen \& Syme, 1985; Pearlin, 1985). Behavioral exchanges characterize social support, as both giving and receiving are not only intended to be beneficial, but also are expected to be perceived as helpful to those involved in the relationship (Dykstra, 2007). In this study, social support referred to what Shearer \& Fleury (2006) describe as a "woman's belief that she is valued, loved, and an integral part of a social relationship" (p. 4). The various types of social support include emotional, informational, instrumental and financial support as well as practical help and selfappraisal (Stansfeld, 2006). 
Social support has been selected to be a control variable in this study based on prior research on older women living in the community. A study conducted by Krause (1997) found that social support indirectly provides older women with a sense of commitment and continuity, as well as a sense of security that someone will be there to help them in the future, if needed. Research suggests that social support is associated with psychological and physical health (Cohen, 1988), as well as having a role in the recovery and prevention of illnesses (Cohen, Gottlieb \& Underwood, 2000). Further, research by Cohen \& McKay (1984) concludes that social support is able to buffer against negative health outcomes while also being a protective factor for psychosocial stressors. Besides this, social support promotes more effective coping, positively influencing older women's ability to maintain their independence and well-being as they age (Krause, 1997). Social support has been identified in the literature as a way to cope with stress and promote resiliency in older women (Aleman \& Paz, 1998; Pearlin \& Skaff, 1995; Quadagno, 1999).

\section{Depression (Control Variable)}

Depression has been selected as a control variable in this study based on prior research on older women and their level of independence and social support. Research has found that depression in older women is significantly associated with lower levels of social support, physical independence and positive affect (Rickwood \& Rylands, 2008). Rickwood \& Rylands (2008) concluded that lack of social support was the strongest predictor of depression among community-dwelling older women. Unmarried women, including those who are widowed and divorced, account for over $60 \%$ of all women over 
age 70 , and these women are at a higher risk of depressive symptoms compared to married women of the same age (Erlangsen, Bllie-Brahe \& Jeune, 2003; Bould, 2008). An additional risk factor for depression among older women is their physical health status, as illnesses, impairments in functioning and chronic pain are stressors that can influence independence late in life (Gatz \& Fiske, 2003). Older women who feel that they are in control of the events in their lives have been found to have lower levels of depression, activity limitation and psychosocial symptoms while having increased longevity and better self-rated health (Denton, 2009). Data from the AHEAD survey (Asset and Health Dynamics of the Oldest Old) found that limitations in mobility and performing self-care were correlated with high depressive symptoms in women 70 and older (Bould, 2008). A study by Gum et al., found that mild depression worsens over time for women with limitations who are receiving home-based care, supporting previous research findings (Andreescu, Chang, Mulsant \& Ganguli, 2008). Depression in older women has been associated with an increased risk of falls and fractures. Depressed older women are also more likely to report their health and functional status as fair to poor (McGuire, Strine, Vachirasudlekha, Mokdad \& Anderson, 2008). Functional status is older women's “ability to take care of self, to perform physical activities, and to participate in activities of daily living" (Pomeroy, Holleran \& Franklin, 2003). Krause, Liang \& Yatomi (1989) found that there was a relationship between social support and depression in older adults, as satisfaction with support tended to precede changes in depressive symptoms, although initial levels of depression were unrelated to level of satisfaction with social support. A systematic review conducted by Barnett \& Gotli (1989) found that excessive dependency may predispose individuals to depression, while 
smaller social networks, fewer close relationships and less perceived adequacy of relationships can influence depression symptoms as well. Depression in older adults has been identified as the most significant risk factor for suicide (National Institute of Mental Health [NIMH], 2004). Additional risk factors for suicide among older adults include physical, medical or mental illnesses, social isolation, being widowed or divorced, substance abuse, poverty, hopelessness, psychosocial factors, aging itself and access to lethal means (Pierpont \& McGinty, 2005). 


\section{CHAPTER III: METHODOLOGY}

\section{Research Design}

This study investigated the relationship between older women and their informal caregivers. A mixed methods design was selected for this study to address the proposed research questions. The use of both quantitative and qualitative approaches helped to gather information that could not be answered by quantitative or qualitative methods alone. Happ (2009) described that, "investigations in geriatrics and gerontology frequently focus on complex circumstances of interaction (caregiving) and are often conducted in complicated systems (families) that lend well to mixed methods approaches" (pp 122-23). A mixed methods design was used to understand the older women's independence from the perspective of both the informal caregivers and the older women themselves. In this study design, there were two distinct interactive components: 1) quantitative data was collected to assess the relationship between the variables and 2) in-depth semi-structured qualitative interviews were conducted as a follow-up to the quantitative results to further explain the findings (Creswell \& Plano Clark, 2011). The quantitative and qualitative components were implemented during a single phase of the study (Creswell \& Plano Clark, 2011). All subjects participated in the quantitative component of the study and only a few participated in the qualitative component. Both sets of data (quantitative and qualitative) were analyzed after the data collection process.

According to Creswell \& Plano Clark (2007), there are four basic levels of collecting and analyzing data within mixing methods research designs: 
- Within Level 1, data from the qualitative and quantitative components are collected and analyzed separately.

- In Level 2, the results of one of the methods, either the qualitative or the quantitative, informs the other method.

- Level 3 is described by separating the qualitative and quantitative results and comparing them within a table or in a discussion.

- At Level 4, data transformation is used to merge the qualitative and quantitative data or additional analysis is conducted. (pp. 137-143)

In the final interpretation of this study, the results from the quantitative and qualitative components were combined at Level 1 to demonstrate what was learned from the mixed-methods study design. In the present study, a mixed methods approach was selected to gathered knowledge about the physical aspects of independence as well as the psychosocial and behavioral aspects (Happ, 2009).

\section{Study Sites}

Older women participants of this study were receiving ongoing care and personal assistance from two social service agencies at the time of data collection. Approval was received from both study sites prior to the start of recruitment and data collection (Appendix A).

Agency A provides a full range of short and long-term services that are designed to help individuals maintain the highest level of self-sufficiency, while improving their quality of life and focusing on the prevention of premature placement in nursing homes 
or institutions. Agency A offers home and community-based services to over 4,500 older adults in Miami-Dade County, Florida. Agency B services 3,700 people daily, offering a full range of health care services for older adults that are designed to maximize the potential of each client through leading-edge care and independence-enhancing activities. Agency B's community programs focus on supporting older adults' desire to maintain their independence in their own homes so that they can enjoy a longer, healthier life and avoid placement in a nursing home.

\section{Study Sample}

The population for this study consisted of older women-informal caregiver dyads. The sample of older women were recruited from two agencies located in Miami-Dade County: Agency A and Agency B. Older women included those 74 years of age or older, who were noninstitutionalized and living within their household and were receiving assistance from an informal caregiver. Informal caregivers of the older women were family members, neighbors or friends, or others who provided uncompensated care to these older women. Informal caregivers included both males and females and their ages varied.

A sample size of 103 pairs (206 total participants) was determined through a power analysis using the G-power 3.1 software with the following parameters: effect size of .15; alpha of .05; power of .8 and 7 predictors. The research plan was to recruit older women participants from the study sites using a convenience sampling strategy until the desired sample size was reached ( $\mathrm{n}=103$ dyad pairs) or a period of 6 months of data 
collection had elapsed. Persons with Dementia or Alzheimer's were excluded from the study.

A purposive sampling approach was used to recruit participants for the qualitative interviews. The inclusion criteria for this study was that older women participants were 74 years of age or older, therefore, the purposive sampling approach intended to obtain older women in both the "old" (74-84 years) and "oldest-old" (85+ years) age categories. The strategy for recruiting older women-informal caregiver pairs for the qualitative interviews was to ask every $5^{\text {th }}$ pair who completed the quantitative interviews, if they would be interested in participating in the additional qualitative interview. If an older woman or her informal caregiver declined to participate in the additional qualitative interview, the next dyad pair in the sample who completed the quantitative interview was asked until a pair agreed to participate. Recruitment of every $5^{\text {th }}$ older woman-informal caregiver pair then resumed, until the desired sample size was reached. The intended sample size for the qualitative interviews was 10 pairs, however, due to recruitment difficulties, only 4 pairs were interviewed. Both members within the older womeninformal caregiver dyad were interviewed separately.

\section{Rationale for a Smaller Study than Originally Intended}

The intended sample size for this study was 103 pairs, however, the study's actual sample size was 25 pairs due to recruitment barriers. A decision was made to end the data collection after 15 months. This decision was influenced by the amount of data collected within those 15 months, as it was speculated that extending the data collection would not guarantee that the full intended sample size would be reached. Furthermore, 
extending the time spent on data collection was not advantageous because of limited financial resources. The initial hypotheses and research questions proposed for the study remained after data collection concluded, however, the analysis had to be modified due to the sample size not being large enough. The initial plan to complete multiple regressions were not feasible, rather, Pearson correlations $(r)$ were calculated to answer Hypothesis 1a, 2a, 3a to understand the relationship between the major study variables. Limitations dues to recruitment barriers are further addressed in the Discussion section.

\section{Data Source}

Dyad pairs (one older woman and one informal caregiver) were selected to participate in this study. The older woman in the dyad pair was a client of either Agency A or Agency B. The informal caregiver in the dyad was not required to be a client of either agency. The setting granted the researcher to access Agency A and Agency B's client databases. Each client at Agency A and Agency B has spent time with a case manager to complete Florida's Department of Elder Affairs' 701A and 701B forms to determine their eligibility for services. The 701A form contains questions regarding demographics, physical and functional health (ADLs and IADLs), resources available to the client, nutrition status, tobacco use and a caregiver assessment. The 701B form contains all the same items of the 701A form plus questions on the mental health/behavior/cognition of the client, health conditions, medications, social resources and an environment assessment. The information from each client's 701A and 701B forms is listed in the agency database. The client databases from Agency A and Agency B were accessed to find older women who met the following inclusion criteria: 1) 74 
years of age or older; 2) non-institutionalized; 3) living in Miami-Dade county or Broward county; 4) had at least one informal caregiver; and 5) no dementia or Alzheimer's. Older women who met the inclusion criteria were assigned numbers for identification purposes. Case managers and the researchers of this study detailed the recruitment and data collection processes to the potential participants. Clients were excluded from participating in the study if they had cognitive impairments, severe hearing impairments or aphasia (partial or total loss of an individual's ability to communicate verbally due to brain damage). Exclusion of these clients was necessary as these impairments limited the ability to gather a reliable assessment of their status.

Potential older women participants were selected through a database or client list from Agency A and Agency B using a convenience sampling strategy. Case managers at Agency A and Agency B met with the researchers of this study to have an opportunity to learn about the study and to ask questions regarding the process. The case managers spoke to selected participants briefly describing the study. Case managers informed the participants that they will be contacted shortly by the researchers of the study via phone regarding their interest in the study. In addition, older women were asked to provide the name and contact information of their primary caregiver during this phone conversation. Caregivers were also contacted by the researchers to assess their level of interest in participating in the study. The research plan was to recruit older women participants from the study sites until the desired sample size was reached ( $\mathrm{n}=103$ dyad pairs) or a period of 6 months of data collection had elapsed. Both the older woman and her informal caregiver had to both agree to participate in the study. If only one member of 
the caregiver-care recipient dyad agreed to participate and the other did not, the dyad was not interviewed for the study.

The older women and informal caregivers were asked separately for their willingness to participate in the study. Verbal consent was read to all participants immediately before data collection (Appendix B). Older women and informal caregivers were told that their participation in this study was completely voluntary and that they would not be penalized if they refused to participate or if they decided that they want to stop at any point in the process. In addition, the benefits of participating were described to potential participants, specifically, that ultimately the information gained could be used to improve services and resources for older women and their informal caregivers.

\section{Language Administration}

Survey questionnaires and qualitative research used in the data collection of this study were conducted in English and Spanish. The items and all possible responses on the qualitative measures were read aloud by the researcher to the older women-informal caregiver participants in either English or Spanish. The participants would state aloud which answer best described their opinion. The researcher created a score sheet that encompassed all 62 items within the quantitative interview to ensure that data could be collected consistently during the interviews to reduce errors. In the qualitative data collection process, the researcher asked semi-structured questions to the participants in either English or Spanish. These qualitative interviews were voice recorded and then transcribed. No research was conducted in Creole, French, Russian or Hebrew. 


\section{Pilot Trial}

One wave of data collection was conducted and used for the study. Prior to the data collection process, a pilot trial was conducted to obtain accurate estimates of the time required to compete the interview process (Jacobson, 2004). Piloting the study with a small population prior to data collection addressed issues with the interviewing process and identified instruments that were not working for this population and these were corrected prior to data collection. The pilot trial used the same cross-sectional design as the present study. The small sample used in the pilot trial had characteristics similar to the sample of the present study. In addition, the pilot trial was useful for the researchers to gain experience and confidence, as well as to familiarize the researchers with the interview process and measurements used. Equally important, the pilot trial was beneficial in anticipating and resolving potential problems that could have occurred during the data collection process. The pilot trial included two older women-informal caregiver pairs who met the inclusion and exclusion criteria that was used within this study.

\section{Data Collection Procedures}

Assessments for this study were administered through individual face-to-face interactions with participants by the Principal Investigator and the Spanish Speaking Research Assistant. All the instruments used in the quantitative data collection were administered to both informal caregivers and the older women. For instance, when an older women was answered questions on health, she described her own health, while an informal caregiver responded to this same question by describing the older woman's 
heath, not their own. Older women were individually interviewed within their own residences and informal caregivers were interviewed at their own residences or at the residences of the older women. Assessment questions from the survey instruments were read aloud to the participants and the researchers recorded the responses. Participants were provided with a copy of the instruments to read and follow along during the verbal interview process. Notes were also taken immediately after the interviews to document participants' non-verbal responses, body language or additional comments they made during the interview process. The quantitative interview portion took less than one hour per participant. Several instruments were used to measure the dependent, independent and control variables in this study. Data collected from the responses was analyzed to determine how perceptions differ between informal caregivers and the older women themselves. The research plan was to interview older women and their informal caregivers on the same day to avoid potential contamination of the data resulting from the discussion of instrument items between members in the dyad, however, due to scheduling conflicts, this was not always possible.

To further understand the dynamic of the relationship between older women and informal caregivers, selected dyad pairs were asked to participate in additional qualitative interviews after they completed the quantitative portion. Consent from both members of the dyad was obtained prior to conducting the qualitative interviews. Data was collected through semi-structured interviews, allowing participants to respond openly. Participants were selected to participate in additional qualitative interviews to further understand the dynamic of the relationship between older women and informal caregivers. The initial 
plan for the study was to conduct 20 qualitative interviews in total ( 10 older womeninformal caregiver dyads), however, due to recruitment difficulties, there were 8 total qualitative interviews conducted from 4 older women-informal caregiver dyads. Data was collected through semi-structured interviews, allowing participants to respond openly. Interviews provided an understanding of individuals' meaning-making and their own perspectives on social concerns. Individual interviews were digitally recorded, then transcribed and coded by the researchers in a qualitative data analysis software (ATLAS ti). Several steps were taken to ensure that the qualitatively interviewed participants maintain their confidentiality (Laerd, 2010). The transcripts were reviewed several times to code the data until the major research themes were identified. Verbal consent obtained from the participants grants the researcher permission to use any of their quotations from the interviews in papers, publications or presentations. Names were changed for individuals' quotations to ensure that individuals cannot be identified.

\section{Missing Data}

Missing data occurred infrequently in this study due to the administration of questionnaires by an interviewer, rather than being completed by the individuals through self-reports, however, there were cases where participants either refused to answer questions or did not feel that there was a suitable option that represented their viewpoint. Missing data was handled using a mean substitution approach, where missing values from a single question were substituted with the mean scores from all the responses on that specific individual item (Information Technology Services, 2013). In particular, one question on the Attitudes Towards Own Aging scale was difficult for some participants to 
answer and required the use of mean substitution. This question was, "As you get older, are things better or worse than you thought they would be?". Only dyad pairs of informal caregivers and older women were included in the data analysis. In cases where only one member of the caregiver-care recipient dyad participated and the other did not participate, data for that dyad was discarded. In addition, missing data and outliers were rechecked with the raw data to ensure that they were not due to a data entry mistake.

\section{Data Analysis}

Quantitative data was analyzed to compare the differences between informal caregivers' viewpoints and the older women's own viewpoint. The data was analyzed to: 1) obtain the means and standard deviations of the values; 2) find correlations that existed between the viewpoints of informal caregivers and older women's own report on measures of the variables; 3) conduct two-tailed paired t-tests to measure differences in the means within dyads of informal caregivers and older women and 4) understand the statistical significance of the data collected with the instruments.

The demographic data was analyzed to describe the characteristics of the older women and informal caregivers within the sample. Exploratory analysis was conducted to examine patterns in individual item scores through obtaining the means, standard deviations and ranges of the demographic variables.

Qualitative data was collected through semi-structured interviews, allowing participants to respond openly. Individual interviews were digitally recorded and transcribed. The data was coded for themes by the researchers, separately, in a 
qualitative data analysis software (ATLAS ti). The transcripts were reviewed several times to code the data until the major research themes were identified. Themes and categories were compared for similarities and differences in the ATLAS ti software.

\section{Human Subjects}

This study posed no known risks to the subjects while participating that are greater than those faced in their normal lives. There were no immediate or long-range risks, discomforts and/or inconveniences foreseeable to subjects associated with the procedures used in this study. A human subjects application was submitted for review (expedited status) to Florida International University's Institutional Review Board and approved for this research study. The IRB reviewed the procedures of the study and gave confirmation to proceed with all research objectives (Appendix M). The IRB protocol was amended twice to add a Spanish speaking interpreter to the research staff and to include Spanish qualitative interviews (Appendix M). The researcher and research associates working on this project have successfully completed an IRB training on conducting Human Subjects Research (Appendix N).

The primary issues of this study were ensuring the confidentiality of the participants and the security of the data. All completed surveys were stored in a locked file cabinet within an office at FIU that only the researcher and advisor had access to. The data collected had no identifiable information (eg., names, birthdates, social security numbers, etc). The final analyzed results are described in-group format and it is not possible to track the responses back to specific individuals. No identifiable data was stored on a computer, laptop, PDA or removable media and all data was stripped of 
identifiers or coded before it was actually imputed into statistical software. In the case that participants disclosed any signs of abuse or suicide ideation, the researchers had a professional responsibility to report harm done to oneself or another individual. All participants understood this mandatory disclosure when they consented to the study. No participants in the study disclosed any signs of abuse or suicide ideation.

\section{Assessment Measures}

\section{Quantitative Measures}

Measures for this study were selected based on several important reasons for use with this population. Instruments were chosen based on use in prior studies with older women, psychometric properties which included adequate validity and reliability, item formatting and length of instrument. These factors are thought to reduce response burden. Shortened versions of instruments with established properties were used for time purposes and to keep the participant attentive and engaged during the interview. Specifically, shorter versions of some instruments were used to reduce the number of questions that participants were asked during the quantitative interviews. This included the use of a shortened version of the SF-36, as the original SF-36 had 36 questions and the Short-Form 12 Health Survey Version 2 (SF-12v2) used in this study had only 12 questions. In addition, the Abbreviated Duke Social Support Index with 11 items was used rather than the original 35 item instrument. The researchers had knowledge on how to use the data collection measurements prior to administration of the instruments. The assessment measures were administered to both the older women and informal caregivers. The older women answered questions from their own perspective, while 
informal caregivers responded to the same questions by describing their perspective on the older women, not themselves. The following variables were examined: 1) independence, 2) relationship between older women and their informal caregivers; 3) the roles of both the informal caregiver and older women; 4) attitudes toward aging; 5) age identity; 6) health; 7) social support; and 8) depression.

For this study, independence (dependent variable) was assessed through activities of daily living and instrumental activities using the Katz Index of Independence in Activities of Daily Living (Appendix C), the Lawton Instrumental Activities of Daily Living Scale (Appendix D). These measures were treated as two separate dependent variables in the analysis.

\section{Katz Index of Independence in Activities of Daily Living}

The Katz Index of ADL was used to assess the functional status of the older women in their ability to perform activities of daily living in six functions: bathing, dressing toileting, transferring, continence, and feeding. Participants' identified the description that best explained the level of independence for each of the six daily living functions. Descriptions corresponded with number scores for each of the six questions with 0 (dependent), .5 (receives assistance) or 1 (independent). Total scores for the Katz Index could range from 0 to 6 . Scores of $0-2$ indicate severe functional impairment, a 4 indicates moderate impairment and a score of 6 indicates full functioning (Shelkey \& Wallace, 2012). The Katz Index of Activities of Daily Living has good test-retest reliability with Guttman characteristics-coefficient of reproducibility of 0.95-0.98

(Richmond, Tang, Tulman, Fawcett \& McCorkle, 2004). The Katz ADL scale also has 
high construct validity with the Mini-Mental State Exam (.76), concurrent validity that correlates with the degree of actual assistance by the patient and also predictive validity with the longitudinal course of function, measured by mobility and house confinement (Richmond et al., 2004). The Katz ADL scale requires 5 to 10 minutes to administer. The Katz ADL scale is in public domain, therefore permission to use this instrument in the study was not required.

\section{Lawton Instrumental Activities of Daily Living}

The Lawton IADL scale measures independent living skills that are more complex than the functions measured in the Katz ADL scale. The Lawton IADL scale measures 8 domains of function for women: ability to use telephone, shopping, food preparation, housekeeping, laundry, mode of transportation, responsibility for own medications and ability to handle finances. Scores can range from 0 (low function, dependent) to 8 (high function, independent) (Graf, 2007). The scale was found to have internal consistency of 0.92 and interrater reliability of 0.85 (Richmond et al., 2004). In addition, the Lawton IADL scale has concurrent validity with significant correlations with physical classification and mental status questionnaire (Richmond et al., 2004). In the present study $(n=25)$, the internal consistency of the Lawton IADL scale was $\alpha=0.66$. Self-reported assessments of functioning are easy to administer and are used clinically due to their significant predictive and concurrent validity (Angel \& Frisco, 2002). The Lawton IADL scale requires approximately 10 minutes to administer. The Lawton IADL scale is in public domain, therefore permission to use this instrument in the study was not required. 


\section{Attitude Toward Own Aging}

Attitude Toward Own Aging subscale of the Philadelphia Geriatric Center Morale Scale (PGCMS) (Appendix E) was used in this study to measure the independent variable of the same name (Lawton, 1975). This subscale has been used in a number of recent studies to measure self-perceptions of aging and satisfaction with aging (KleinspehnAmmerlahn et al., 2008; Kotter-Gruhn, Kleinspehn-Ammerlahn, Gerstorf \& Smith, 2009; Levy, Slade \& Kasl, 2002). The subscale contains the following five questions: 1) Do things keep getting worse as you get older? 2) Do you have as much pep as you had last year? 3) Do you feel that as you get older you are less useful? 4) As you get older, are things (better/worse) than you thought they would be? and 5) Are you happy now as you were when you were younger? For each question, a high-morale response received a score of 1 and a low-morale response was scored a 0 . Scores for the subscale could range from 0 to 5, with higher scores indicating a more positive attitude toward aging. The PGCMS is in public domain, therefore permission to use the Attitude Toward Own Aging subscale for the present study was not required.

\section{Age Identity}

In this study, age identity is an independent variable and refers to subjective age perception. This measure of age identity is the difference between older women's subjective age and her chronological age, where a positive value suggests a younger age identity and a negative value suggests an older age identity (Barrett, 2003). Age identity was assessed though a single-item question through the perspective of both the informal caregiver and the older women themselves. The following question was asked to 
evaluate the older women's felt age: "Many people feel older or younger than they actually are. What age do you feel most of the time?" (Barrett, 2003).

\section{Dyadic Relationship Scale}

The Dyadic Relationship Scale (DRS, Appendix F), which was first developed by Poulshock \& Deimling (1984) and revised by Sebern \& Whitlatch (2007), was used in this study to measure the independent variable (relationship between older women and their informal caregivers) by assessing the positive and negative aspects of the interaction. Although the DRS has been used mainly for family caregivers, the scale has been used to measure the relationship of caregivers who were friends of the recipient as well as those classified as "other" (Sebern \& Whitlatch, 2007). The DRS was found to have good reliability and validity for both older adults and their caregivers. Caregivers were asked 11-items while older women were asked 10-items, with responses ranging from strongly agree ( $($ core $=3$ ) to strongly disagree $($ score $=0$ ). The two subscales of the DRS are dyadic strain and positive dyadic interaction. Questions referred to the relationship dynamics within the last month including: "I felt depressed because of my relationship her/him", "I felt resentful toward her/him" (negative dyadic strain), "I have had more patience than I have had in the past", "I felt closer to him/her than I have in a while" (positive dyadic interaction). Higher scores on these subscales indicate increased levels of dyadic strain and positive dyadic interaction, respectfully (Sebern \& Whitlatch, 2007). Both Dr. Sebern of Marquette University and Dr. Whitlatch of the Margaret Blenkner Research Institute have given permission to use the DRS in the present study (C. Whitlatch, personal communication, February 8, 2012). 


\section{Short-Form 12 Version 2 Health Survey}

The Short-Form 12 Health Survey Version 2(SF-12v2) (Appendix G), is a 12 item instrument derived from the Medical Outcomes Study (MOS) Questionnaire and developed by Ware, Kosinkski \& Ganndek (2000). The SF-12 was used in this study to measure health (a control variable). The survey was designed to measure health generically through eight dimensions: physical functioning (PF), role limitations (RP), bodily pain (BP), social functioning (SF), general mental health covering psychological distress and well-being $(\mathrm{MH})$, role limitations due to emotional problems (RE), vitality (VT) and general health perceptions (GH). The SF-12v2 was administered through personal interviews, asking the older women about their own health as well as asking for the informal caregivers' viewpoint on the older women's health. The instrument required less than 10 minutes to administer. Scores from the eight sections are calculated to form two summary scores, a physical (PCS) and a mental component (MCS). The SF-12 has been found to have good validity (.80-.90) when compared to studies with physical and mental health components, while reliability exceeded the minimum standard of .70 for both internal consistency and test-retest measures (Ware \& Gandek, 1999). When comparing 15 studies, the reliability exceeded .80 for most studies while physical and mental scores generally exceeded .90 (Ware \& Gandek, 1999). The researchers were given permission to use the SF12v2 and the scoring software for this dissertation study with a non- commercial license agreement through the Office of Grants and Scholarly Research at Optuminsight Life Sciences, Inc. (Appendix H) 


\section{Abbreviated Duke Social Support Index}

The 11-item Abbreviated Duke Social Support Index (DSSI) (Appendix I) developed by Koenig and colleagues (1993) was used in this study to measure older women's level of social support (a control variable). The DSSI measures multiple dimensions of social support, with two subscales: the social interaction subscale (4 items) and the subjective support subscale ( 7 items). The 11 -item version was found to perform at a comparable level to the original 35 -item version among a sample of chronically ill older adults (Koenig, Westlund, George, Hughes, Blazer \& Hybels, 1993). Among a sample of community dwelling people 70 and older, the 11-item DSSI was found to have overall good internal consistency $(0.77)$ and test-retest reliability (ranging from 0.70 to 0.81) (Goodger, Byles, Higganbotham \& Mishra, 2008). In the present study, the DSSI had an internal consistency of $\alpha=.70$. Dr. Harold Koenig of Duke University gave the researchers permission to use the DSSI in the present study (H. Koenig, personal communication, February 16, 2012). Since the DSSI measures social support from family and friends, it may overlap with the main concept of the present study, which is the relationship between older women and their informal caregivers and caregiver support. To avoid measuring caregiver social support, the following statement was made before administering the DSSI: "Please answer the following questions regarding social support that you have received from family and friends within the last week. Do not include support received from NAME (informal caregiver) in your responses”. 


\section{Patient Health Questionnaire}

The Patient Health Questionnaire (PHQ-9) (Appendix J) was developed by Spitzer, Kroenke, Williams(1999) and adapted from the Primary Care Evaluation of Mental Disorders Patient Health Questionnaire (PRIME-MD PHQ). The PHQ-9 was used in this study to measure the control variable of depression in older women. The PHQ-9 is a nine item self-administered depression module that evaluates an individual's symptoms and problems over the last two weeks, with four possible answer choices: not at all (0 pts); several days ( $1 \mathrm{pt})$; more than half the days (2 pts) and nearly every day (3pts) (Kroenke, Spitzer, Williams 2001). Scores can range from 1 to 27, as depression severity increases with higher scores. Interpretation of scores for the PHQ-9 is as follows: minimal depression (total score of 1-4); mild depression (total score of 5-9); moderate depression (total score of 10-14); moderately severe depression (total score of 15-19); and severe depression (total score of 20-27). In older adult populations, the PHQ-9 was found to have high test-retest reliability, significant positive internal consistency $(r=0.88)$ and positive convergent validity with the Geriatric Depression Scale $(r=0.74)$ and the Center for Epidemiological Studies Depression Scale $(r=0.66)$ (Han, Ahn Jo, Kwak, Pae, Steffens, Jo \& Park, 2008; Lamers, Jonkers, Bosma, Penninx, Knottnerus \& van Eijk, 2007). In the present study, the PHQ-9 had an internal consistency of $\alpha=.58$. The PHQ-9 is in public domain, therefore permission to use this instrument in the study was not required. The PHQ-9 has been adapted from PRIMEMDTODAY through an educational grant from Pfizer Inc. Depression is generally untreated or undertreated among older adults even though the prevalence in this population is more than one in every nine (Sirey, Bruce, Carpenter, Booker, Reid, Newell 
\& Alexopoulos, 2008). Findings suggest that depression is twice as high in older adults receiving home care compared to those receiving primary care (Bruce, McAvay, Taue, Brown, Meyers, Keohane, Jagoda \& Weber, 2002). Since participant recruitment for this study was conducted through home care agencies, it was important to understand the level of depression for the older women in the sample. Of particular concern for this study was question 9 of the PHQ9: "thoughts that you would be better off dead, or of hurting yourself in some way". Subjects who respond to question 9 with "several days", "more than half the days" or "nearly every day", were specifically inquired about their suicide thoughts, plans and behaviors to estimate their suicide risk. All signs of suicidal behavior were taken seriously. Preventative measures were planned in the event that a participant disclosed suicide ideation. These preventative measures included receiving emergency help from a trained professional and being referred to a mental health provider, doctor or licensed professional for treatment, assistance and support.

\section{Demographic Characteristics}

A demographic questionnaire (Appendix K) was developed by the researchers to understand the characteristics of the sample. Items in the questionnaire include questions regarding age, gender, race, education, marital status, income, number of children, who determined whether caregiving should take place (were they asked, did they volunteer, was it imposed, etc). Variables were coded numerically on SPSS. Some of the demographic characteristics (eg. gender, race, ethnicity) helped to understand the nature of the relationship between older women and their informal caregiver. 


\section{Qualitative Measures}

Pairs of older women and their informal caregivers were selected for an additional qualitative interview, with data collected through semi-structured questions (Appendix L) with probing to increase understanding of three areas: the relationship between older women and their informal caregivers, the roles of both informal caregivers and older women, older women's views on independence and attitudes about aging. There were 17 items on the qualitative measure; 5 items on the relationship, 5 items on the roles with in the relationship, 3 items on independence and 4 items regarding attitudes towards aging. Items on role were adapted from Ryan et al., 2005. The semi-structured qualitative questions and prompts were developed by the researcher of the present study. 


\section{CHAPTER IV: RESULTS}

This chapter provides the results for both the quantitative and qualitative data that was collected for the present study. In this study, there were 25 older women-informal caregiver pairs; therefore 25 older women and 25 informal caregiver participated in the quantitative interviews, providing the data for the demographic characteristics of the sample, as well as the findings for the major study variables.

\section{Demographic Characteristics}

The demographic characteristics of the sample are displayed in Table 2.

\section{Age}

The mean age of the older women participants was 84.60 years $(\mathrm{SD}=6.93)$. The sample ranged in age from 74 to 97 years old. Informal caregivers in the sample had a mean age of 57.74 years $(\mathrm{SD}=7.03)$, with a range of 44 to 73 years old.

\section{Educational Attainment}

Educational attainment for the older women in the sample ranged from $2^{\text {nd }}$ grade to a Bachelor's, with the majority of the older women participants having completed high school or less $(\mathrm{n}=18)$. Informal caregivers, on average, had a higher level of educational attainment compared to the older women, with $68 \%(n=17)$ having post-secondary education. Approximately $16 \%$ of the informal caregivers in this study had graduate degrees. One older woman did not report her education level. 


\begin{tabular}{|c|c|c|}
\hline Variables & Older Women \% & Caregivers \% \\
\hline \multicolumn{3}{|l|}{ Characteristics } \\
\hline \multicolumn{3}{|l|}{ Gender } \\
\hline Female & 100 & 84 \\
\hline Male & ----- & 16 \\
\hline \multicolumn{3}{|l|}{ Ethnicity } \\
\hline Hispanic & 28 & 28 \\
\hline \multicolumn{3}{|l|}{ Race } \\
\hline White/ Non-Hispanic & 8 & 4 \\
\hline Black/ Non-Hispanic & 60 & 64 \\
\hline Other & 4 & 4 \\
\hline \multicolumn{3}{|l|}{ Marital Status } \\
\hline Single & 0 & 32 \\
\hline Married & 20 & 40 \\
\hline Widowed & 64 & 16 \\
\hline Divorced & 12 & 0 \\
\hline Separated & 4 & 12 \\
\hline \multicolumn{3}{|l|}{ CG Relationship to Older Woman } \\
\hline Daughter & ----- & 80 \\
\hline Son & ----- & 12 \\
\hline Friend & ---- & 4 \\
\hline Husband & ----- & 4 \\
\hline \multicolumn{3}{|l|}{ Living Situation } \\
\hline Live with Caregiver & 44 & ----- \\
\hline Does not live with caregiver & 56 & ----- \\
\hline \multicolumn{3}{|l|}{ Income } \\
\hline$<$ US $\$ 10,000$ & 28 & 4 \\
\hline US $\$ 10,000$ - US $\$ 20,000$ & 36 & 16 \\
\hline US $\$ 20,000$ - US $\$ 40,000$ & 4 & 36 \\
\hline$>\operatorname{US} 40,000$ & 0 & 24 \\
\hline Not reported & 32 & 20 \\
\hline
\end{tabular}




\section{Income of the Sample}

Approximately $28 \%$ of older women participants had a household income of $\$ 10,000$ or less, while 9 older women stated that their income was $\$ 10,001-\$ 20,000$. The remaining older women participants in the sample $(n=8)$ did not wish to provide their income level. Older women reported that most of their monthly income came from Social Security. Fifty-six percent of the older women in the sample $(n=14)$ supported only themselves by their yearly income. Informal caregivers in the study reported their income in the range from $\$ 0$ to $\$ 80,000$, with $36 \%$ of caregivers having and income between $\$ 20,001-\$ 40,000$ and $20 \%$ with incomes between $\$ 40,001$ and $\$ 60,000$. Over half $(52 \%)$ of the caregivers reported that their household income supported more than one individual. Five caregivers did not provide their income information during the interview.

\section{Ethnic/ Racial Characteristics and Place of Birth}

Sixty percent of the older women participants in this study identified as Black /African American $(n=15)$, while 28\% $(n=7)$ identified as Hispanic/Latino and $8 \%(n=2)$ were White/Caucasian. Fifteen (60\%) older women participants were born in the U.S., while $40 \%$ were born in countries other than the U.S. Of those born outside of the U.S., seven (28\%) older women participants were born in Spanish speaking countries (Cuba, Puerto Rico and Columbia), while 12\% were born in West Indian Countries (Jamaica, Bahamas, Haiti). The ethnic breakdown for the informal caregiver participant in this study were as follows: 64\% Black/African American $(n=16), 28 \%$ Hispanic/Latino $(n=$ 7), and 4\% White/Caucasian $(n=1)$. Sixty percent of caregivers were born within the 
United States and 24\% were born in Cuba. The countries of Puerto Rico, Jamaica, Haiti and Columbia each had one caregiver who was born there. Only one older woman was born in Miami-Dade county, while $28 \%$ of informal caregivers $(n=7)$ were born in Miami-Dade county.

\section{Language}

In the sample of older women, the primary languages were reported as English $(\mathrm{n}=17)$, Spanish $(\mathrm{n}=7)$ and French $(\mathrm{n}=1)$. Eighteen older women completed the interview for this study in English, while 7 were in Spanish. Seventy-six percent $(n=19)$ informal caregiver's primary language was English, while 20\% $(\mathrm{n}=5)$ was Spanish and 4\% was French $(\mathrm{n}=1)$. Twenty caregiver interviews were conducted in English and 5 were in Spanish. The participants who stated their primary language was French, also were fluent in English and Spanish. These two interviews were conducted in English.

\section{Religious Affiliation of the Sample}

Thirty-six percent of the older women participants in the sample reported that they were very active in their religious practice, while $4 \%$ stated they were active, $36 \%$ were somewhat active, and 16\% were not active. Two women did not report their level of religious participation. Religious affiliation among the older women included Catholic $(\mathrm{n}=7)$, Baptist $(\mathrm{n}=8)$, Pentecostal $(\mathrm{n}=3)$, Methodist $(\mathrm{n}=2)$, Jehovah's Witness $(\mathrm{n}=2)$, Jewish $(n=1), 7^{\text {th }}$ Day Adventist $(n=1)$ and Christian $(n=1)$. The sample of informal caregivers consisted of 4 Catholics, 6 Baptists, 4 Methodists, 3 Christians, $17^{\text {th }}$ Day Adventist, 1 Anglican and 1 Jehovah's Witness. Two caregivers stated that they were not 
religious and one caregiver did not report their religious affiliation. Thirty-two percent of caregivers described their religious participation as very active, $12 \%$ described their participation as active, $28 \%$ as somewhat active and $20 \%$ reported that they were not active in their religious preference. Two caregivers in the sample did not report their level of religious participation.

\section{Relationship Status}

All of the older women participants in this study had been married at least once in their lives. Five older women reported that they were currently married, 16 were widowed, 3 were divorced and 1 was separated. Seventy-six percent $(n=19)$ of informal caregivers in this sample reported that they had been married at some point in their lives. The current relationship status of informal caregivers in the sample was as follows: 8 were single, 10 were married, 4 were widowed and 3 were separated.

\section{Caregiving Relationships}

This study focused on the relationship between older women and their informal caregivers. Twenty-three older women in the sample were the mother of their caregiver. Eighty percent $(\mathrm{n}=20)$ of the caregivers were the daughters of the older woman, while $12 \%(\mathrm{n}=3)$ were sons. There was one friend caregiver and one husband caregiver in the sample. All but one of the older women had biological children. Twenty caregivers in the sample also had children of their own. 


\section{Descriptive Findings for the Major Study Variables}

\section{Katz Index of Independence in Activities of Daily Living}

The Katz Index of Independence in Activities of Daily Living (Katz ADL) was used to measure the functional status of the older women in the sample. The possible range of scores is 0 to 6 , with lower scores indicating functional impairments and a score of 6 indicating full functioning. Older women in this sample had scores ranging from 0.5 to $6(M=4.38 ; S D=1.50)$. Scores of the informal caregiver's perception of the older woman's functioning ranged from 1 to $6 .(M=3.86 ; S D=1.67)$.

\section{Lawton Instrumental Activities of Daily Living}

The Lawton Instrumental Activities of Daily Living (Lawton IADL) used in this study consisted of an 8 item measure, with the possible range of scores from 0 (low function) to 8 (high function). In this study, the sample of older women had a mean score of $3.56(S D=1.64)$ with scores ranging from 1 to 7 . The informal caregiver's perception of the older woman's functioning had scores ranging from 0 to $6(M=2.76 ; S D=1.72)$

\section{Attitude Toward Own Aging}

Attitude Toward Own Aging was measured in this study using a subscale from the Philadelphia Geriatric Center Morale Scale (PGCMS). Possible scores for the subscale range from 0 to 5 , with higher scores indicating greater satisfaction with the aging process. Scores for the older women ranged from 0 to 4 and had a mean of 2.04 $(S D=1.37)$. Informal caregiver's perception of the older woman had a mean of 2.08 (SD 1.61), with scores ranging from 0 to 5 . 


\section{Age Identity}

Age Identity was measured in this study using a single-item question, "Many people feel older or younger than they actually are. What age do you feel most of the time?". The answer to the single-item question was subtracted from the older woman's chronological age to obtain the Age Identity score. A positive score suggests a younger age identity and a negative score suggests an older age identity. Age Identity for older women in this sample ranged from -8 to $78(M=16.68 ; S D=23.96)$. The lowest score of -8 was from an older woman whose chronological age was 80 , who felt like she was 88 . The highest score for age identity was 78, as an older women, who was 96 years of age, stated that she felt 18 years old. Caregiver's perception of the older women's Age Identity had scores ranging from -3 to 77 with a mean of $14.48(S D=21.24)$. The lowest score of -3 was derived from an informal caregiver who believed that the older women felt 80 years old, while their chronological age was 77 . The highest age identity score among informal caregivers was 77, where a caregiver thought the women felt 13 years old and had a chronological age of 90 years old.

\section{Dyadic Relationship Scale}

The Dyadic Relationship Scale (DRS) was used in this study to access the relationship between the older woman and informal caregiver. Older women were asked 10-items while the informal caregivers were asked 11-items. The DRS consisted of two subscales: positive dyadic interaction and negative dyadic strain. Higher scores on the subscales demonstrated increased levels of positive dyadic interaction and negative dyadic strain, respectfully, within the relationship. Possible cores for the positive dyadic 
interaction range from 0 to 18 , while negative dyadic scores can range from 0 to 12 for the older women responses and 0 to 15 for the caregiver responses. In this sample, the older women's positive dyadic interaction scores ranged from 9 to 17 and a mean score of $12.56(S D=1.87)$. The mean score for negative dyadic strain among older women was 3.32 ( $S D=2.16$ ), with scores ranging from 0 to 8 . The positive dyadic interaction scores for caregivers in the sample ranged from 2 to $18(M=12.36 ; S D=3.74)$, while negative dyadic strain had scores ranging from 0 to 13 with a mean score of $4.04(S D=3.03)$.

\section{Short-Form 12 Version 2 Health Survey}

The Short-Form 12 Version 2 Health Survey (SF-12 v 2) was used in this study to measure health status through two summary scores: a physical (PCS) and a mental component (MCS). PCS and MCS summary scores of less than 50 demonstrate worse physical and mental health, while scores of greater than 50 indicate better health. Older women in the sample had a mean physical component score of $38.27(S D=7.88)$ with scores ranging from 22 to 57 and a mean mental component score of 53.23(SD=7.05) with scores ranging from 42 to 66 . Caregivers' perception of the older women's physical component had scores ranging from 23 to 61 and a mean of $36.75(S D=9.08)$ while the mental component score ranged from 31 to 72 .

\section{Abbreviated Duke Social Support Index}

The Abbreviated Duke Social Support Index (DDSI) was used with this sample to measure older women's level of social support. Possible scores for the DSSI range from 0 to 33 for the 11-item measure. Older women in the sample had scores ranging from 19 
to 32 with a mean score of 26.08 ( $S D=3.67)$. Informal caregivers' perception of the older women's level of social support had a mean score of $27.36(S D=2.86)$ and scores ranging from 20 to 32 .

\section{Patient Health Questionnaire}

The Patient Health Questionnaire (PHQ-9) is a nine item instrument to measure depression, with possible scores ranging from 1 to 27 , with higher scores indicating increased depression severity. Among this sample of older women, the mean score was $4.52(S D=3.23)$ with scores ranging from 0 to 12 . For informal caregivers in this sample, their perception of depression severity of the older women yielded scores in the range of 0 to 19 with a mean score of $6.24(S D=4.84)$. None of the participants in this study expressed suicide risk.

\section{Research Questions and Hypothesis Testing}

Three research questions were proposed for this study and three hypotheses were tested.

\section{Research Question 1}

The first research question for this study asked about the relationship older women and their informal caregivers. Using the Dyadic Relationship Scale, mean scores and standard deviations were calculated for positive dyadic interaction and negative dyadic strain among older women and their caregivers. Findings indicate that both the older women and caregivers in this sample had moderate scores on the positive dyadic interaction subscale (older women $n=12.56, S D=1.87$; caregiver $n=12.36, S D=3.74$ ) and 
low scores on the negative dyadic strain subscale (older women $n=3.32, S D=2.16$; caregiver $n=4.04, S D=3.03$ ). These findings demonstrate that there was moderate positive dyadic interaction and low negative dyadic strain among older women-informal caregiver pairs. Two tailed paired sample t-tests $(\mathrm{df}=24)$ were used to compare the mean scores between older women and informal caregivers for the positive dyadic interaction $(t(24)=.25, p=.81)$ and negative dyadic strain $(t(24)=.92, p=.37)$ scores. These $t$-tests were not significant, therefore, the mean scores between older women and informal caregivers do not differ significantly.

\section{Research Question 2}

The second research question for this study asked a) how age identity influences independence among older women and b) what factors in the caregiving relationship influence older women's age identity. Simple linear regressions were used to understand the predictor variables.

In the analysis on how age identity influences independence among older women, simple linear regressions were conducted with older women's age identity scores as the independent variable with older women's Katz Index of Independence in Activities of Daily Living score and Lawton Instrumental Activities of Daily Living score as the dependent variables. The regression found that older women's age identity had no relationship to the Katz score $(F=.046 ; \mathrm{df}=1 ; \mathrm{b}=-.003 ; \beta=-.045)$. Older women's age identity had a weak relationship to the Lawton Instrumental score $(\mathrm{F}=1.084 ; \mathrm{df}=1$; $\mathrm{b}=.014 ; \beta=.212)$. 
Simple linear regressions were also used in the analysis to understand what factors in the caregiving relationship influence older women's age identity. The subscales within the Dyadic Relationship Scale, both the positive interaction score and the negative dyadic strain score were the independent variable in the analysis, while older women's age identity was the dependent variable. Older women's positive interaction score had a weak relationship to age identity $(\mathrm{F}=.776 ; \mathrm{df}=1 ; \mathrm{b}=2.311 ; \beta=.181)$, while the negative dyadic strain score had no relationship to older women's age identity ( $\mathrm{F}=$ $.002 ; \mathrm{df}=1 ; \mathrm{b}=.113 ; \beta=.010)$.

\section{Research Question 3}

The third research question for this study asked about the differences in attitudes towards aging among older women and caregivers within the sample. Qualitative responses indicated that both older women and informal caregivers did not consider themselves old in comparison to others and that they accepted aging as a normal process in life. Participants described fears associated with getting older as well as how they have been inspired by older adults with active lifestyles. The qualitative theme of Attitudes Towards Aging is discussed in the qualitative findings section within this chapter.

\section{Hypothesis 1a, 2a, 3a}

Hypothesis 1a, 2a and 3a for this study stated the controlling for health status, social support, depression, and all other independent variables in the model, older women who experience lower levels of dyadic strain and greater levels of positive dyadic 
interaction, who have age identities lower than their chronological age, and who have greater positive attitudes toward aging have higher levels of independence. Due to the sample size not being large enough, a multiple regression was not performed and therefore this hypothesis could not be tested. Rather, Pearson correlations $(r)$ were calculated to understand the relationship between the major study variables. Results from two-tailed bivariate correlations for both the older women and caregiver scores are listed in Table 3.

Correlations were conducted using scale scores between the dependent variables (Katz Index of Independence in Activities of Daily Living and Lawton Instrumental Activities of Daily Living) and the following eight variables: 1) attitudes toward own aging, 2) age identity, 3) positive-dyadic interaction, 4) negative-dyadic strain, 5) physical health component, 6) mental health component, 7) social support and 8) depression.

Correlations for older women scores were largest between Katz Index and the physical component score $(r=.442)$, while moderate correlations were found between Katz Index and depression $(r=.350)$, as well as Katz Index and positive dyadic interaction $(r=.330)$. Among older women's Lawton scores, the strongest relationship was with social support $(\mathrm{r}=.443)$, and weaker relationships were with mental health component $(r=.251)$, positive-dyadic interaction $(r=.247)$, as well as age identity $(r=.212)$.

Among informal caregiver's Katz Index scores, the strongest correlation was with the physical health component score $(r=.563)$, followed by weaker correlations with social support $(r=.203)$ and the mental health component score $(r=-.250)$. Informal 
caregiver's Lawton scores had a moderate correlation to both social support $(r=.367)$ and the physical health component score $(r=.329)$. A negative weak relationship was found between older women's Lawton scores and depression with $r=-.224$.

\begin{tabular}{|c|c|c|c|c|}
\hline \multicolumn{5}{|c|}{$\begin{array}{l}\text { Table } 3 \\
\text { Bivariate Correlations Between Variables (Total Scale Scores) }\end{array}$} \\
\hline \multirow[b]{2}{*}{ Assessment Measures } & \multicolumn{2}{|c|}{$\begin{array}{l}\text { Older Women } \\
\qquad(\mathrm{n}=25)\end{array}$} & \multicolumn{2}{|c|}{$\begin{array}{l}\text { Informal Caregiver } \\
\qquad(\mathrm{n}=25)\end{array}$} \\
\hline & Katz & Lawton & Katz & Lawton \\
\hline $\begin{array}{l}\text { Katz Index of Independence in Activities } \\
\text { of Daily Living }\end{array}$ & -------- & & ------- & \\
\hline $\begin{array}{l}\text { Lawton Instrumental Activities of Daily } \\
\text { Living }\end{array}$ & $.506^{* *}$ & -------- & $.678 * * *$ & -------- \\
\hline Attitude Toward Own Aging & .064 & -.010 & -.083 & .159 \\
\hline Age Identity & -.045 & .212 & -.083 & .033 \\
\hline Dyadic Relationship Scale & & & & \\
\hline Positive-Dyadic Interaction & .330 & .247 & .066 & .170 \\
\hline Negative-Dyadic Strain & .051 &.-124 & .056 & .090 \\
\hline Short-Form 12 Version 2 Health Survey & & & & \\
\hline Physical Component & $.442 *$ & .127 & $.563 * *$ & .329 \\
\hline Mental Component & -.157 & .251 & -.250 & .091 \\
\hline Abbreviated Duke Social Support Index & .100 & $.443 *$ & .203 & .367 \\
\hline Patient Health Questionnaire & .350 & .124 & .136 & -.224 \\
\hline
\end{tabular}

Note: All correlations are two-tailed. ${ }^{*} p<.05 \quad{ }^{* *} p<.01 \quad * * * p<.001$ 


\section{Hypothesis 2b}

Hypothesis $2 b$ for this study stated that informal caregivers' perspective of older women's age identity would have a larger disparity than the older woman's own age identity. Using the mean scores to compare age identity, this hypothesis was not supported. The mean score for informal caregivers' perspective of older women's age identity was $14.48(S D=21.24)$, while the older woman's own age identity had a mean score of $16.68(S D=23.96)$. These findings indicate that the informal caregiver's perspective of older women's age identity had a smaller disparity than the older woman's own age identity. A paired sample t-test between older women's and informal caregivers' mean scores of age identity was found to be not significant $(t(24)=.48, p=.64)$.

\section{Hypothesis 3b}

Hypothesis $3 b$ for this study stated that older women would have more positive attitudes towards aging compared to the perspective of their informal caregivers. Using the Attitudes Towards Aging scale, mean scores and standard deviations were calculated for both older women $(m=2.04, S D=1.37)$ and their informal caregivers $(m=2.08$, $S D=1.61)$. These findings indicate a .04 difference between the mean scores of older women and informal caregivers, with the caregivers scoring higher. Two tailed paired sample t-tests were used to compare the mean scores between older women and informal caregivers for the Attitudes Toward Aging $(t(24)=.09, p=.93)$ scores. These t-tests were not significant, therefore, this supports the finding that the mean scores between older women and informal caregivers did not differ. 


\section{Qualitative Findings}

The qualitative findings of this study are based on 8 total interviews, 4 with older women and 4 with informal caregivers. These interviews were conducted to understand about the relationship between older women and their informal caregivers. Participants' qualitative responses were coded by two researchers, separately, to identify which model of caregiving best describes the relationship between the older woman and her informal caregiver. To establish intercoder reliability for the caregiving models, the PI and an additional coder identified themes and quotations to be used in the analysis. When there was a discrepancy between coders, a meeting was held with both coders to determine which caregiver model $/ \mathrm{s}$ best describes the relationship between the older woman and her informal caregiver. In terms of this research study, the caregiving models were used to analyze the older women-informal caregiver dynamic. Themes are discussed and quotations from the interviews are presented to illustrate these themes.

\section{Theme 1: Attitudes Towards Aging}

The first theme that emerged from all the qualitative interviews was attitudes towards aging, which was also measured in the quantitative interviews. This theme was divided into four sub-themes: 1) participants did not consider themselves old in comparison to others, 2) they accepted aging as a normal process in life, 3) they have fears associated with getting older and 4) they are inspired by older adults with active lifestyles. 


\section{Sub-Theme A: Does not feel old in comparison to others}

The first sub-theme that emerged was that participants did not perceive themselves as being old. Both older women and informal caregivers mentioned that they did not feel old because they can compare themselves to people around them who may be older. In addition, how people define "old" changes throughout their lifespan, as a caregiver described that they viewed a certain age as old when they were younger, but now that they are currently that age, their perception of "old" has changed.

I really feel that I'm not old. There is a lot of old people. There are not so old people. People of all ages. I don't feel old. I don't consider some old lady old. I look at people. I don't know their ages, I don't care. (Older Woman)

I will say that old lady and she might be younger than me, you know (Older Woman)

I, um, have this author that I read. Love his books. Love his writing. I've read more from him than anyone else and he may be a few years older than me and I said to myself, god, what am I going to do when he stops writing. You know, so do I think of myself in that same, no, I definitely think that I am outside of that because I virtually thinking that means that I think that I am going to outlive him and oh what am I going to do, who am I going to replace him with, you know. So. Um. I just find that very interesting, it's like Stevie Wonder just had a birthday, a few days ago and um, and I think he's 62 or 63 . Now I remember him when he was 12, being little Stevie Wonder, but I don't remember, I don't know why, I didn't remember that I was only a few years older than him, so there's a way of kinda not putting yourself in them mix and standing back and looking and seeing, so um (Caregiver)

Old used to be like, when I was young, old was when you got your $1^{\text {st }}$ gray hair, but now, people could get gray hair when they are young. Like jeez. I became a grandma at [age]. And I was like, I aint old enough for this, you know. I thought that you were supposed to be gray haired and old, you know. [laughs]. But um, now, I wanna say 80, 85. Then you are old as dirt (Caregiver) 


\section{Sub-Theme B: Accepted aging as a normal process in life}

The second sub-theme to emerge was that aging has been accepted as a normal process in life and something that they have no control over. The idea that aging is not only about chronological time, but also is influenced by a person's mindset was discussed in the interviews. Participants felt that their attitude about aging is an important aspect of their everyday lives.

I feel like you are old if you want to be old. And you, you either like it or you don't like it. (Older Woman)

well, right now, I'm an old lady and there ain't much I can do. (Older Woman)

well, when you get too old, you can't be too independent. I think it's a natural part of aging (Older Woman)

I think it's the way you look at it, whether it is positive or negative. Its just, how you look at it and how you think about it, because that is one process that you got to go through (Older Woman)

that's is something that goes with the territory. You born and you die. So like I said, just live one day at a time. (Older Woman)

I do believe that I'm going to live life, live a long life, relatively healthy and that's my belief. Primarily because that is all I've known, you know. So I have that if I have nothing else. So that's my view (Caregiver)

\section{Sub-Theme C: Fears associated with getting older}

The third sub-theme to emerge was fears associated with getting older. A caregiver stated that their view on aging has changed as a result of interacting with older people. They described a fear that they themselves, may be just as vulnerable as an older person when they reach advanced age. 
I really, age is, is something that I am finding out to be very hard to deal with. I mean, I thought it was a beaut, it is a beautiful thing, don't get me wrong, it is a beautiful thing to get older but what im finding that Is a lot of people are not in good health as they get older and their health depreciates, you know, it goes really bad, really quick and there's no, there's no zest of life there, you know. so my views on aging has changed a lot and im like, I want to get older but it depends highly on my health. I want to be a healthy older person, not someone that has to depend on someone else to take care of me. That's the problem I have with aging is the fear of not being able to care for yourself. That's very scary. (Caregiver)

\section{Sub-Theme D: Inspired by older adults with active lifestyles}

The fourth sub-theme to emerge from the qualitative interviews was that caregivers were inspired by older women with active lifestyles. Although they were taking care of a home-bound older woman, the caregivers were able to also observe older women in everyday life continuing to be physically active. Embracing a lifestyle that incorporates exercising was mentioned as a way to take care of yourself and ensure that mobility is maintained.

well wrinkles ain't good. Um. You know. I never think about getting old. Um. I think the worst part of being old is when you have to have to be in a state like she is, you can't do anything for yourself. you know. I've gone to the mall many many times and seen these little old ladies walking around and them having lunch and I'm like, god. I would kill if my mama could do that, you know. Like I said, my wish is for her is just to be able to walk again. (Caregiver)

If you keep yourself in good, good condition, you can stay here 80, 90 years old. It just depends on how you, um, take care of your body. I'm still playing basketball and I am [age]. I got inspired when I went to [location] in [year] We played in the senior games. And we saw this team of ladies from Detroit. They were 70 and 75 years old, still playing. And I spent every game that they played, me and my best friend went and watched. Cause we were like, people call, people now, around us, ya'll are too old to be playing. And I'm like, we were so inspired by seeing them play and we was inspired by seeing 80, 85 year old men and women 
running track. And they had this big old Olympic thing and did every sport that you could possibly name. they had 80s, 85 year olds playing, running track, swimming and I'm looking like, this is how you maintain, through your diet and how you take care of yourself. Age is not only a number. It is how you live your life and how you take care of yourself. (Caregiver)

\section{Theme II: Opinions on Independence}

The second theme that emerged from the interviews was opinions on independence. The two sub-themes were identified: 1) being able to do everything without assistance and 2) the importance of perseverance by never giving up in order to achieve greater independence.

\section{Sub-Theme E: Independence is being able to do tasks without assistance}

The first sub-theme under Opinions on Independence was viewing independence as being able to do tasks without assistance. Independence was seen as being selfsufficient without needing to rely on others to complete tasks or make decisions.

it's pretty much the ability to take care of yourself and do whatever it is you going to do. Whether that is financially or physically or even spiritually. Um being able to make your own decisions about what you want to happen with your life and how you want your life. (Caregiver)

Just being able to do, to maintain my life for myself, without any assistance from anyone else. And that's what it means to me. (Caregiver)

Well, I am independent, I don't ask anybody for anything. So. I guess I really need it. And. But. Independence. We are all independent. She cant do the things that she used to do. She thinks that she can, the only thing. She thinks she can do anything but I tell her not to. Driving. No. that's a definite no. (Caregiver) 


\section{Sub-Theme F: Perseverance}

Another sub-theme that emerged from the data was perseverance. Older woman acknowledged that they faced challenges, but they also viewed themselves as capable of bettering their lives. These older women were empowering themselves to strive to improve their physical and mental capacities.

I don't think about giving up. There's a lady there, she tells me that she is learning how to walk again. She, she's just cant. And I said, just keep trying. Don't give up. Cause when I first started [program], I couldn't hardly, I was in a wheelchair and I overcome that. It was hard. I aint gonna say it wasn't but it was hard. (Older Woman)

Like I'm trying to think what I am supposed to do and trying to keep in mind what I am supposed to do. That's the hardest part. Trying to remember everything. That's the hardest part of it. I'm dealing with it. (Older Woman)

\section{Theme III: The Caregiving Relationship}

The third major theme from the qualitative interviews was about the characteristics of the relationship between the older women and their informal caregivers. This theme examines the responsibilities, roles as well as the positive and negative interactions within the caregiving relationship.

\section{Sub-Theme G: Responsibilities within the caregiving relationship}

A sub-theme that emerged was the responsibilities within the caregiving relationship. These responsibilities included laundry, finances, food preparation, bathing, assistance related to continence, getting dressed, medication management, transportation and scheduling of appointments. 
I do everything. I wash, I dry. I do everything. She doesn't do anything. When I wash her clothes and I dry her clothes, she has to fold them and put them up. That's all she does. (Caregiver)

anything I ask him to do, I cant do. (Older Woman)

All of the responsibilities that she had prior to her stroke, are now my responsibilities. I pay the bills, I do the cooking, I do all of the things that are unbecoming to me, all of the things I planned my life not to do. (Caregiver)

well sometimes, you see, I have trouble giving myself a bath, she do that. We, I had, we had said that I ne, I don't need a nurse, I got her. She do it. And she do what she wanna do. (Older Woman)

The um provider means that I, I mean, I do everything for her that she would do for herself. Um we wake up in the morning, I get her up, I change her diaper, I get her ready for her bath, if she's having a bath on that day. I get her dressed. I take her vitals. I feed, I don't feed her, but I prepare her meals, um I get her ready, dressed, out the door. I do the washing. (Caregiver)

I made sure that she has her medicines. I made sure that she made it to doctor's appointments. I took her to see the podiatrist. I, it's like whatever, it was a test day, I made sure she got there. You know, so that, it was just normal for me. Its been four years of been doing this so its so normal that it's nothing. You know. It doesn't matter. I don't need anybody else to do it. (Caregiver)

well I wish I could do it myself. Everything. But now that I cant. (Older Woman)

uh food, you know, making her meals, administering her medicine. Checking the insulin, I meant, I'm sorry, the sugar levels. Administering the insulin. It's pretty much nurse duty [laughs]. (Caregiver)

\section{Sub Theme H: Roles within the caregiving relationship}

The second sub-theme in the caregiving relationship was regarding roles.

Caregivers described that roles have changed over time, especially daughters, who felt that they went from being the child to now being the provider and caretaker. In addition, caregivers described that they felt the older woman is their 
responsibility and the role of caregiver was a natural progression. In some

situations, the caregiver felt that their role within the relationship was something

that they did not choose, but were forced into a caregiving role due to family

dynamics.

Well, my relationship today is probably um, one of role reversal. Since I'm her primary caregiver now. (Caregiver)

She is all that remains of my upward level family and she's an only child so there's no uncles or aunts. And for me, its like, she deserves to have her remaining days spent in peace and quiet and that's what I am going to do, so for me, it, it's like, it just my thing to do. It's like now I'm obligated. I don't if that's the right word to use, obligated because, no matter what she's my mom and I will not let her go any other way. Not as long as I had the strength. Now if I was sickly and couldn't take care of her, things might be different and despite all the different injuries and things that I had since she's been with me, you know, we are still living like two peas in a pod. So. You know. So, pretty much. She and I, and I am I. We just gonna be together until God calls one of the two of us or things get to a point where I now longer can handle. (Caregiver)

The role has changed. She will tell you now that I'm the mother and she is the daughter. It flipped because now I have to take care of her, which is not a problem. And we know that the roles had to change after she suffered a stroke. Anybody that tells somebody that they first have the stroke and they are sitting at [hospital] and they are trying to do physical therapy, she says, I don't have to do shit, my daughter is going to take care of me. So I go in and I'm like, you telling these people this. And she says, well its true. And I say, well yes it is true but I need help. Its just me and you. I need help. And she tries. She tries. The only thing we tell her is don't go near the stove. (Caregiver)

She is absolutely my sole responsibility. I put that on nobody else. Nobody else. That's just me. And that's because when I was younger, my sister and I made a, kind of a pact that um she would take care of my grandparents til both of them passed on, which she did and my responsibility was my parents. And my father, god bless him, is already gone, so I still have my mama. So (Caregiver)

I've been doing it ever since I was 10 years old. So I guess, its, you know, I took care of my father for nine years before he passed away so I guess, you know, everybody just says, oh well, she is going to do it. Leave her to it. (Caregiver) 
well, I'm an only child so we are very close. And uh, basically, I just do everything for her. She did it for me when we were growing up, so the tables are turned so now I have to take care of her. Its not that I have to, I do. That's my job. So. That's it (Caregiver)

I'm able to take care of me and my mom. I take care of her. I mean, she is going to be my number one priority with anything (Caregiver)

I don't have worries. I am the boss. (Older Woman)

\section{Sub-Theme I: Positive interactions within the caregiving relationship}

An additional sub-theme that emerged was positive interactions within the caregiving relationship. Positive interactions included being able to adapt to situations, feeling a special bond within the relationship and being grateful for having more time to spend with each other. Reciprocity within the relationship were observed in the interactions between the caregiver and care recipient.

My wish for many years, for my mama to be able to walk again. And it isn't going to happen, um, but it's always been a wish. If I could change something, it would be for her to be healthy enough for her to take care of herself. It's not going to happen so I decided that I just wish for these days to be as calming and as peaceful for her as they can be. (Caregiver)

You really have to really really really try to enjoy every moment that you can. And I don't say that lightly cause I try to laugh all the time. I try to smile all the time. I try to keep a positive spin on everything, even when it is hard and it is stressful, I try not to let things bother me. I just don't. I choose to not to sit and wallow. It does me no good. It does me no good. What is wallowing going to solve. So [laugh]. I just don't, I don't, I try not to stress myself out about anything. The biggest worries I have is, I feeling like I don't matter. In the big picture of things, what matters is her. Its just her and as long as she is okay, and like I said, every day that she opens them eyes, I've been gifted another day. (Caregiver)

Doesn't complain. She doesn't ever say she is hurting or anything, so, her biggest complaint is sitting here and she gets up wanting something. And I'm like, how did you do that, "I don't know". So I'm like, okay, when you figure it out, you tell me what you want me to help you with, okay. And she says, alright. You know, and as long as she's okay, I'm okay. You 
know, I'm just trying to roll with whatever is going on with her. (Caregiver)

More or less, my grandmother and my aunt, raised me more than she did. When my grandmother was alive, we were more like sisters cause my grandmother was the one, the authority figure for all of us. All two grandkids so, she was the authority figure when she passed away. We still have this connection. I always knew that she was my mother but we were more like sisters because my grandmother called, we, each one of us called my grandmother, mom. So. That was it. (Caregiver)

\section{Sub-Theme J: Negative interactions within the caregiving relationship}

The fourth sub-theme within the caregiving relationship is regarding negative interactions. Caregivers described feeling burned out and having conflicts with older women. In addition, caregivers stated that they feel their caregiving responsibilities are consuming their personal lives and that they feel powerless within their situation.

See every now and then, she'll thank me um and I now know that she appreciates me but when I first started doing this, I used to light into her and let her know that she was very ungrateful and that um, I know that her life is difficult and is changed but so has mine and I'm doing my best. Uh she told me the other day, "thank you for taking such good care of me" . and I was like really surprised, you know, but um mostly our, our conflicts since I came here, mostly has to do with, I'm very critical, always have been. Um, but I don't just criticize to be a bitch. I understand the definition of criticism and typically I follow the letter. If I got something to complain about, I also have a number of suggestions as how better to do it (Caregiver)

I'm definitely burned out. I can't tell you how many times I break down in the course of a day. And the things that I try to do, this is how I've lived for ten years. There's no wonder everything goes to the floor, there is no space. You pick up something, you are going to drop it. Because, and it's the same way in the kitchen. It's like, I'm yelling and screaming.

(Caregiver)

Now, I, me and my husband don't even have time to, you know, have a life to ourselves because everything surrounded, you know, she cant be left alone. Somebody has to be here so therefore that cuts my life back, the 
little bit that I would be able to do, you know, and I just feel that if they were able, if they at least tried, you know, let me take mom for a couple of hours, and it would be good, but it never happens and it just really gets to me now because I'm not in a place to where I feel comfortable, I feel happy, you know what I am saying. If I was better off, than yea, I would be fine. But I'm not so. (Caregiver)

And I just thought, can somebody work with me to help make this. I'm not doing all this for me. And what I've discovered is that I don't have any choices, really, you know, I can, I'm just tired. I've never tried to live anybody else's life because I've never had children, I've never been a mother, I don't know anything about life other than taking care of me. And that's what I want to go back to. Now, I mean, I don't have any illusions about it. I gladly do whatever I can for my mother but this situation isn't working. Um and it would be easier for me, if I didn't live here, but I suspect that its going to take me a long time to, I would just, I'm just tired because it's almost as if we are all living on borrowed time and no one has stopped, except for me and maybe my dad has but I don thave these conversations with him because he has to keep going. (Caregiver)

\section{Theme IV: Family System}

The family system was a theme that emerged from the interviews, describing positive and negative interactions within the family.

\section{Sub-Theme K: Supportive Family System}

Another sub-theme in the interviews was having a supportive family system as a caregiver described that other family members were willing and able to help with some of the caregiving responsibilities. The family support system included both immediate family members as well as those in the extended family. Families utilize individual strengths to provide continual care to the older woman.

[CG son] takes her to the simple stuff, like when she has to go and I can't make it. He will take her to get her like mammogram or stuff like that, pick her up from dialysis, take her to dialysis, but anything, like a hospital and anything that she needs to deal with her diabetes or her sugar or uh dialysis, I, her medicine. If I go out of town, I leave it, day by day in 
ziplocs so he will know what goes. He gives her insulin shots. We, it's like a tag team between the both of us. Cause he cares just as much as I do about my mom. He's always here so, you say, you going to the hospital, he's going to be right there. He's coming. So, it's like a tag team and we both take care of her together. Those two are like peas in a pod. They, they have secrets. They are like this [crossed fingers]. And uh, I guess it was like when my grandmother was around, me and her were the two partners. Now I'm the one with the more authority and its like those two are hooked up. So when cant get it from me, she is gonna get it from him. So. That's how that goes. (Caregiver)

We all help each other and if I need them, um to watch my mom, I have a cousin, I have two or three cousins that are more than willing to bring her, tell us what to do, we got it. One of them I, well the both of them, the children from my cousins are nurses. So if she goes to my cousin over there [name], she's a nurse. If she goes to my cousin [name], her daughter [name] is a nurse. So, everything is, you know, we all help each other. You know, we don't have that many people left, but we are all close knit. If you pick up the phone and say I need, and its alright. Come on. Let's go. If I, if [CG son] can't watch her, he has to go to work or whatever, I can always call my cousin or his girl friend and its like, and my cousin will come. Everybody is checking. Everybody is picking up. So. That's about basically it. We all pitch in and we will do that until, until they leave this world. And nobody is ever going to complain. (Caregiver)

\section{Sub-Theme L: Non-supportive Family System}

The last sub-theme to emerge in the qualitative interviews was about nonsupportive family systems. Concerns regarding other family members being uninvolved in the life of the older woman, as well as caregivers feeling like they don't have a voice amongst their family were identified as non-supportive family systems. In addition, selfcenteredness among individual family members was described as causing tension and conflicts within the family system.

no I have two brothers who are deceased and if they were alive, they would be useless so, its not like. I mean, I say that, based on how they lived their lives. Um so no, there really, I have somehow have got to find a way to get to that. (Caregiver) 
I said, you know, when we first brought you home, um, I encouraged them not to lift you but allow you to do to it on your own because that is what would make you stronger. Well my voice was never heard, so um. And the only times she does, did it, now she does it because I insist and I have insisted for two years that she can get her body from that wheelchair to that bed. You are not helping her (Caregiver)

its um its very frustrating. Um there are things that I gave up on, like we need a ramp. With a ramp, there would be a lot of independence, I wouldn't require anybody to be here. I could get her down that ramp and on our way, whether we were walking to the corner or if I was getting her ready for STS. But instead that money ends up going to red light tickets. (Caregiver)

even my children, all of them, including the one that lives here, don't have a good, overall feeling about her because she never was like a real grandmother to them. (Caregiver)

She longs for her sons. Her sons have always been, you know, well, I guess that is my personal feelings that she's always loved them more, and you know, and she's cared for me, but now that she needs all of us, its just me. They, you know, I've been, I've gone through a lot of hard issues with them as far as my mom is concerned. (Caregiver)

My husband has issues with it all, so. He is very hurt by it cause his family is very close knit. He has a close knit family. They, you know, oh my god, you go to the hospital any time with his dad now there, its like 5 or 6 people. My family, they don't nothing about being close, don't know nothing about caring, anything. They are very selfish, self centered people. All for themselves and he doesn't understand that. He doesn't understand it, so. Causes us issues. But oh well. (Caregiver) 


\section{CHAPTER V: DISCUSSION}

The purpose of this study was to explore the relationship between older women and their informal caregivers. The primary finding of this study was that there were both positive and negative experiences within the relationship dynamic of older women and their informal caregivers. The theoretical foundation of this study suggests that caregiving models are important to understand the dynamics in the caregiving relationship.

This study intended to recruit over 200 participants, however, this was not feasible and the study yielded an insufficient sample size, reducing the statistical power of the quantitative results. The study used a convenience sampling strategy among older women receiving home care in Miami, Florida. Throughout the quantitative closedended interviews, several participants described experiences and details relating to the closed-ended questions. The PI of the present study took notes of comments said during interviews, as well as observations that were made as a result of interacting with participants.

The findings from this study show that age identity had no relationship to the Katz Index of Activities in Daily Living. This is not consistent with research by Bowling and colleagues (2005), which found a significant association between age identity and functional status. In addition, age identity in this study was found to have a weak relationship to the Lawton Instrumental Activities of Daily Living (IADL) score. These findings are contrary to those of Moser, Spagnoli \& Santos-Eggimann (2011) who found that there was a strong association with negative perceptions of aging with difficulties in 
IADLs. This could be due to the multiple regression that was conducted by Moser et al., (2011), as the present dissertation study was able to perform a multiple regression due to the insufficient sample size.

\section{Dynamics within the Caregiving Relationship}

Caregivers who described the relationship with their mother as draining and stressful, also indicated that they felt their life was on hold as a result of the caregiving relationship. In particular, caregivers who felt overwhelmed with the responsibilities of caring for their mother also experienced tension and strain within the relationship due to family history and personality differences. A few of the caregivers who lived with the older woman indicated that they wanted a separate life and identity from caregiving while also feeling that they weren't getting enough help from other family members. It appeared that certain caregivers experienced burden and burn-out, stating that they did not have enough time to do the things they want, and that they weren't able to maintain an outside job or that they were too tired to take care of themselves through exercise or socializing. These findings were consistent with Litwin (2014), who suggested that relationship closeness between the caregiver and care recipient can moderate negative caregiver outcomes. Moreover, the lack of emotional bonding between the caregiver and care recipient causes higher levels of stress, a greater sense of burden and an increase in depression symptoms for the caregiver (Litwin, 2014). In contrast, emotional bonds within the caregiving relationship can be a protective factor against the burdens resulting from caregiving responsibilities (Litwin, 2014). 
Caregivers in the sample described that they learned from the experience, including gaining patience and strength, increasing their ability to have real emotional love for others, while also understanding that the relationship can improve over time through continued honest communication. Furthermore, caregivers felt grateful to still have the older women in their lives, as one caregiver stated that they were not prepared for life without their mother and would want more time with her. Encouraging the older woman to be active and do things on her own is a positive uplift within the relationship, as the focus is strengths-based rather than based on the limitations of the individual. Cohesiveness with the caregiving relationship suggests that the older women and their caregivers are a team, as they experience the journey through the aging process and grow together as a unit.

In certain situations, the older woman accepted the caregiver's behavior, regardless of her own feelings about the situation, in an attempt to not cause conflict in the relationship. In this study, it was observed that older women felt guilty when their sons were the informal caregiver, with the older women expressing that they give their sons too many responsibilities while also feeling like their sons didn't have a life of their own as a result of the caregiving responsibilities. It appeared that although older women reported they were satisfied with their caregiving relationship with their son, they also felt that they couldn't fully express their needs and desires for fear of losing their son as a caregiver. Older women who received care from daughters did not express these concerns or fears, but rather, seemed to believe that daughters naturally assumed the role of informal caregiver, while sons' were not as receptive to accepting that responsibility. 
Interestingly, older women who had multiple sons and only one daughter, had been receiving most of their care from their sole daughter. This finding is relevant to research by Berg-Weger, Burkemper, Tebb \& Rubio (2001), found that there were variations in the type of care provided by female and male caregivers within a family with female caregivers providing the more stereotypical "female tasks" such as shopping, cleaning and handling health issues, while the male caregivers focused more on household maintenance and visiting the older adult parent. Differences in gender expectation may influence the dynamics within the caregiving relationship. Further, older women in the study felt that their sons' priorities shifted after marriage, stating that the son became more focused on their spouse's family and the son's mother-in-law or father-in-law rather than his own parents' needs and wishes.

Caregivers who treat older women as a child or engage in non-encouraging communication, may continue to treat the vulnerable older women in this manner if patronizing behavior is not addressed (Edwards \& Noller, 1998). In this study, older women who did not feel their emotional needs were being met by their caregiver, utilized other people in their support system for encouragement and socialization. It was observed that a lack of reciprocity between members of the caregiving relationship attributed to unmet needs and less satisfaction among individuals in the relationship. This finding is consistent with research by Horowitz, Goodman \& Reinhardt (2004), where they found that a lack of congruence within the caregiving dynamic could cause negative interactions within the relationship. Further, Lyons and colleagues (2002) 
suggested that caregiver characteristics are more predictive of the caregiver's own wellbeing than the characteristics of the care recipient.

\section{Implications for Social Work}

This study contributes to the field of gerontological social work in several ways. Findings from this study can lead to improvements in social work practice, theory and research, as well as provide future directions for social policy and services.

\section{Research}

The findings from this study may contribute to understanding the psychosocial determinants of independence and healthy aging of older women. The influence of caregiving on older women's independence needs to be further explored. This study examined factors relating to self-care activities, attitudes toward aging, age identity, depression, health, social support and interactions within the caregiving relationship. The present study was a cross-sectional design and did not analyze the caregiving relationship over time, specifically the history of the relationship, how the caregiving relationship began or the uniqueness of each relationship. Dynamics within family systems or between friends can shift as individuals pass through developmental phases and reciprocity in a relationship can vary throughout the lifespan. Feelings of reciprocity, appreciation and validation over time could have an impact on older women-informal caregiver relationships as well as family systems that experience addiction, abuse or exploitation. Therefore, future research should examine caregiving dynamics as a 
continual process, with collective experiences over days, weeks, months or years, rather than a static one.

During the recruitment phase of this study, case managers and social workers from the home care agencies provided the researcher with potential older womeninformal caregiver participants. However, there were instances when the older woman or the informal caregiver was contacted and stated that they either did not have a caregiver or that they were not the caregiver for the older woman. Since individuals did not identify themselves as a caregiver and older women did not feel that they have a caregiver, it may be useful to explore other terminology with this population. The term "informal caregiver" may carry connotations when speaking to older adult populations, therefore, researchers need to be aware of how this term is perceived by both older women and the people who provide assistance to them. Conducting focus groups could be beneficial for researchers to learn about undertones that are associated with the term "caregiver", as this knowledge would inform future studies.

The older women in the sample were receiving home care services through an agency either through Medicare or Medicaid funding. Undocumented immigrants, however, are legally unable to access home care resources using federal and state allocated programs. Research on undocumented immigrants and their caregiver-care recipient relationships could provide insight to this specific part of the aging population and their access to adequate care and resources.

Research is needed to help practitioners and educators understand gender-based developmental factors on independence. Older women are an understudied population 
and there are few strategies aimed at addressing developmental risk factors that are a result of life-cycle changes and adjustments that may impact independence in later life. . findings from this study may provide guidance for constructing strategies to enhance gerontological social work practices relevant to help and managing relationships between

older women and their informal caregivers. The descriptions of the characteristics of the interaction between older women and informal caregivers may also inform future research aimed at optimizing this relationship to improve healthy aging outcomes in general. Research can aid in the understanding of older women's needs as well as recognize the influence of interactions and relationships on their independence.

\section{Practice}

Scharlach and colleagues (2000) stated, "Overarching social work goals in an aging society include preservation of maximum independence, optimal functioning, dignity, and quality of life, through personal empowerment and effective and efficient service utilization" ( $\mathrm{p}$ 525). Identifying older women's deficits in physical function at an earlier stage can reduce their risk of disability and dependence in the future while also helping anticipate and prioritize their needs to provide further support and services (Brach, VanSwearingten, Newman \& Kriska, 2002). The role of social workers with this population consists of both clinical and macro-level approaches to help older women live as independently as possible within a community-based setting. This study can help provide practitioners with knowledge on the caregiving relationship to improve and strengthen communication among older women and their caregivers. Improving communication within the caregiving dyad may lead to improved health outcomes for 
older women. Social workers and case managers at home care agencies should work with older women and their informal caregivers to establish individual goals. Examples of older women's goals may include increasing their mobility and strength or maintaining their level of social interaction through adult day programs or church activities. Informal caregivers' may be interested in reducing their stress levels or reducing their caregiving responsibilities to be able to resume full-time work. Discrepancies between individuals' goals could cause tension within the caregiving relationship, therefore, social worker practitioners should encourage older women and their caregivers to effectively problem solve. Social workers engage in care coordination across settings to assist older women and their informal caregivers in meeting their needs though community resources and professional organizations.

Performing daily activities is important for older women as routines and meaningful activities can increase feelings of independence and self-efficacy at their current stage as well as at a later time in life (Oswald et al., 2007). Knowledge gained from this study can inform about risk and protective factors, provide knowledge for potential assessments and lead to preventative intervention efforts in maintaining independence at home for older women.

\section{Policy}

There is a need to create new health care policies that agree with not only current needs of the older female population, but the needs and concerns of future generations as well. The long-term care workforce is unprepared to meet the needs of older women due to the inability to recruit qualified and committed individuals, high turnover rates and the 
increase in demand for services due to the aging Baby Boomer population. There is a great need to provide care to older women through both informal and formal caregiving; however, the current direct care (paid and unpaid) workforce is expected to be insufficient to meet the demand of the rapidly increasing aging population (SimonRusinowitz et al., 2010).

Older women and informal caregivers would potentially benefit from increases in services and funding for home and community-based care, however, the ability for agencies to implement provisions may be limited by their organizational capacities and current commitments to providing care. There is a need for the government to find costeffective and proven ways to provide services and resources to older women living in the community. In addition, preventative health programs should be developed to provide older women and informal caregivers with information on the aging process while aiming to alleviate potential health risks in the future. Communication, collaboration and partnerships among local, state and federal programs are necessary to provide adequate resources, services and funding within the community and improve the continuum of care (Kunkel \& Lackmeyer, 2010). In addition, government and policy makers need to know about evidence-based approaches to home- and community-based services to provide best outcomes for older women's physical, emotional and social well-being.

\section{Limitations}

There are limitations in this study due to the cross-sectional design. Since data is only collected at one point in time, a cross-sectional design identifies associations, but not causality between variables. Although the assessment measures were read aloud to 
participants, the study relied on the viewpoints of older women and their informal caregivers and there may have been response bias, social desirability bias or other inaccuracies that could have affected the findings. Additionally, it is important to note the design and structure of the residence of the older women, where some of the interviews occurred with "thin walls" and may have caused some participants to respond in a socially or culturally acceptable manner to avoid conflict with the other individual in the caregiver-care recipient relationship.

Every effort was made to gather data of the proposed sample size of 206, however, the study yielded an insufficient sample size, reducing the statistical power of the results. Recruitment of participants for this study was difficult due to multiple factors. First, staff turnover at the two agency sites limited the researcher's ability to have continual, sustained contact with case managers and their supervisors throughout the duration of the data collection process. The researcher was in contact with numerous staff members at the agency sites, however, when a staff member left an agency, the researcher had to establish contact with a new staff member who did not have knowledge of the research project. The staff turnover, as well as the reestablishing of rapport, led to lapses in the data collection process. Second, Florida implemented the Statewide Medicaid Managed Care (SMMC) during the 2013-2014 fiscal year. Individuals who were Medicaid recipients in Florida were required to enroll in the SMMC to continue receiving their home and community-based services offered through the agencies. Case managers at the agencies had to meet with all their clients during the enrollment period to assist in choosing a managed care plan to ensure that their clients would not have 
interruptions in service delivery. This transition to SMMC was overwhelming to the two agency study sites due to the lack of staff and resources to accommodate the mandates by the State of Florida. As a result, the researchers in this study faced difficulties in communicating with case managers and management at the study sites during the SMMC enrollment period, with a substantial lapse in data collection from October 2013 through February 2014. Third, the researcher was not able to provide incentives to the case managers to encourage referrals due to agency policies that prohibit staff from accepting gifts. Motivating case managers and staff at the two agency study sites to provide participant referrals was especially difficult for the researcher. Fourth, individuals may have declined to participate in this study due to cultural and ethnic views regarding the mistrust of health research, which may have limited the diversity within the sample. In addition, foreign born residents and immigrants may not be entirely acculturated to American culture, and therefore may have varying opinions on the expectations of the relationship and roles between older women and informal caregivers. Lastly, limited financial resources contributed to the limited duration of time for data collection, as continual data collection to meet the desired sample size of 204 would have not been financially feasible for the researcher

The interview process for this study was about forty-five minutes for each participant. The researchers were present during data collection, which could have influenced the responses of older women and their caregivers. A convenience sampling strategy was used for this study due to the lack of available potential participants at the two agency study sites. This sampling bias limits the ability to generalize the findings of 
this study. . A snow-ball sampling strategy might have been more effective in collecting data among a home-bound population. Another limitation for this study was that data was collected in Miami-Dade County and did not include other dense urban cities. An inclusion criteria for the study was that participants spoke in English and/or Spanish, while those who spoke other languages were excluded. The Haitian-Creole population in Miami was not extensively examined in this study. This study did not interview individuals with Alzheimer's or dementia. In addition, there are multiple factors that influence independence in older women. Although this study attempted to look at seven specific factors (relationships between older women and their informal caregivers, roles of both the informal caregiver and older women, attitudes toward aging, age identity, health, social support, and depression), there are additional factors that were not examined in this study. Factors that can be expected to affect independence in older women but were not measured in this study include: access to reliable transportation, fear of falling, as well as safety and crime within the community. Additionally, the length of time for the caregiving relationship in months or years was not measured in this study.

\section{Future Studies}

The strengths and limitations of this study can provide insight for conducting future research among community-living older women and their informal caregivers. Dynamics within the caregiving relationship are complex. Studies that address the caregiving relationship from both a physical and psychosocial perspective are limited. Generally, the informal caregivers' role is seen as assisting with the older women's selfcare, and less on understanding the psychosocial aspects of the relationship. Caregivers 
do however, provide direct care to older women as well as psychosocial support. Although the present study included social support, depression and health status in the analysis, there is a need to examine additional aspects regarding the emotional, cultural, social, spiritual and mental health within caregiving relationships and whether these aspects have an effect on an older women's ability to perform self-care activities. Furthermore, the conceptualization of the informal caregiving interaction as a process has not been clearly defined in the literature, affecting the ability to compare results across studies. Future investigation is needed to formally define the elements within the caregiving relationship that influence an older women's ability to live within the community and promote the highest level of independence while reducing the risk of institutionalization.

Cho (2007) developed a framework that could be useful in future studies that examine the informal caregiving relationship and its influence on the health outcomes among older women. The present study did not examine the differences that could occur between various types of informal caregivers. It is possible that the interactions between older women and spousal caregivers would be different than interactions between older women and their children or relatives. In the present study, it was observed that older women interacted differently with informal caregivers who were sons compared to daughters. Understanding the differences in expectations and roles among older women and their daughters or sons should be explored more extensively. Specifically, the viewpoint of role reversal would be interesting for researchers to identify, as there were older women in this study that suggested that when they were younger, they took care of 
their daughter, but now they are older, the daughter takes care of them. Interestingly, older women did not state that their relationship with a son caregiver had experienced this type of role reversal. Observing the differences among older women- daughter relationships compared to older women-son relationships could provide insight into family dynamics and gender expectations. Moreover, future studies could examine whether the type of care that is provided in the relationship is influenced by whether the informal caregiver is a family member or non-family member.

Cho's (2007) theoretical framework also discussed the nature of the caregiving relationship, stating that it is determined by five factors, including: 1) availability, 2) familiarity, 3) motivation, 4) care recipient's preference and 5) burden. These five factors were not specifically measured in the present study, and therefore, would be areas of the caregiving relationship that should warrant further investigation. Availability refers to the proximity of the caregiver to the older women as well as the length of commitment for the caregiving roles, while familiarity relates to understanding the needs and wants of both the caregiver and care recipient as well as preferences and common culture (Cho, 2007). The care recipient's preference suggests that the recipient may prefer care from one person over another (Cho, 2007). Exploring these five factors within the context of qualitative interviews could provide rich information about the dynamics within the caregiving relationship that could inform researchers and lead to standardized measures. 


\section{Conclusion}

This study provides practical information that can be easily applied to caregiving relationships and gerontological social work. Independent living is influenced by physical, cognitive and emotional functioning as well as the availability of social support and access to resources (Skelton, Kunik, Regev \& Naik, 2010). The factors that influence caregiver health and burden have been well-documented in the literature, however, understanding the relationship dynamic from both perspectives within the caregiver-care recipient dyad have not been as extensively explored. The present study conducted community-based research among older women receiving home care and their primary informal caregivers. Older women may interact with more than one caregiver, therefore, it may be necessary to examine the collective role of sole, primary, secondary and potential caregivers (Horowitz, 1992) as well as gain an in-depth understanding of family dynamics and the family system's influence on the relationship between older women and their primary informal caregivers. Future research should focus on exploring the caregiving system over time in a longitudinal design, rather than observing solely dyadic caregiving relationships at one moment in time. Increasing scientific knowledge of the factors that influence women's functional health could lead to improved approaches in service delivery within the homes of older women to improve older women's ability to live independently. 


\section{LIST OF REFERENCES}

AARP, Public Policy Institute, AARP. Global Aging Program \& AARP (2006). European experiences with long-term care: France, the Netherlands, Norway, and the United Kingdom. Washington, DC: AARP.

Aberg, A. C., Sidenvall, B., Hepworth, M., O'Reilly, K. \& Lithell, H. (2004). Continuity of the self in later life: Perceptions of informal caregivers. Qualitative Health Research, 14(6), 792-815.

Adams, K. B.. (2006). Late adulthood. In J. B. Ashford, LeCroy, C. W. \& Lortie, K. L. (Eds.). Human behavior in the social environment: A multidimensional perspective $\left(3^{\text {rd }}\right.$ ed.). Belmont, CA: Thomson Brooks/Cole (pp.568-626).

Aleman, S. \& Paz, J. (1998). The Yaqui elderly, cultural oppression, and resilience. Journal of Aging and Ethnicity, 1, 113-127.

American Community Survey and Puerto Rico Community Survey (2010). 2010 Subject Definitions. Retrieved from http://www.census.gov/acs/www/Downloads/data_documentation/SubjectDefinitions/201 $\underline{0 \_ \text {ACSSubjectDefinitions.pdf. }}$

Andreescu, C., Chang, C-CH., Mulsant, BH. \& Ganguli, M. (2008). Twelve-year depressive symptom trajectories and their predictors in a community sample of older adults. Int Psychogeriatr, published online by The International Psychogeriatrics Association.

Angel, R. J. \& Frisco, M. L. (2002). Self-assessments of health and functional capacity among older adults. In J. H. Skinner, J. A. Teresi, D. Holmes, S. M. Stahl \& A. L. Stewart (Eds.). Multicultural measurement in older populations. (p. 129-146). New York, NY: Springer Publishing Company, Inc.

Arno, P., Levine, C. \& Memmott, M. (1999). The economic value of informal caregiving. Health Affairs, 18(2), 182-188.

Bader, J. E. (1985). Respite care: Temporary relief for caregivers. In S. Golub \& Freedman, R. J. (Eds.). Health needs of women as they age. (pp. 39-52). New York, NY: The Haworth Press, Inc.

Barnett, P. A. \& Gotlib, I. H. (1989). Psychosocial functioning and depression: Distinguishing among antecedents, concomitants, and consequences. Psychological Bulletin, 104(1), 97-126.

Barrett, A. E. (2003). Socioeconomic status and age identity: The role of dimensions of health in the subjective construction of age. Journal of Gerontology: Social Sciences, 58B(2), 101-109. 
Barrett, A. E. \& von Rohr, C. (2008). Gendered perceptions of aging: An examination of college students. Int'l J. Aging and Human Development, 67(4), 359-386.

Bayliss, E. A., Steiner, J. F.., Fernald, D. H., Crane, L. A. \& Main, D. S. (2003).

Descriptions of barriers to self-care by persons with comorbid chronic diseases. Annals of Family Medicine, 1(1), 15-21.

Beeber, A. S. (2008). Interdependence: Building partnerships to continue older adults' residence in the community. Journal of Gerontological Nursing, 34(1), 19.

Berg-Weger, M., Burkemper, E., Tebb, S. \& McGartland Rubio, D. (2001). The wellbeing of siblings who share care. Journal of Gerontological Social Work, 35:1, 89-105.

Biddle, B. J. (1979). Role theory: Expectations, identities, and behaviors. New York, NY: Academic Press.

Biddle, B. J. (1979). Role theory: Expectations, identities, and behaviors. New York, NY: Academic Press.

Bishop, C. E. (1999).. where are the missing elders? The decline in nursing home use, 1985 and 1995. Health Affairs, 18(4), 146-155.

Bookman, A., Harrington, M., Pass, L. \& Reisner, E. (2007). Family caregiver handbook. Cambridge, MA: Massachusetts Institute of Technology.

Bould, S. (2008). A population health perspective on disability and depression in elderly women and men. Journal of Aging \& Social Policy, 17(2), 7-24.

Bowling, A. (2005). Aging well: Quality of life in old age. New York, NY: Open University Press.

Brach, J. S., VanSwearingen, J. M., Newman, A. B. \& Kriska, A. M. (2002). Identifying early decline of physical function in community-dwelling older women: Performancebased and self-report measures. Physical Therapy, 82(4), 320-328.

Bradley, J. M. \& Cafferty, T. P. (2001). Attachment among older adults: Current issues and directions for future research. Attachment \& Human Development, 3(2), 200-221.

Bruce, M. L., McAvay, G. J., Raue, P. J., Brown, E. L., Meyers, B. S., Keohane, D. J., Jagoda, D. R. \& Weber, C. (2002). Major depression in elderly home health care patients. American Journal of Psychiatry, 159(8), 1367-1374.

Caffrey, C., Sengupta, M., Moss, A., Harris-Kojetin, L. \& Valverde, R. (2011). Home health care and discharged hospice care patients: United States, 2000 and 2007.

National Health Statistics Reports, 38, Hyattsville, MD: National Center for Health Statistics

Calasanti, T. M. \& Slevin, K. F. (2001). Gender, social inequalities, and aging.

Lanham, MD: Altamira Press - a division of Rowman and Littlefield Publishers, Inc. 
Chadiha, L. A. \& Adams, P. (2003). Physical health and economic well-being of older African American women: Toward strategies. In B. berkman \& L. Harootyan (Eds.). Social work and health care in an aging society: Education, policy, practice and research (pp. 149-176). New York, NY: Springer Publishing Company.

Chapin, R., Nelson-Becker, H. \& MacMillan, K. (2006). Strengths-based and solutionsfocused approaches to practice. In B. Berkman \& S. D'Ambruoso (Eds.). Handbook of social work in health and aging. (p. 789-796). New York, NY: Oxford University Press.

Cho, E. (2007). A proposed theoretical framework addressing the effects of informal caregivers on health-related outcomes of elderly recipients in home health care. Asian Nursing Research, 1(1): 23-34.

Clark, N. M., Becker, M. H., Janz, N. K., Lorig, K. R., Bakowski, W. \& Andereson, L. (1991). Self management of chronic disease by older adults: A review and questions for research. Journal of Aging and Health, 3(1), 3-27.

Clarke, L. H. (2011). Facing age: Women growing older in anti-aging culture.

Lanham, MD: Rowan \& Littlefield Publishers, Inc.

Coady, N. \& Lehmann, P. (2001). An overview of and rationale for a generalist-eclectic approach to direct social work practice. In P. Lehmann \& N. Coady (Eds.). Theoretical perspectives for direct social work practice: A generalist-eclectic approach. (pp. 3-26).

Cohen, S. (1988). Psychosocial models of social support in the etiology of physical disease. Health Psychology, 7, 269-297.

Cohen, S., Gottlieb, B. H. \& Underwood, L. G. (2000). Social relationships and health. In S. Cohen, L. G. Underwood \& B. H. Gottlieb (Eds.). Social support measurement and intervention: A guide for health and social scientists. (pp. 3-28). New York, NY: Oxford University Press.

Cohen, S. \& McKay, G. (1984). Social support, stress, and the buffering hypothesis: A theoretical analysis. In A. Baum, S. E. Taylor \& J. E. Singer. Handbook of psychology and health. Pp. 253-267. Hillsdale, NJ: Erlbaum.

Cohen, S. \& Syme, S. L. (1985). Issues in the Study and Application of Social Support. In S. Cohen \& S. L. Syme (Eds.)-. Social Support and Health. Pp. 3-22. Orlando, FL: Academic Press, Inc.

Collins, A. L. (2008). Is positive well-being protective of mobility limitations among older adults? The Journals of Gerontology, Series B:Psychological Sciences, 63(6), P321.

Collins, K. \& Strumpf, E. (2000). Living longer, staying well: Promoting good health for older women. The Commonwealth Fund. 
Cox, E. A. \& Parsons, R. R. (1996). Empowerment-oriented social work practice: Impact on late life relationships of women. Journal of Women and Aging, 8, 129-143.

Creswell, J. W. \& Plano Clark, V. L. (2011). Designing and conducting mixed methods research. $\left(2^{\text {nd }}\right.$ ed.). Thousand Oaks, CA: SAGE Publications, Inc.

Crimmins, E., Kim, J. \& Sole-Auro, A. (2010). Gender differences in health: Results from SHARE, ELSA, and HRS. The European Journal of Public Health, 21(1), 81-91.

Davis, L. V. (1996). Role theory and social work treatment. In F. J. Turner (Ed.) Social work treatment: Interlocking theoretical approaches. (4 ${ }^{\text {th }}$ ed.) (pp. 581-600). New York, NY: The Free Press.

Davis, N. C. \& Friedrich, D. (2010). Age stereotypes in middle-aged through old-old adults. Int'l J. Aging and Human Development, 70(3), 199-212.

Demo, D. H. (1992). The self-concept over time: Research issues and directions. Annual Review of Sociology, 18(1)., 303-326.

Denton, M. M. (2009). Where would you turn for help? Older adults' awareness of community support services. Canadian Journal on Aging, 27(4), 359-370. DHHS. (1999). Health, United States, 1999: Health and Aging Chartbook. (PHS99-1232-1). Hyattsville, MD: Department of Health and Human Services.

DHHS. (1999). Health, United States, 1999: Health and Aging Chartbook. (Chartbook, DHHS PHS 99-1232-1). Hyattsville, MD: Department of Health and Human Services.

Department of Health and Human Services: Centers for Medicare and Medicaid Services. (2014). Home health care: What it is and what to expect. Retrieved from http://www.medicare.gov/what-medicare-covers/home-health-care/home-health-carewhat-is-it-what-to-expect.html.

Doress-Worters, P. B. \& Siegal, D. L. (1994). The new ourselves, growing older: Women aging with knowledge and power. New York, NY: Simon \& Schuster.

Dykstra, P. (2007). Aging and social support. In G. Ritzer (Ed.) Blackwell Encyclopedia of Sociology. (pp. 83-93).

Eckert, J. K., Morgan, L. A. \& Swamy, N. (2004). Preferences for receipt of care among community-dwelling adults. Journal of Aging \& Social Policy. 16(2), 49-65.

Edwards, H. (2001). Family caregiving, communication, and the health of care receivers. In M. L. Hummert \& J. F. Nussbaum (Eds.). Aging, communication, and health: Linking research and practice for successful aging. (pp. 203). Mahway, NJ: Lawrence Erlbaum Associates, Publishers.

Elderly women: A diverse and growing population. (2011). ElderIssues, Inc. Retrieved from 
http://www.elderissues.com/library/index.cfm? fuseaction=article \&art id $=122 \& C F I D=80$ 510\&CFTOKEN $=29796888 \& \mathrm{x}=1732170$.

Elon, R., Phillips, C., Loome, J. F., Denman, S. \& Woods, A. (2000). General issues and comprehensive approach to assessment of elders. Comprehensive geriatric assessment. New York: McGraw Hill, 1. 39.

Erlangsen, A., Billie-Brahe, U. \& Jeune, B. (2003). Differences in suicide between the old and the oldest old. Journal of Gerontology : Social Sciences. 58B(5), S314-S322.

Farlex, I. (2011). The free dictionary: Functional limitation. Retrieved from http://medical-dictionary.thefreedictionary.com/functional+limitation.

Federal Interagency Forum on Aging-Related Statistics. (2010). Older Americans 2010: Key indicators of well-being. Washington, D. C.: U. S. Government Printing Office.

Fox, J. (2008). Applied regression analysis and generalized linear models. Thousand Oaks, CA: Sage Publications.

Gallo, J. J., Bogner, H. R., Fulmer, T. \& Paveza, G. J. (2006). Handbook of Geriatric Assessment. Sudbury, MA: Jones and Bartlett Publishers.

Gannon, L. R. (1999). Women and aging: Transcending the myths. New York, NY: Routledge.

Garner, J. D. (1999). Feminism and feminist gerontology. Journal of women \& aging, 11(2-3), 3-12.

Gatz, M. \& Fiske, A. (2003). Aging women and depression. Professional Psychology: Research and Practice. 34(1) 3-9.

Gaylord, S. (2001). Women and aging: A psychological perspective. In J. D. Garnder \& S. O. Mercer (Eds.), Women as they age ( $2^{\text {nd }}$ ed., pp. 49). New York, NY: The Haworth Press.

Germain, C. \& Gitterman, A. (1980). The life model of social work practice. New York: Columbia University Press.

Gitlin, L. N., Winter, L., Dennis, M. P., Corcoran, M., Schinfeld, S. \& Hauck, W. W. (2006). A randomized trial of a multicomponent home intervention to reduce functional difficulties in older adults. Journal of the American Geriatrics Society, 54(5), 809-816.

Goodger, B., Byles, J., Higganbotham, N., \& Mishra, G. (2008). Assessment of a short scale to measure social support among older people. Australian and New Zealand Journal of Public Health 23(3), 260-265.

Gorman, B. K. \& Read, J. G. (2006). Gender disparities in adult health: An examination of three measures of morbidity. Journal of Health and Social Behavior, 47(2), 95-110. 
Graf, C. (2007). The Lawton Instrumental Activities of Daily Living (IADL) Scale. The Hartford Institute for Geriatric Nursing, 23. Retrieved from consultgerirn.org/uploads/File/trythis/try_this_23.pdfs/File/trythis/try this_23.pdf.

Greene, R. R. (2000). Social work with aged and their families ( $2^{\text {nd }}$ ed.). Hawthorne, NY: Aldine De Gruyter.

Greene, M. G. \& Adelman, R. D. (2001). Building the physician-older patient relationship. In M. L. Hummert \& J. F. Nussbaum (Eds.). Aging, communication, and health: Linking research and practice for successful aging. (pp. 101). Mahwah, NJ: Lawrence Erlbaum Associates, Publishers.

Greene, R. R. \& Cohen, H. (2008). Sociocultural and spiritual aspects of functional age. In R. R. Greene (Eds.). Social work with the aged and their families. ( $3^{\text {rd }}$ ed., 109-128). New Brunswick, NJ: Transaction Publishers.

Greene, V. J., Caracelli, J. C. \& Graham, W. F. (1989). Toward a conceptual framework for mixed-method evaluation designs. Educational Evaluation and Policy Analysis. 11(3), 255-274.

Greenwald, M. (2004). Gender differences: Do men and women view long-term care differently? Findings from a national study. The MetLife Mature Market Institute and AARP Healthcare Options.

Han, C., Ahn Jo, S., Kwak, Ji-H., Pae, C., Steffens, D., Jo, I. \& Park, M. H. (2008). Validation of the Patient Health Questionnaire-9 Korean version in the elderly population: the Ansan Geriatric study. Comprehensive Psychiatry, 49, 218-223.

Happ, M. B. (2009). Mixed methods in gerontological research: Do the qualitative and quantitative data "touch"?. Research in Gerontological Nursing, 2(2), 122-127.

Harahan, M. F. \& Stone, R. L. (2009). Who will care? Building the geriatric long-term care labor force. In R. B. Hudson (Ed.). Boomer Bust? Economic and political issues of the graying society. (vol. 2: The boomers and their future). Westport, CT: Praeger Publishers.

Harding, T. (1997). Lives worth living: The independence and inclusion of older people. London: Help the Aged.

Harris-Kojetin, L., Sengupta, M., Park-Lee, E.. \& Valverde, R. (2013). Long-term care services in the United States: 2013 Overview. National health care statistics; no. 1. Hyattsville, MD: National Center for Health Statistics.

Harvard School of Public Health, NORC, Kaiser, United Hospital Fund, Visiting Nurse Services of New York. (1998). Long Term Care from the Caregiver's Perspective.

Healthy Places: Healthy places terminology. (2010). Centers for Disease Control and Prevention. Retrieved from http://www.cdc.gov/healthyplaces/terminology.htm . 
Hill-Burton Act. (2011). Wikipedia. Retrieved from http://en.wikipedia.org/wiki/Hill\%E2\%80\%93Burton_Act.

Himes, C. L. \& Fang, Y. (2007). Social lives in later life. In J. M. Wilmoth \& K. F. Ferraro (Eds.). Gerontology: Perspectives and Issues $\left(3^{\text {rd }}\right.$ ed). New York: Springer Publishing Company.

Holland, D. (2008). Alarming rates of poverty persist among older women. AARP. Retrieved from http://www.aarp.org/about-aarp/press-center/info022008/alarming rates of poverty persist among older wome.html.

Horowitz, A., Goodman, C. \& Reinhardt, J. P. (2004). Congruence between disabled elders and their primary caregivers. The Gerontologist, 44(4), 532-542.

Howes, C. (2007). Who will care for the women? In H. Hartmann \& S. Lee (Eds.) Women and Retirement Security. New York: Russell Sage Foundation.

Hudson, R. B. (2010). Analysis and advocacy in home- and community-based care: An approach in three parts. Journal of Gerontological Social Work. 53(1), 3-20.

Information Technology Services. (2013). Research consulting: General FAQ \#25 Handling missing or incomplete data. Retrieved from http://ssc.utexas.edu/software/faqs/general\#General_22.

Jacobson, S. F. (2004). Evaluating instruments for use in clinical nursing research. In M. Frank-Stromborg \& S. J. Olsen (Eds.). Instruments for clinical health-care research. ( $3^{\text {rd }}$ ed., pp.3-19). Sudbury, MA: Jones and Bartlett Publishers, Inc.

Joint Rural Health Advisory Committee and State Community Health Services Advisory Committee Work Group. (2006). Creating healthy communities for an aging population. Minnesota Department of Health.

Kahana, E., Kahana, B. \& Wykle, M. (2009). "Care-Getting": A conceptual model of marshalling support near the end of life. Current Aging Science. 3, 71-78.

Kahana, E. \& Young, R. (1990). Clarifying the caregiving paradigm: Challenges for the future. In D. E. Biegel \& A. Blum (Eds). Aging and caregiving: Theory, research, and policy. Newbury Park, CA: Sage Publications, Inc. (pp 76-97).

Kelly, L. E., Knox, V. J. \& Gekoski, W. L. (1998). Health \& wellness resource center women's views of institutional versus community-based long-term care. Research on Aging, 20(2), 218-28.

Kimberley, D. \& Osmond, L. (2011). Role theory and concepts applied to personal and social change in social work treatment. In F. J. Turner (Ed). Social work treatment: Interlocking theoretical approaches. ( $5^{\text {th }}$ ed., pp. 413-427). 
Kleinspehn-Ammerlahn, A., Kotter-Gruhn, D. \& Smith, J. (2008). Self-perceptions of aging: Do subjective age and satisfaction with aging change during older age? Journal of Gerontology: Psycholgocial Sciences, 63B(6), P377.

Koenig, H. G., Westlund, R. E., George, L. K., Hughes, D. C., Blazer, D. G. \& Hybels, C. (1993). Abbreviating the Duke Social Support Index for use in chronically ill elderly individuals. Psychosomatics, 34(1), 61-69.

Konetzka, R. T. \& Werner, R. M. (2009). Disparities in long-term care: Building equity into market-based reforms. Medical Care Research and Review, 66(5), 491-521.

Kotter-Gruehn, D., Kleinspehn-Ammerlahn, A., Gerstorf, D. \& Smith, J. (2009). Selfperceptions of aging predict mortality and change with approaching death: 16-year longitudinal results from the Berlin Aging Study. Psychology and Aging, 24(3), 654-667.

Krause, N. (1997). Anticipated support, received support, and economic stress among older adults. The Geronotological Society of America. 52B(6), P284-P293.

Krause, N., Liang, J. \& Yatomi, N. (1989). Satisfaction with social support and depressive symptoms: A panel analysis. Psychology and Aging. 4(1), 88-97.

Kroenke, K., Spitzer, R. L. \& Williams, J. B. W. (2001). The PHQ-9: Validity of a brief depression severity measure. Journal of General Internal Medicine, 16, 606-613.

Kropf, N. P., Schneder, R. L. \& Stahlman, S. D. (1993). The status of gerontology in baccalaureate social work education. Educational Gerontology, 19(7), 623-634.

Kunkel, S. R. \& Lackmeyer, A. E. (2010). The role of the aging services network in balancing and transforming the long-term care system. Public Policy \& Aging Report, 20(1), 16.

Lab \#1: Data Screening. (2008). Retrieved from www.psychwiki.com/images/7/79/Lab1DataScreening.doc.

Laerd Dissertation. (2010). Research strategy and research ethics. Retrieved from http://dissertation.laerd.com/articles/research-strategy-and-research-ethics.php.

Lamers, F., Jonkers, C. C. M., Bosma, H., Penninx, B. W. J. H., Knottnerus, J. A., van Eijk, J. Th.M. (2007). Summed score of the Patient Health Questionnaire-9 was a reliable and valid method for depression screening in chronically ill elderly patients. Journal of Clinical Epidemiology, 61, 679-687.

Lawton, M. P. (1975). The Philadelphia geriatric center morale scale: A revision. Journal of Gerontology, 30, 85-89.

Leveille, S., Penninx, B.,Melzer, D., Izmirlian, G. \& Guralnik, J. (2000). Sex differences in the prevalence of mobility disability in old age: The dynamics of incidence, recovery, and morality. Journal of Geronotology: Social Sciences, 55B, S41. 
Levy, B. R., Slade, M. D. \& Kasl, S. V. (2002). Longitudinal benefit of positive selfperceptions of aging on functional health. The Journals of Geronotlogy Series A:Biological Sciences and Medical Sciences, 57(5), P. 409.

Levy, B. R., Slade, M. D., Kunkel, S. R. \& Kasl, S. V. (2002). Longevity increased by positive self-perceptions of aging. Journal of Personality and Social Psychology, 83(2), 261-270.

Li, L. W. \& Conwell, Y. (2007). Mental health status of home care elders in Michigan. The Gerontologist, 47(4), 528-534.

Lingler, J. H., Sherwood, P. R., Crighton, M. H., Song, M. K. \& Happ, M. B. (2008). Conceptual challenges in the study of caregiver-care recipient relationships. Journal of Nursing Research, 57(5). 367-372.

Litwin, H., Stoeckel, K. J. \& Roll, A. (2014). Relationship status and depressive symptoms among older co-resident caregivers, Aging \& Mental Health, 18(2), 225-231.

Long-Term Care (2009) Retrieved October 31, 2011, from http://www.medicare.gov/longtermcare/static/home.asp.

Lui, C., Everingham, J., Warburton, J., Cuthill, M. \& Bartlett, H. (2009). What makes a community age-friendly: A review of international literature. Australian Journal on Ageing, 28(3), 116-121.

Lustbader. W. (1993). Counting on kindness: The dilemmas of dependency. New York: Free Press.

Lyons, K. S. \& Sayer, A. G. (2005). Using multilevel modeling in caregiver research. Aging \& Mental Health, 9(3), 189-195.

Lyons, K. S., Zarit, S. H., Sayer, A. G. \& Whitlatch, C. J. (2002). Caregiving as dyadic process: Perspectives from caregiver and receiver. Journal of Geronotology:

Psychological Sciences, 57B, P195-P204.

Macia, E., Lahmam, A., Baali, A., Boetsch, G. \& Chapuis-Lucciani, N. (2009).

Perception of age stereotypes and self-perceptions of aging: A comparison of French and Moroccan populations. Journal of Cross-Cultural Gerontology, 24, 391-410.

Magasi, S. \& Hammel, J. (2009). Women with disabilities' experiences in long-term care: A case for social justice. American Journal of Occupational Therapy, 63, 35-45.

Marshall, G. (1998). Informal care. A dictionary of sociology. Retrieved from Encyclopedia.com: http://www.encyclopedia.com/doc/1088-informalcare.html.

McDowell, I. \& Newell, C. (1996). Measuring health: A guide to rating scales and questionnaires $\left(2^{\text {nd }}\right.$ ed). New York: Oxford University Press. 
McGuire, L. C., Strine, T. W., Vachirasudlekha, S., Mokdad, A. H. \& Anderson, L. A. (2008). The prevalence of depression in older U. S. women: 2006 Behavioral risk factor surveillance system. Journal of women's health. 17(4), 501-507.

McInnis-Dittrich, K. (2005). In P. Quinlin (Ed.). Social work with elders: A biopsychosocial approach to assessment and intervention. Boston, MA: Pearson Education, Inc.

Merrill, S. S., Seeman, T. E., Kasl, S. V. \& Berkman, L. F. (1997). Gender differences in the comparison self-reported disability and performance measures. The Journals of Geronotology Series A:Biological Sciences and Medical Sciences, 52(1), M19.

Minichiello, V. (2000). Perceptions and consequences of ageism: Views of older people. Ageing and Society, 20(3), 253.

Morris, J. (1993). Gender and disability. In J. Swan, V. Finkelstein, S. French \& Oliver (Eds.). Disabling barriers- enabling environments ( $1^{\text {st }}$ ed., pp 85-92). Newbury Park, CA: Sage Publictions.

Murtagh, K. \& Hubert, H. (2004). Gender differences in physical disability among an elderly cohort. American Journal of Public Health, 94(8), 1406-1411.

NASDA. (2014).. About adult day services. Retrived from nadsa.org/learn-more/aboutadult-day-services/.

Nathanson, I. L. \& Tirrito, T. . (1998). In B. Tucker \& S. Gamer (Eds.) Gerontological social work: Theory into practice. New York, NY: Springer Publishing Company, Inc.

National Alliance for Caregiving and AARP (2004). Caregiving in the U.S. MetLife Foundation.

The National Nursing Home Survey: 2004 Overview. (2009). Vital and Health Statistics, 13(167). Retrieved from http://www.cdc.gov/nchs/data/series/sr 13/sr13 167.pdf.

NewsHour Health Unit (2011). A history: The evolution of nursing home care in the United States. Retrieved from http://www.pbs.org/newshour/health/nursinghomes/timeline.html.

Newman, A. B. \& Brach, J. S. (2001). Gender gap in longevity and disability in older persons. Epidemiologic Reviews, 23(2), 343-350.

Olson, L. K. (2003). The not so golden years: Caregiving, the frail elderly, and the longterm care establishment. Lanhma, MD: Rowman \& Littlefield Publishers, Inc.

Oswald, F., Wahl, H., Schilling, O., Nygren, C., Fange, A., Sixsmith, A. . . Iwarsson, S. (2007). Relationships between housing and health aging in very old age. The Gerontologist, 47(1), 96-107. 
Parker, M., Baker, P. S. \& Allman, R. M. (2002). A life-space approach to functional assessment of mobility in the elderly. Journal of Geronotological Social Work, 35(4), 34.

Parks, J. A. (2003). No place like home? Feminist ethics and home health care. Bloomington, IN: Indiana University.

Payne, M. (1997). Modern social work theory. ( $2^{\text {nd }}$ ed). Chicago, IL: Lyceum Books, Inc.

Pearlin, L. I. (1985). Social structure and processes of social support. In S. Cohen \& S. L. Syme (Eds.). Social support and health. Pp. 43-60. Orlando, FL: Academic Press, Inc.

Pearlin, L. I. \& Skaff, M. M. (1995). Stressors and adaptation in late life. In M. Gatz (Ed). Emerging issues in mental health and aging, 97-123. Washington, DC.: American Psychological Association.

Pearson, V. L. (2000). Assessment of function in older adults. In R. L. Kane \& R. A. Kane (Eds.). Assessing older persons. (pp. 17). New York: Oxford University Press.

Pierpont, J. H. \& McGinty, K. (2005). Suicide. In C. N. Dulmus \& L. A. Rapp-Paglicci (Eds.) Handbook of preventive interventions for adults (pp. 56-75). Hoboken, NJ: John Wiley \& Sons, Inc.

Pinquart, M. (2002). Good news about the effects of bad old-age stereotypes. Experimental Aging Research, 28, 317-336.

Pinquart, M. \& Sorensen, S.. (2001). Gender differences in self-concept and psychological well-being in old age: A meta-analysis. The Journals of Gerontology Series A, Biological Sciences and Medical Sciences, 56(4), P195-P213.

Pirkl, J. J. (2009). The demographics about aging: Characteristics of our aging population. Transgenerational Design Matters. Retrieved from http://transgenerational.org/aging/demographics.htm.

Pomeroy, E. C., Holleran, L. K. \& Franklin, C. (2003). Adults. In C. Jordan \& C. Franklin (Eds.), Clinical Assessment for Social Workers: Quantitative and Qualitative Methods ( ${ }^{\text {nd }}$ ed.). Chicago, IL:Lyceum Books, Inc.

Population Division, U.S. Census Bureau (2008). Table 12. Projections of the population by age and sex for the United States: 2010 to 2050. (NP2008-T12).

Poulshock, S. W. \& Deimling, G. T. (1984). Families caring for elders in residence: Issues in the measurement of burden. Journal of Geronotology, 39(2), 230-239.

Price, D. \& Ginn, J. (2003). Sharing the crust? Gender, partnership status and inequalities in pension accumulation. In S. Arber, K. Davidson \& J. Ginn (Eds.), Gender 
and aging: Changing roles and reltaionships (pp. 127). Philadelphia, PA: Open University Press.

Putnam, M. \& Stark, S. (2006). Aging and functional disability. In B. Berkman \& S. D'Ambrusoso (Eds.) Handbook of social work in health and aging (pp. 79). New York, NY: Oxford University Press.

Quadagno, J. (1999). Aging and the Life Course. Boston: McGraw-Hill.

Rabiner, D. J., Konrad, T. R., De Friese, G. H., Kincade, J., Bernard, S. L., Woomert, A., Arcury, T. \& Ory, M. G. (1997). Metropolitan versus nonmetropolitan differences in functional status and self-care practice: Findings from a national sample of communitydwelling older adults. The Journal of Rural Health, 13(1), 14-28.

Richmond, T., Tzah Tang, S., Tulman, L., Fawcett, J. \& McCorkle, R. (2004). Measuring function. In M. Frank-Stromborg \& S. J. Olsen (Eds.). Instruments for clinical health-care research. ( $3^{\text {rd }}$ ed., pp 83-99). Sudbury, MA: Jones and Bartlett Publishers, Inc.

Rickwood, D. \& Rylands, K. J. (2008). Predicting depression in a sample of older women living in a retirement village. Australian Journal on Ageing, 19(1), 40-42.

Robbins, S. P., Chatterjee, P. \& Canda, E. R. (2006). Contemporary human behavior theory: A critical perspective for social work. $\left(2^{\text {nd }}\right.$ ed.) New York, NY: Pearson Education, Inc.

Roberto, K. A. (1999). Older women, their children, and grandchildren: A feminist perspective on family relationships. Journal of Women \& Aging, 11(2), 67-84. Rosow, I. (1967). Social integration of the aged. New York: Free Press.

Rose, M., Ejaz, F. K., Noelker, L. S. \& Castora-Binkley, M. (2010). Recent findings on home and community-based services across the states. Public Policy \& Aging Report, 20(1), 10 .

Rosow, I. (1967). Social integration of the aged. New York: Free Press.

Rothery, M. (2008). Critical ecological systems theory. In N. Coady \& P. Lehmann (Eds.) Theoretical perspectives for direct social work practice: A generalist-eclectic approach ( $2^{\text {nd }}$ ed. pp 89- 118). New York, NY: Springer Publishing Company.

Ryan, C. E., Epstein, N. B., Keitner, G. I., Miller, I. W. \& Bishop, D. S. (2005). Evaluating and treating families: The McMaster approach. New York, NY: Routledge, Taylor and Francis Group, LLC.

Salive, M. E. \& Guralink, J. M. (1997). Disability outcomes of chronic disease and their implications for public health. In T. Hickey, M. A. Speers \& T. R. Prohaska (Eds.), Public health aging (pp. 87-106). Baltimore, MD: Johns Hopkins University Press. 
Schafer, M. H. \& Shippee, T. P. (2010). Age identity, gender and perceptions of decline: Does feeling older lead to pessimistic dispositions about cognitive aging? Journal of Geronotology: Social Sciences, 65B(1), 91.

Schriver, J. M., (2001). Human behavior in the social environment: Shifting paradigms in essential knowledge for social work practice ( $3^{\text {rd }}$ ed.). Chicago: Nelson-Hall Publishers.

Schneider, R. L., Council on Social Work Education, Kropf, N. P. \& Virginia Commonwealth University School of Social Work. (1989). Essential knowledge and skills for baccalaureate social work students in geronotology. Washington, D.C.; Richmond, VA: Council on Social Work Education; Virginia Commonwealth University, School of Social Work.

Sebern, M. \& Whitlatch, C. J. (2007). Dyadic Relationship Scale: A measure of the impact of the provision and receipt of family care. The Gerontolgist 47(6).

Senior Resource Center. (2010). Aging in place. Retrieved from http://www.seniorresource.com/ageinpl.htm\#place.

Sheafor, B. W. \& Horejsi, C. R. (2003). Techniques and guidelines for social work practice. $\left(6^{\text {th }}\right.$ ed.). New York, NY: Pearson Education- Allyn and Bacon.

Shearer, N. \& Fleury, J. (2006). Social support promoting health in older women. Journal of Women \& Aging. 18(4), 3-17.

Shelkey, M. \& Wallace, M. (2012). Katz Index of Independence in Activities of Daily Living (ADL). The Hartford Institute for Geriatric Nursing, 2. Retrieved from consultgerirn.org/uploads/File/trythis/try this_2.pdf.

Sherman, F. T. (2006). This geriatrician's greatest challenge: Caregiving. Geriatrics, 61(3), 9.

Simon-Rusinowitz, L., Loughlin, D. M., Ruben, K. \& Mahoney, K. J. (2010). What does research tell us about a policy option to hire relatives as caregivers. Public Policy \& Aging Report. 20(1), 32.

Sirey, J., Bruce, M. L., Carpenter, M., Booker, D., Reid, C., Newell, K. A. \& Alexopoulos, G. S. (2008). Depressive symptoms and suicidal ideation among older adults receiving home delivered meals. International Journal of Geriatric Psychiatry, $23,1306-1311$.

Skelton, F., Kunik, M. E., Tziona, R. \& Aanand, N. D. (2010). Determining if an older adult can make and execute decisions to live safely at home: a capacity assessment and intervention model. Archives of Geronotology and Geriatrics. 50(3), 300-305.

Social Determinants of Health: Definitions. (2011). Centers for Disease Control and Prevention. Retrieved from http://www.cdc.gov/socialdeterminants/Definitions.html. 
Spitzer, R. L., Kroenke, K., \& Williams, J. B. W. (1999). Patient health questionnaire study group. Validity and utility of a self-report version of PRIME-MD: the PHQ Primary Care Study. JAMA, 282, 1737-1744.

Stansfeld, S. A. (2006). Social support and social cohesion. In M. Marmot \& R. G. Wilkinson (Eds). Social determinants of health. ( $2^{\text {nd }}$ ed. pp., 149-171). New York, NY: Oxford University Press.

Stringfello, A. (2011). AHCA/NCAL Profiles Assisted Living in the U.S. Retrieved from http://www.seniorhomes.com/w/ahca-ncal-profiles-assisted-living-in-the-us/.

Tabloski, P. A. (2004). Global aging: Implications for women and women's health. JOGNN: Clinical Issue, 33, 627-638.

Tiemens, B. G. (1999). Management of mental health problems in primary care: The doctor, the patient, and the medical model. University of Groningen. Thomas, C. (2007). Sociologies of disability and illness: Contested ideas in disability studies and medical sociology. Basingstoke, NY: Palgrave Macmillan.

Thomas, C. (2007). Sociologies of disability and illness: Contested ideas in disability studies and medical sociology. Basingstoke, NY: Palgrave Macmillan.

Thomas, E. J. \& Biddle, B. J. (1966). The nature and history of role theory. In B. J. Biddle \& E. J. Thomas (Eds). Role theory: Concepts and research. (pp. 3-19). New York, NY: John Wiley \& Sons, Inc.

Turnham, H. (n.d.). Federal Nursing Home Reform Act from the Omnibus Budget Reconciliation Act of 1987 or simply OBRA '87 SUMMARY. Retrieved from http://www.ncmust.com/doclib/OBRA87summary.pdf.

U.S. Census Bureau (2010). Profile of general population and housing characteristics: 2010 Demographic Profile Data. Retrieved http://factfinder2.census.gov/faces/tableservices/jsf/pages/productview.xhtml?src=bkmk.

Van Wijk, C., van Vliet, K. \& Kolk, A. (1996). Gender perspectives and quality of care towards appropriate and adequate health care for women. Social Science \& Medicine, 43(5), 707-720.

Verbrugge, L. M. (1989). Recent, present and future health of American adults. Annual Review of Public Health, 10, 33-61.

Vernon, A. \& Qureshi, H. (2000). Community care and independence: Self sufficiency or empowerment? Critical Social Policy, 63(20), 255-275.

Ware, J. E., Jr. \& Gandek, B. (1999). Overview of the SF-36 Health Survey and the International Quality of Life Assessment (IQOLA) Project. Journal of Clinical Epidemiology, 51(11), 903-912. 
Ware, J. R. Jr., Kosinski, M. \& Gandek, B. (2000). SF-36 Health Survey: Manual and interpretation guide. Lincoln, RI: Quality Metric Inc, B6-B11.

Weitz, T. \& Estes, C. L. (2001). Adding aging and gender to the women's health agenda. Journal of Women \& Aging, 13(2), 3-20.

Wilson, K. B. (2007). Historical evolution of assisted living in the Unites States, 1979 to the Present. The Gerontologist, 47(Special Issue III), 8-22.

World Health Organization (WHO). (1998). The role of the pharmacist in self-care and self-medication. Geneva: World Health Organization, Report No.: WHO/DAP/98.13.

World Health Organization (WHO). (2010). Definition of an older or elderly person. Retrieved from http://www.who.int/healthinfo/survey/ageingdefnolder/en/index.html

Young, H. M. \& Cochrane, B. B. (2004). Healthy aging for older women. The Nursing Clinics of North America. 39, 131-143.

Young, R. F. \& Kahana, E. (1994). Caregiving issues after a heart attack: Perspectives on elderly patients and their families. In E. Kahana, D. Biegel \& M. Wykle (Eds). Family caregiving across the lifespan. (pp. 262-284). Newbury Park, CA: Sage Publication.

Zijlstra, G., van Haastregt, J., Ambergen, T., van Rossum, E., van Eijk, J., Tennstedt, S. \& Kempen, G (2009). Effects of a multicomponent cognitive behavioral group intervention on fear of falling and activity avoidance in community-dwelling older adults: Results of a randomized controlled trial. Journal of the American Geriatrics Society, 57(11), 2020-2028. 
APPENDICES 
Appendix A:

Agencies' Approval for Study 
August 7, 2012

Florida International University

Robert Stempel School of Public Health and Social Work

11200 sW 8 th Street, AHC11390W2

Miami, Florida 33199

Dear Dissertation Proposal Committee:

As the President and CEO of of support for the research study entitled Predictors of Independent Living Outcomes Among Older Women Receiving Informal Care to be conducted with clients of $\square$ in collaboration with your Doctoral studies at Florida International University.
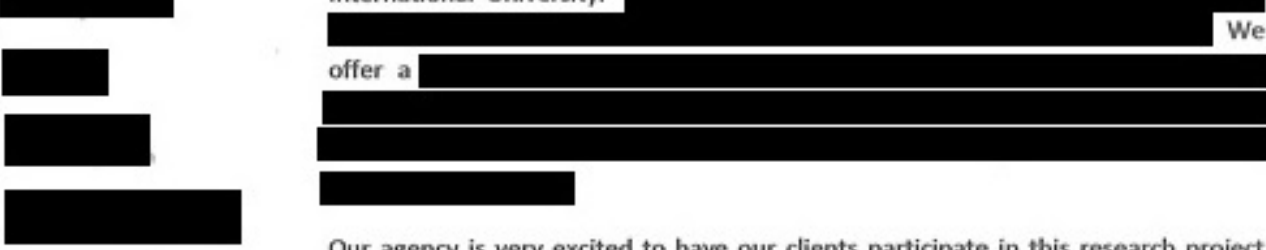

offer a

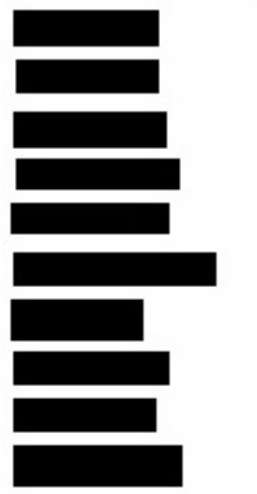

Our agency is very excited to have our clients participate in this research project that addresses the importance of understanding the relationship and interaction between informal caregivers and older women. Findings from this project will inform us about ways to assist older women in maintaining their independence to live safely within the community and furthermore, help to understand whether informal caregivers are influential in this goal. We currently recognize the importance of informal caregiving

However, we have yet to extensively study the relationship and interaction between older women and their informal caregivers.

Knowledge gathered from this study will be used to improve services and resources for older women and their informal caregivers while also aiding in the development of interventions to maximize independent living among older women. As part of our collaboration on this project, we agree to provide Julie Grochowski or a member of her research team the ability to identify and meet with our clients and their informal caregivers to administer a voluntary questionnaire and interview. This activity will be arranged by Julie Grochowski and the individual clients. This research activity will take approximately 1 hour per participant to complete. We have been assured that the study will have IRB approval from Florida International University and that all data collected will be confidential and anonymous. 
Florida International University

Dissertation Proposal Committee

Page 2 of 2

We expect that this partnership will be mutually beneficial for those involved by informing both future research and practice.

On behalf of 1 and myself, we look forward to this

opportunity to collaborate with a student from Florida International University.

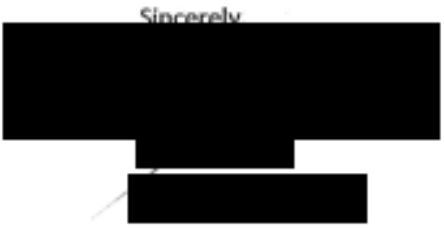




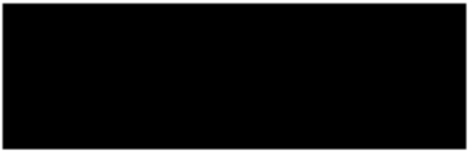

December 3, 2012

Dear Members of the IRB Committee at FIU

I am pleased to be writing a letter of support for the research study entitied Predictors of Independent Living Outcomes Among Older Women Receiving Informal Care to be conducted with clients of

in collaboration with your Doctoral student at Florida International University.

Our agency is very excited to have our consented clients and their informal caregivers participate in this research project that addresses the importance of understanding the relationship and interaction between informal caregivers and older women. Findings from this project will inform us about ways to assist older women in maintaining their independence to live safely within the community and furthermore, help to understand whether informal caregivers are influential in this goal. We currently recognize the importance of informal caregiving as our community programs focus on supporting older adults' desire to maintain their independence in their own homes so that they can enjoy a longer, healthier life and avoid placement in a nursing home. However, we have yet to extensively study the relationship and interaction between older women and their informal caregivers.

Knowledge gathered from this study will be used to improve services and resources for older women and their informal caregivers while also aiding in the development of interventions to maximize independent living among older women. As part of our collaboration on this project, we agree to provide Julie Grochowski or a member of her research team the ability to identify potential participants and meet with our clients and their informal caregivers to administer a voluntary questionnaire and interview. This activity will be arranged by Julie Grochowski and the individual clients in coordination with our staff. Individual interviews will take place at the participant's residence or another location of their choice. We understand that this research activity will take approximately 1 hour per participant to complete. Prior to data collection, each participant will receive an informative letter and provide consent to volunteer in this research study.

We have been assured that the study will have IRB approval from Florida International University and that all data collected will be confidential and anonymous. To the best of our knowledge, we understand that the study will not harm our clients more than anything they experience in their 
everyday lives. In the case that a participant discloses any sign distress, the researchers understand that they have a professional responsibility to report such matters to our staff.

We expect that this partnership will be mutually beneficial for those imvolved by informing both future research and practice. The benefit our clients will receive in participating is that ultimately the information gathered will be used to improve our services and resources for older women and their informal caregivers.

We look forward to this as another opportunity to collaborate with Florida international University.

Sincerely,

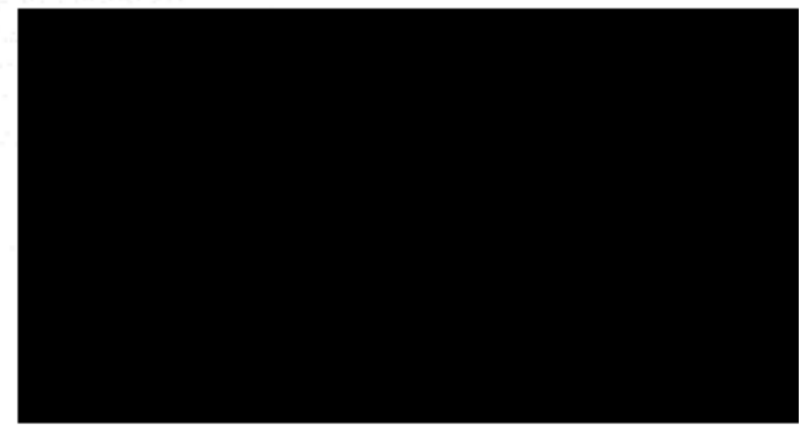


Appendix B:

IRB Verbal Consents

English and Spanish Versions 
\begin{tabular}{|l|l|}
\hline RU IRB Approval: & $10 / 4 / 2013$ \\
\hline RU/RBExpiation: & $10 / 4 / 224$ \\
\hline
\end{tabular}

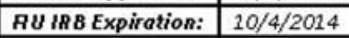

\begin{tabular}{|l|l|}
\hline RUU IRB Number: & IRB-13-0407 \\
\hline
\end{tabular}

\title{
FIU] UNIVERSITY
}

\author{
ADULT VERBAL CONSENT TO PARTICIPATE IN A RESEARCH STUDY \\ Predictors of Independent Living Outcomes Among Older Women Receiving Informal Care
}

Hello, my name is Julie Grochowski. You have been selected to be in a research study about older women who receive care from family, friends and neighbors. The purpose of this study is to better understand the relationship and interaction between older women and their caregivers. If you decide to participate, you will be one of 206 people in this research study. If you agree to be in the study, I will be asking you to complete a questionnaire that will take approximately 45 minutes of your time. I will be reading the questions al oud to you and you will be provided with a copy of the questionnaire so you can read and foll ow al ong. I will record your responses for each question

This study involves the participation of an older woman and her informal caregiver. Therefore, your permission will be needed to interview your caregiver. Your caregiver will not be interviewed without your permission. A caregiver is anyone who provides you with help, such as family members, friends and neighbors.

There are no foreseeable risks or benefits to you for participating in this study. It is expected that this study will benefit society by informing us about ways to assist ol der women in maintaining their independence to live safely within the community.

There is no cost or payment to you. A small non-monetary gift will be provided to you upon completion of the interview. If you have questions while taking part, please stop me and ask.

All your answers will be strictly confidential. In any sort of report we might publish, we will not include any information that will make it possible to identify you as a participant. Research records will be stored securely and only the researcher team will have access to the records.

We will ensure that there will be no way to identify and link answers from questionnaires and interviews to any individual. In the case that you disclose any signs of abu se or suicide ideation, I have a professional responsibility to report harm done to oneself or another individual.

If you have questions for one of the researchers conducting this study, you may contact Julie Grochowski at 305-962-8718 or by email at jgroc001@fiu.edu.

Page 1 of 2 
FIU IRB Approval: $10 / 4 / 2013$

FIU IRB Expiration: $10 / 4 / 2014$

\begin{tabular}{|l|l|}
\hline FIU IRB Number: & IRB-13-0407 \\
\hline
\end{tabular}

If you would like to talk with someone about your rights of being a subject in this research study or about ethical issues with this research study, you may contact the FIU Office of Research Integrity by phone at 305-348-2494 or by email at ori@fiu.edu.

Your participation in this research is voluntary, and you will not be penalized or lose benefits if you refuse to participate or decide to stop at any time. Do you consent to participate in this study? 
\begin{tabular}{|l|l|}
\hline RU IRB Approval: & $10 / 4 / 2013$ \\
\hline RU/RBExpiation: & $10 / 4 / 224$ \\
\hline
\end{tabular}

\begin{tabular}{|l|l|}
\hline BU IRB Expiration: & $10 / 4 / 2014$ \\
\hline
\end{tabular}

\begin{tabular}{|l|l|}
\hline RUU IRB Number: & IRB-13-0407 \\
\hline
\end{tabular}

\title{
FIU] UNIVERSITY
}

\author{
ADULT VERBAL CONSENT TO PARTICIPATE IN A RESEARCH STUDY \\ Predictors of Independent Living Outcomes Among Older Women Receiving Informal Care
}

Hello, my name is Julie Grochowski. You have been selected to be in a research study about older women who receive care from family, friends and neighbors. The purpose of this study is to better understand the relationship and interaction between older women and their caregivers. If you decide to participate, you will be one of 206 people in this research study. If you agree to be in the study, I will be asking you to complete a questionnaire that will take approximately 45 minutes of your time. I will be reading the questions al oud to you and you will be provided with a copy of the questionnaire so you can read and foll ow al ong. I will record your responses for each question

This study involves the participation of an older woman and her informal caregiver. Your carerecipient has granted permission to include you in this research study.

There are no foreseeable risks or benefits to you for participating in this study. It is expected that this study will benefit society by informing us about ways to assist ol der women in maintaining their independence to live safely within the community.

There is no cost or payment to you. A small non-monetary gift will be provided to you upon completion of the interview. If you have questions while taking part, please stop me and ask.

All your answers will be strictly confidential. In any sort of report we might publish, we will not include any information that will make it possible to identify you as a participant. Research records will be stored securely and only the researcher team will have access to the records.

We will ensure that there will be no way to identify and link answers from questionnaires and interviews to any individual. In the case that you disclose any signs of abuse or suicide ideation, I have a professional responsibility to report harm done to oneself or another individual.

If you have questions for one of the researchers conducting this study, you may contact Julie Grochowski at 305-962-8718 or by email at jgroc001@fiu.edu.

Page 1 of 2 
FIU IRB Approval: $10 / 4 / 2013$

FIU IRB Expiration: $10 / 4 / 2014$

\begin{tabular}{|l|l|}
\hline FIU IRB Number: & IRB-13-0407 \\
\hline
\end{tabular}

If you would like to talk with someone about your rights of being a subject in this research study or about ethical issues with this research study, you may contact the FIU Office of Research Integrity by phone at 305-348-2494 or by email at ori@fiu.edu.

Your participation in this research is voluntary, and you will not be penalized or lose benefits if you refuse to participate or decide to stop at any time. Do you consent to participate in this study? 
\begin{tabular}{|l|l|}
\hline RU IRB Approval: & $10 / 4 / 2013$ \\
\hline RU/RBExpiation: & $10 / 4 / 224$ \\
\hline
\end{tabular}

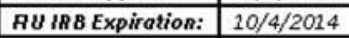

\begin{tabular}{|l|l|}
\hline RUU IRB Number: & IRB-13-0407 \\
\hline
\end{tabular}

\title{
FIU] UNIVERSITY
}

\author{
ADULT VERBAL CONSENT TO PARTICIPATE IN A RESEARCH STUDY \\ Predictors of Independent Living Outcomes Among Older Women Receiving Informal Care
}

Hello, my name is Julie Grochowski. You have been selected to be in a research study about older women who receive care from family, friends and neighbors. The purpose of this study is to better understand the relationship and interaction between older women and their caregivers. If you decide to participate, you will be one of 206 people in this research study. If you agree to be in the study, I will be asking you to complete a questionnaire and interview that will take approximately 1 and a half hours of your time.

For the first part, I will be reading the questions aloud to you and you will be provided with a copy of the questionnaire so you can read and follow along. I will record your responses for each question. For the second part, I will ask you open-ended questions, which you can answer in any way you like. For this part of the interview, I will be digitally recording our conversation and at a later date, I will transcribe it.

This study involves the participation of an older woman and her informal caregiver. Therefore, your permission will be needed to interview your caregiver. Your caregiver will not be interviewed without your permission. A caregiver is anyone who provides you with help, such as family members, friends and neighbors.

There are no foreseeable risks or benefits to you for participating in this study. It is expected that this study will benefit society by informing us about ways to assist ol der women in maintaining their independence to live safely within the community.

There is no cost or payment to you. A small non-monetary gift will be provided to you upon completion of the interview. If you have questions while taking part, please stop me and ask.

All your answers will be strictly confidential. In any sort of report we might publish, we will not include any information that will make it possible to identify you as a participant. Research records will be stored securely and only the researcher team will have access to the records.

We will ensure that there will be no way to identify and link answers from questionnaires and interviews to any individual. In the case that you disclose any signs of abuse or suicide ideation, I have a professional responsibility to report harm done to oneself or another individual.

Page 1 of 2 
If you have questions for one of the researchers conducting this study, you may contact Julie Grochowski at 305-962-8718 or by email at jgroc001@ fiu.edu.

If you would like to talk with someone about your rights of being a subject in this research study or about ethical issues with this research study, you may contact the FIU Office of Research Integrity by phone at 305-348-2494 or by email at ori@fiu.edu.

Your participation in this research is voluntary, and you will not be penalized or lose benefits if you refuse to participate or decide to stop at any time. Do you consent to participate in this study? 
\begin{tabular}{|l|l|}
\hline RU IRB Approval: & $10 / 4 / 2013$ \\
\hline RU/RBExpiation: & $10 / 4 / 224$ \\
\hline
\end{tabular}

\begin{tabular}{|l|l|}
\hline BU IRB Expiration: & $10 / 4 / 2014$ \\
\hline
\end{tabular}

\begin{tabular}{|l|l|}
\hline RUU IRB Number: & IRB-13-0407 \\
\hline
\end{tabular}

\title{
FIU] UNIVERSITY
}

\author{
ADULT VERBAL CONSENT TO PARTICIPATE IN A RESEARCH STUDY \\ Predictors of Independent Living Outcomes Among Older Women Receiving Informal Care
}

Hello, my name is Julie Grochowski. You have been selected to be in a research study about older women who receive care from family, friends and neighbors. The purpose of this study is to better understand the relationship and interaction between older women and their caregivers. If you decide to participate, you will be one of 206 people in this research study. If you agree to be in the study, I will be asking you to complete a questionnaire and interview that will take approximately 1 and a half hours of your time.

For the first part, I will be reading the questions aloud to you and you will be provided with a copy of the questionnaire so you can read and follow along. I will record your responses for each question. For the second part, I will ask you open-ended questions, which you can answer in any way you like. For this part of the interview, I will be digitally recording our conversation and at a later date, I will transcribe it.

This study involves the participation of an older woman and her informal caregiver. Your carerecipient has granted permission to include you in this research study.

There are no foreseeable risks or benefits to you for participating in this study. It is expected that this study will benefit society by informing us about ways to assist ol der women in maintaining their independence to live safely within the community.

There is no cost or payment to you. A small non-monetary gift will be provided to you upon completion of the interview. If you have questions while taking part, please stop me and ask.

All your answers will be strictly confidential. In any sort of report we might publish, we will not include any information that will make it possible to identify you as a participant. Research records will be stored securely and only the researcher team will have access to the records.

We will ensure that there will be no way to identify and link answers from questionnaires and interviews to any individual. In the case that you disclose any signs of abuse or suicide ideation, I have a professional responsibility to report harm done to oneself or another individual. .

Page 1 of 2 
If you have questions for one of the researchers conducting this study, you may contact Julie Grochowski at 305-962-8718 or by email at jgroc001@fiu.edu.

If you would like to talk with someone about your rights of being a subject in this research study or about ethical issues with this research study, you may contact the FIU Office of Research Integrity by phone at 305-348-2494 or by email at ori@fiu.edu.

Your participation in this research is voluntary, and you will not be penalized or lose benefits if you refuse to participate or decide to stop at any time. Do you consent to participate in this study? 
\begin{tabular}{|l|l|}
\hline FU IRB Approval: & $10 / 4 / 2013$ \\
\hline ing
\end{tabular}

\begin{tabular}{l|l|}
\hline AU IRB Expiration: & $10 / 4 / 2014$ \\
\hline
\end{tabular}

\begin{tabular}{|l|l|}
\hline AU IRB Number: & IRB-13-0407 \\
\hline
\end{tabular}

\section{FIU UNIVERSITY}

\section{CONSENTIMIENTO VERBAL DE ADUL TOS PARA PARTICIPAR EN UN ESTUDIO DE INVESTIGACIÓN}

Los pronósticos de resultados de vida independiente entre mujeres mayores que reciben cuidados informales

Hola, mi nombre es Julie Grochowski. Usted ha sido sel eccionado para participar en un estudio de investigación sobre las mujeres mayores que reciben atención por parte de familiares, amigos y vecinos. El propósito de este estudio es comprender mejor la relación y la interacción entre las mujeres mayores y sus cuidadores. Si usted decide participar, usted será una de 206 personas en este estudio de investigación. Si usted acepta participar en el estudio, le pedirán que llene un cuestionario que tendrá unos 45 minutos de su tiempo. Voy a estar leyendo las preguntas en voz al ta y se le proporcionará una copia del cuestionario para que pueda leer y seguirlas. Voy a grabar sus respuestas para cada pregunta.

Este estudio cuenta con la participación de una mujer mayor y la persona que la cuida. Por lo tanto, se necesita su permiso para entrevistar a la persona que la cuida. Esta persona no será entrevistado sin su permiso. Un cuidador es alguien que le proporciona ayuda, tales como familiares, amigos y vecinos

No hay riesgos previsibles $\circ$ beneficios para usted por participar en este estudio. Se espera que este estudio beneficiará a la sociedad al informarnos sobre las formas de ayudar a las mujeres mayores a mantener su in dependencia para vivir con seguridad dentro de la comunidad.

No hay ningún costo $\circ$ pago a usted. Usted recibirá un regal o pequeño no monetario una vez terminada la entrevista. Si tiene al gun a pregunta durante su participación, por favor pare y pregunte.

Todas sus respuestas serán estrictamente confidenciales. En cualquier tipo de informe que podríamos publicar, no incluiremos ninguna información que permita identificarle como participante. Los registros de la investigación se almacenan de forma segura y sólo el equipo investigador tendrá acceso a los registros.

Nos aseguraremos de que no habrá manera de identificar y relacionar las respuestas de los cuestionarios y entrevistas a cualquier individuo. En el caso de que usted revele signos de abuso - ide as suicidas, tengo la responsabilidad profesional de informar el daño hecho a sí mismo o a otra persona. 
FIU IRB Approval: $10 / 4 / 2013$

FIU IRB Expiration: $10 / 4 / 2014$

\begin{tabular}{l|l}
\hline FIU IRB Number: & IRB-13-0407 \\
\hline
\end{tabular}

Si tiene alguna pregunta para uno de los investigadores que realizaron este estudio, puede ponerse en contacto con Julie Grochowski al 305-962-8718 o por correo electrónico a jgroc001@fiu.edu.

Si a usted le gustaria hablar con alguien acerca de sus derechos de ser un sujeto en este estudio de investigación o sobre cuestiones éticas con este estudio de investigación, puede comunicarse con la Ofícina de Integridad de la Investigación FIU por teléfono al 305-348-2494 o por correo electrónico a ori@fiu.edu.

Su participación en esta investigación es voluntaria, y usted no será penalizado o perderá beneficios si usted se niega a participar o decide parar en cualquier momento. ¿Usted da su consentimiento para participar en este estudio? 
\begin{tabular}{|l|l|}
\hline FU IRB Approval: & $10 / 4 / 2013$ \\
\hline ing
\end{tabular}

\begin{tabular}{l|l|}
\hline AU IRB Expiration: & $10 / 4 / 2014$ \\
\hline
\end{tabular}

\begin{tabular}{|l|l|}
\hline AU IRB Number: & IRB-13-0407 \\
\hline
\end{tabular}

\section{FIU UNIVERSITY}

\section{CONSENTIMIENTO VERBAL DE ADUL TOS PARA PARTICIPAR EN UN ESTUDIO DE INVESTIGACIÓN}

Los pronósticos de resultados de vida independiente entre mujeres mayores que reciben cuidados informales

Hola, mi nombre es Julie Grochowski. Usted ha sido sel eccionado para participar en un estudio de investigación sobre las mujeres mayores que reciben atención por parte de familiares, amigos y vecinos. El propósito de este estudio es comprender mejor la relación y la interacción entre las mujeres mayores y sus cuidadores. Si usted decide participar, usted será una de 206 personas en este estudio de investigación. Si usted acepta participar en el estudio, le pedirán que llene un cuestionario que tendrá unos 45 minutos de su tiempo. Voy a estar leyendo las preguntas en voz al ta y se le proporcionará una copia del cuestionario para que pueda leer y seguir a lo largo. Voy a grabar sus respuestas para cada pregunta.

Este estudio cuenta con la participación de una mujer mayor y la persona que la cuida. La persona que usted cuida ha concedido permiso para incluirlo en este estudio de investigación.

No hay riesgos previsibles o beneficios para usted por participar en este estudio. Se espera que este estudio beneficiará a la sociedad al informarnos sobre las formas de ayudar a las mujeres mayores a mantener su in dependencia para vivir con seguridad dentro de la comunidad.

No hay ningún costo $\circ$ pago a usted. Un regalo no monetario pequeño se proporcionará a usted una vez terminada la entrevista. Si tiene alguna pregunta durante su participación, por favor parar y preguntar.

Todas sus respuestas serán estrictamente confidenciales. En cualquier tipo de informe que podríamos publicar, no incluiremos ninguna información que permita identificarle como participante. Registros de la investigación se almacena de forma segura y sólo el equipo investigador tendrá acceso a los registros.

Nos aseguraremos de que no habrá manera de identificar y relacionar las respuestas de los cuestionarios y entrevistas a cualquier individuo. En el caso de que usted revele signos de abuso o ide ación suicida, tengo la responsabilidad profesional de informar daño hecho a sí mismo o a otra persona.

Si tiene alguna pregunta para uno de los investigadores que realizar on este estudio, puede ponerse en contacto con Julie Grochowski al 305-962-8718 o por correo electrónico a jgroc001@fiu.edu. 
FIU IRB Approval: $10 / 4 / 2013$

FIU IRB Expiration: $10 / 4 / 2014$

\begin{tabular}{l|l}
\hline FIU IRB Number: & IRB-13-0407 \\
\hline
\end{tabular}

Si a usted le gustaría hablar con alguien acerca de sus derechos de ser un sujeto en este estudio de investigación o sobre cuestiones éticas con este estudio de investigación, puede comunicarse con la Oficina de Integridad de la Investigación FIU por teléfono al 305-348-2494 o por correo electrónico a ori@fiu.edu.

Su participación en esta investigación es voluntaria, y usted no será penalizado o perderá beneficios si usted se niega a participar o decide parar en cualquier momento. ¿Usted da su consentimiento para participar en este estudio? 
\begin{tabular}{|l|l|l|}
\hline FU IRB Approval: & $4 / 2 / 2014$ \\
\hline
\end{tabular}

FU IRB Expiration: $10 / 4 / 2014$

\begin{tabular}{l|l|}
\hline RU IRB Number: & IRB-13-0407 \\
\hline
\end{tabular}

\section{FIU |⿴囗十) UNIVERSITY}

\section{CONSENTIMIENTO VERBAL DE ADUL TOS PARA PARTICIPAR EN UN ESTUDIO DE INVESTIGACIÓN \\ Los pronósticos de resultados de vida independiente entre mujeres mayores que reciben cuidados informales}

Hola, mi nombre es Julie Grochowski. Usted ha sido seleccionado para participar en un estudio de investigación sobre las mujeres mayores que reciben atención por parte de familiares, amigos y vecinos. El propósito de este estudio es comprender mejor la relación y la interacción entre las mujeres mayores y sus cuidadores. Si usted decide participar, usted será una de 206 personas en este estudio de investigación.

$\mathrm{Si}$ acepta participar en este estudio, le pediré que complete un cuestionario y entrevista que tomará aproximadamente una hora y media de su tiempo.

Para la primera parte, le leeré las preguntas en voz al ta y se le proporcionará una copia del cuestionario para que pueda leer y seguir las preguntas. Grabaré sus respuestas para cada pregunta. Para la segunda parte, le haré preguntas abiertas, las cuales puede contestar como usted quiera. Para esta parte de la entrevista, grabaré digitalmente nuestra conversación y posteriormente será transcrita.

Este estudio cuenta con la participación de una mujer mayor y la persona que la cuida. Por lo tanto, se necesita su permiso para entrevistar a la persona que la cuida. Esta pers ona no será entrevistada sin su permiso. Un cuidador es alguien que le proporciona ayuda, tales como familiares, amigos y vecinos.

No hay riesgos previsibles $\circ$ beneficios para usted por participar en este estudio. Se espera que este estudio beneficie a la sociedad al informarnos sobre las formas de ayudar a las mujeres mayores a mantener su in dependencia para vivir con seguridad dentro de la comunidad.

No hay ningún costo $\circ$ pago a usted. Usted recibirá un regal o pequeño no monetario una vez terminada la entrevista. Si tiene al gun a pregunta durante su participación, por favor pare y pregunte.

Todas sus respuestas serán estrictamente confidenciales. En cualquier tipo de informe que podríamos publicar, no incluiremos ninguna información que permita identificarle como participante. Los registros de la investigación se almacenan de forma segura y sólo el equipo investigador tendrá acceso a los registros.

Nos aseguraremos de que no habrá manera de identificar y relacionar las respuestas de los cuestionarios y entrevistas a cualquier individuo. En el caso de que usted revele signos de abuso 
FIU IRB Approval: $\quad 4 / 2 / 2014$

FIU IRB Expiration: $10 / 4 / 2014$

\begin{tabular}{l|l}
\hline FIU IRB Number: & IRB-13-0407 \\
\hline
\end{tabular}

o ideas suicidas, tengo la responsabilidad profesional de informar el daño hecho a sí mismo o a otra persona.

Si tiene alguna pregunta para uno de los investigadores que realizaron este estudio, puede ponerse en contacto con Julie Grochowski al 305-962-8718 o por correo electrónico a jgroc001@fiu.edu.

Si a usted le gustaría hablar con alguien acerca de sus derechos de ser un sujeto en este estudio de investigación o sobre cuestiones éticas con este estudio de investigación, puede comunicarse con la Oficina de Integridad de la Investigación FIU por teléfono al 305-348-2494 o por correo electrónico a ori@fiu.edu.

Su participación en esta investigación es voluntaria, y usted no será penalizado o perderá beneficios si usted se niega a participar o decide parar en cualquier momento. ¿Usted da su consentimiento para participar en este estudio? 
\begin{tabular}{|l|l|l|}
\hline FU IRB Approval: & $4 / 2 / 2014$ \\
\hline
\end{tabular}

\begin{tabular}{l|l|l}
\hline FU IRB Expiration: & $10 / 4 / 2014$ \\
\hline
\end{tabular}

\begin{tabular}{l|l|}
\hline RU IRB Number: & IRB-13-0407 \\
\hline
\end{tabular}

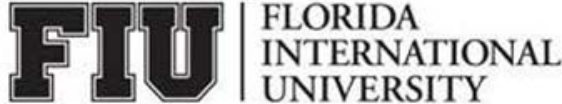

\section{CONSENTIMIENTO VERBAL DE ADUL TOS PARA PARTICIPAR EN UN ESTUDIO DE INVESTIGACIÓN}

Los pronósticos de resultados de vida independiente entre mujeres mayores que reciben cuidados informales

Hola, mi nombre es Julie Grochowski. Usted ha sido sel eccionado para participar en un estudio de investigación sobre las mujeres mayores que reciben atención por parte de familiares, amigos y vecinos. El propósito de este estudio es comprender mejor la relación y la interacción entre las mujeres mayores y sus cuidadores. Si usted decide participar, usted será una de 206 personas en este estudio de investigación. Si acepta participar en este estudio, le pediré que complete un cuestionario y entrevista que tomará aproximadamente una hora y media de su tiempo.

Para la primera parte, le leeré las preguntas en voz alta y se le proporcionará una copia del cuestionario para que pueda leer y seguir las preguntas. Grabaré sus respuestas para cada pregunta. Para la segunda parte, le haré preguntas abiertas, las cuales puede contestar como usted quiera. Para esta parte de la entrevista, grabaré digitalmente nuestra conversación y en una fecha posterior, será transcrita.

Este estudio cuenta con la participación de una mujer mayor y la persona que la cuida. La persona que usted cuida ha concedido permiso para incluirlo en este estudio de investigación.

No hay riesgos previsibles o beneficios para usted por participar en este estudio. Se espera que este estudio beneficie a la sociedad al informarnos sobre las formas de ayudar a las mujeres mayores a mantener su in dependencia para vivir con seguridad dentro de la comunidad.

No hay ningún costo $\circ$ pago a usted. Un regalo no monetario pequeño se proporcionará a usted una vez terminada la entrevista. Si tiene alguna pregunta durante su participación, por favor parar y preguntar.

Todas sus respuestas serán estrictamente confidenciales. En cualquier tipo de informe que podríamos publicar, no incluiremos ninguna información que permita identificarle como participante. Registros de la investigación se almacena de forma segura y sólo el equipo investigador tendrá acceso a los registros.

Nos aseguraremos de que no habrá manera de identificar y relacionar las respuestas de los cuestionarios y entrevistas a cualquier individuo. En el caso de que usted revele signos de abuso - ide ación suicida, tengo la responsabilidad profesional de informar daño hecho a sí mismo o a otra persona. 
FIU IRB Approval: $\quad 4 / 2 / 2014$

FIU IRB Expiration: $10 / 4 / 2014$

\begin{tabular}{l|l}
\hline FIU IRB Number: & IRB-13-0407 \\
\hline
\end{tabular}

Si tiene alguna pregunta para uno de los investigadores que realizaron este estudio, puede ponerse en contacto con Julie Grochowski al 305-962-8718 o por correo electrónico a igroc001@fiu.edu.

Si a usted le gustaría hablar con alguien acerca de sus derechos de ser un sujeto en este estudio de investigación o sobre cuestiones éticas con este estudio de investigación, puede comunicarse con la Oficina de Integridad de la Investigación FIU por teléfono al 305-348-2494 o por correo electrónico a ori@fiu.edu.

Su participación en esta investigación es voluntaria, y usted no será penalizado o perderá beneficios si usted se niega a participar o decide parar en cualquier momento. ¿Usted da su consentimiento para participar en este estudio? 
Appendix C

Katz Index of Activities of Daily Living

English and Spanish Versions 


\section{Index of Independence in Activities of Daily Living}

(Katz Index of ADL)

\begin{tabular}{|c|c|c|}
\hline \multicolumn{3}{|c|}{$\begin{array}{l}\text { Patient's Name: } \\
\text { Instructions: For each area of functioning listed below, check the description that applies. (The word "assistance" means supervision, direction, or personal assistance.) } \\
\text { Data recorded on the evaluation form is converted into an overall ADL grade with the aid of definitions in the table on the following page. }\end{array}$} \\
\hline \multicolumn{3}{|l|}{ BATHING - etther sponge bath, tub bath, or shower } \\
\hline $\begin{array}{l}\text { Receives no assistance (gets in and out of tub by } \\
\text { self if tub is usual means of bathing) }\end{array}$ & $\begin{array}{l}\text { Receives assistance in bathing only one part of the } \\
\text { body (such as back or a leg) }\end{array}$ & $\begin{array}{l}\text { Receives assistance in bathing more than one part } \\
\text { of the body (or not bathed) }\end{array}$ \\
\hline \multicolumn{3}{|c|}{ DRESSING - gets clothes from closets and drawers - including underclothes, outer garments, and using fasteners (including braces, if worn) } \\
\hline $\begin{array}{l}\text { Gets clothes and gets completely dressed without } \\
\text { assistance }\end{array}$ & $\begin{array}{l}\text { Gets clothes and gets dressed without assistance } \\
\text { except for assistance in tying shoes }\end{array}$ & $\begin{array}{l}\text { Receives assistance in getting clothes or in getting } \\
\text { dressed, or stays partly or completely undressed }\end{array}$ \\
\hline \multicolumn{3}{|c|}{ TOILETING - going to the "toilet room" for bowel and urine elimination, cleaning self after elimination, and arranging clothes } \\
\hline $\begin{array}{l}\text { Goes to "toilet room," cleans self, and arranges } \\
\text { clothes without assistance (may use object for } \\
\text { support such as cane, walker, or wheelchair and } \\
\text { may manage night bedpan or commode, emptying } \\
\text { same in morning) }\end{array}$ & $\begin{array}{l}\text { Receives assistance in going to "toilet room" or in } \\
\text { cleaning self or in arranging clothes after } \\
\text { elimination or in use of night bedpan or commode }\end{array}$ & $\begin{array}{l}\text { Doesn't go to rocm termed "toilet" for the } \\
\text { elimination process }\end{array}$ \\
\hline TRANSFER & & \\
\hline $\begin{array}{l}\text { Moves in and out of bed as well as in and out of } \\
\text { chair without assistance (may be using object for } \\
\text { support such as cane or walker) }\end{array}$ & Moves in and out of bed or chair with assistance & Doesn't get out of bed \\
\hline CONTINENCE & & \\
\hline $\begin{array}{l}\qquad \square \\
\text { Controls urination and bowel movement completely } \\
\text { by self }\end{array}$ & Has occasional "accidents" & $\begin{array}{l}\qquad \\
\text { Supervision helps keep urine or bowel control, } \\
\text { catheter is used, or is incontinent }\end{array}$ \\
\hline FEEDING & & \\
\hline $\begin{array}{c}\square \\
\text { Feeds self without assistance }\end{array}$ & $\begin{array}{l}\text { Feeds self except for getting assistance in cutting } \\
\text { meat or buttering bread }\end{array}$ & $\begin{array}{l}\qquad \square \\
\text { Receives assistance in feeding or is fed partly or } \\
\text { completely by using tubes or intravenous fluids }\end{array}$ \\
\hline (Katz et al., 1963) & & \\
\hline
\end{tabular}




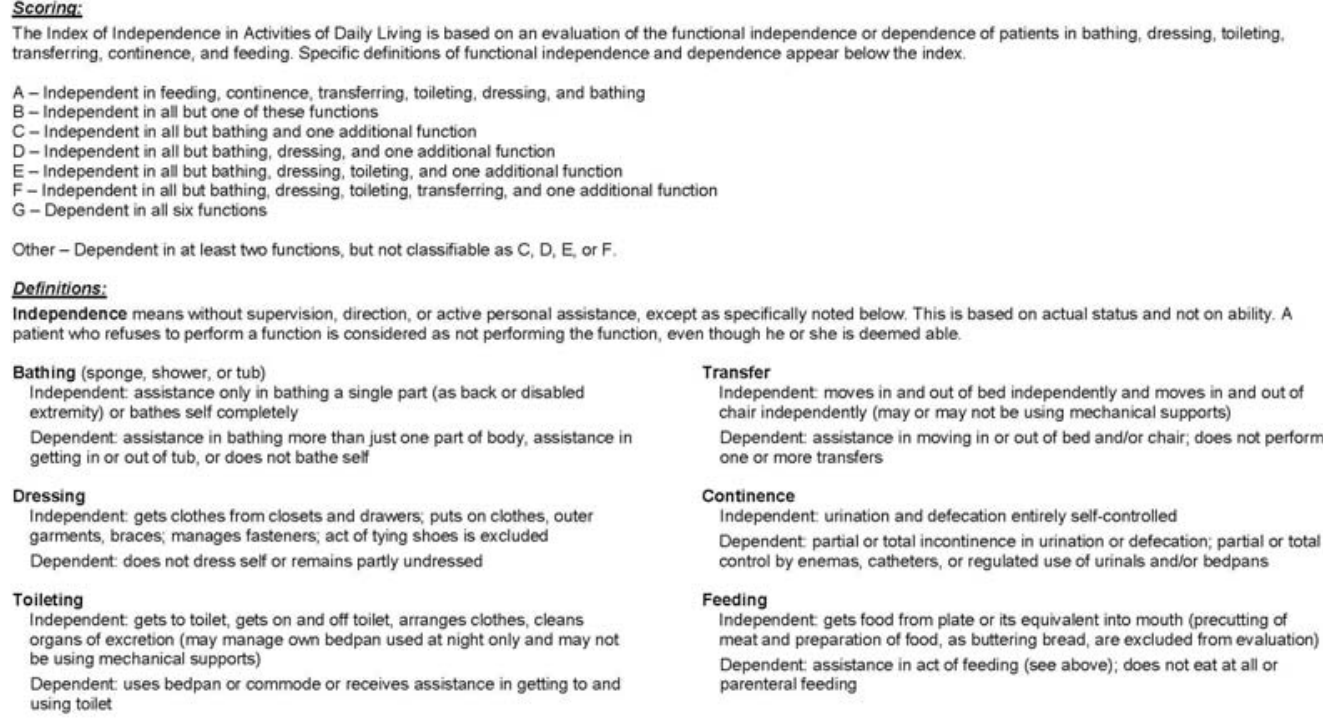

Bathing (sponge, shower, or tub)

Independent assistance only in bathing a single part (as back or disabled

extremity) or bathes self completely

Dependent assistance in bathing more than just one part of body, assistance in

getting in or out of tub, or does not bathe self

Dressing

Independent gets clothes from closets and drawers, puts on clothes, outer garments, braces manages fasteners, act of tying shoes is excluded

Dependent: does not dress self or remains partly undressed

Toileting

Independent gets to toilet, gets on and off toilet, arranges clothes, cleans organs of excretion (may manage own bedpan used at night only and may not

be using mechanical supports)

Dependent uses bedpan or commode or receives assistance in getting to and using toilet

Transfer

independent moves in and out of bed independenty and moves in and out of chair independently (may or may not be using mechanical supports) Dependent. assistance in moving in or out of bed and/or chair; does not perform one or more transfers

Continence

Independent urination and defecation entirely self-controlled Dependent partial or total incontinence in urination or defecation; partial or total control by enemas, catheters, or regulated use of urinals and/or bedpans

Feeding

Independent gets food from plate or its equivalent into mouth (precutting of meat and preparation of food, as buttering bread, are excluded from evaluation Dependent assistance in act of feeding (see above); does not eat at all or parenteral feeding

Sources:

- Katz S, Downs TD, Cash HR, Grotz RC. Progress in development of the index of ADL. Gerontologist. 1970;10(1):20-30

- Katz S, Ford AB, Moskowitz RW, Jackson BA, Jaffe MW. Studies of illness in the aged. The Index of ADL' a standardized measure of biological and psychosocial function. JAMA. 1963;185(12):914-9. 


\section{Baños}

\begin{tabular}{|c|c|c|}
\hline $\begin{array}{c}\text { Recibe ninguna ayuda } \\
\text { (se baña por completo sin } \\
\text { ayuda y entra y sale de la } \\
\text { bañera / ducha por uno } \\
\text { mismo }\end{array}$ & $\begin{array}{c}\text { Recibe asistencia para } \\
\text { bañarse sólo una parte del } \\
\text { cuerpo (como la espalda o }\end{array}$ & $\begin{array}{c}\text { Recibe asistencia para } \\
\text { bañarse más de una parte } \\
\text { del cuerpo, al entrar o salir } \\
\text { de la bañera / ducha. }\end{array}$ \\
\hline
\end{tabular}

\section{Vestir}

\begin{tabular}{|c|c|c|}
\hline $\begin{array}{c}\text { Obtiene la ropa y se viste } \\
\text { completamente sin ayuda }\end{array}$ & $\begin{array}{c}\text { Obtiene la ropa y se viste } \\
\text { sin ayuda, excepto para la } \\
\text { ayuda en amarrarse los } \\
\text { zapatos }\end{array}$ & $\begin{array}{c}\text { Recibe ayuda para } \\
\text { conseguir ropa o vestirse, o } \\
\text { se queda parcial o } \\
\text { totalmente desnuda }\end{array}$ \\
\hline
\end{tabular}

\section{Ir al baño}

\begin{tabular}{|c|c|c|}
\hline $\begin{array}{c}\text { Va al baño, se limpia, y se } \\
\text { encarga de la ropa sin } \\
\text { ayuda. }\end{array}$ & $\begin{array}{c}\text { Recibe ayuda para ir al } \\
\text { baño o limpiarse o en el } \\
\text { arreglo de ropa después de } \\
\text { (puede utilizar objetos de } \\
\text { la eliminación o en el uso y } \\
\text { limpieza del orinal de noche } \\
\text { o inodoro. }\end{array}$ & $\begin{array}{c}\text { No va a la habitación } \\
\text { llamada " baño " para el } \\
\text { proceso de eliminación }\end{array}$ \\
$\begin{array}{c}\text { andador o silla de rueda y } \\
\text { puede usar orinal de noche } \\
\text { o inodoro, y lo vaciá por la } \\
\text { mañana) }\end{array}$ & & \\
\hline
\end{tabular}

\section{Transferir}

Se mueve dentro y fuera de la cama, y tambien dentro y fuera de la silla sin ayuda (puede ser con objeto de apoyo, como bastón o andador)
Se mueve dentro y fuera de la cama o la silla con asistencia
No sale de la cama 


\section{Continencia}

\begin{tabular}{|c|c|c|}
\hline $\begin{array}{c}\text { Controla la vejiga y el } \\
\text { movimiento intestinal } \\
\text { completamente por si } \\
\text { misma }\end{array}$ & $\begin{array}{c}\text { Tiene "accidentes" } \\
\text { ocasionales }\end{array}$ & $\begin{array}{c}\text { Tiene supervisión de } \\
\text { mantener la orina o control } \\
\text { de la vejiga, se utiliza un } \\
\text { catéter o es incontinente. }\end{array}$ \\
\hline
\end{tabular}

\section{Feeding}

\begin{tabular}{|c|c|c|}
\hline Come solo sin ayuda & $\begin{array}{c}\text { Come solo a excepción de } \\
\text { recibir asistencia en el corte } \\
\text { de carne o mantequilla pan }\end{array}$ & $\begin{array}{c}\text { Recibe asistencia para la } \\
\text { alimentación o se alimenta } \\
\text { en parte o en su totalidad } \\
\text { mediante el uso de tubos o } \\
\text { fluidos intravenosos. }\end{array}$ \\
\hline
\end{tabular}




\title{
Appendix D
}

Lawton Instrumental Activities of Daily Living Scale

\author{
English and Spanish Versions
}




\section{The Lawton Instrumental Activities of Daily Living Scale}

\section{Ability to Use Telephone}

1. Operates telephone on own initiative; looks up and dials numbers.

2. Dials a few well-known numbers

3. Answers telephone, but does not dial

4. Does not use telephone at all

\section{Shopping}

1. Takes care of all shopping needs independently........ 1

2. Shops independently for small purchases................... 0

3. Needs to be accompanied on any shopping trip ......... 0

4. Completely unable to shop.

\section{Food Preparation}

1. Plans, prepares, and serves adequate meals independently

2. Prepares adequate meals if supplied with ingredients

3. Heats and serves prepared meals or prepares meals but does not maintain adequate diet.

4. Needs to have meals prepared and served.

\section{Housekeeping}

1. Maintains house alone with occasion assistance (heavy work)

2. Performs light daily tasks such as dishwashing, bed making.

3. Performs light daily tasks, but cannot maintain acceptable level of cleanliness

4. Needs help with all home maintenance tasks

5. Does not participate in any housekeeping tasks.

\section{Laundry}

1. Does personal laundry completely

2. Launders small items, rinses socks, stockings, etc......... 1

3. All laundry must be done by others .... 0

\section{Mode of Transportation}

1. Travels independently on public transportation or drives own car.

2. Arranges own travel via taxi, but does not otherwise use public transportation .......................... 1

3. Travels on public transportation when assisted or accompanied by another 1

4. Travel limited to taxi or automobile with assistance of another... 0

5. Does not travel at all.....................................................

\section{Responsibility for Own Medications}

1. Is responsible for taking medication in correct dosages at correct time. . .1

2. Takes responsibility if medication is prepared in advance in separate dosages...

3. Is not capable of dispensing own medication ............ 0

\section{Ability to Handle Finances}

1. Manages financial matters independently (budgets, writes checks, pays rent and bills, goes to bank): collects and keeps track of income............................ 1

2. Manages day-to-day purchases, but needs help with banking, major purchases, etc ............................. 1

3. Incapable of handling money ....................................... 0

\section{Scoring: For each category, circle the item description that most closely resembles the client's}

highest functional level (either 0 or 1 ).

Lawton, M.P., \& Brody, E.M. (1969). Assessment of older people: Self-maintaining and instrumental activities of daily living. The Gerontologist, 9(3), 179-186.

Copyright $($ The Gerontological Society of America. Reproduced [Adapted] by permission of the publisher.

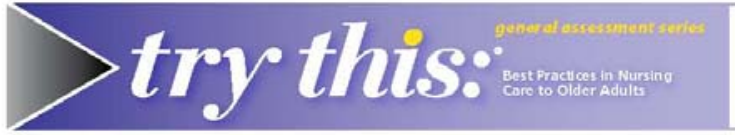




\section{Escala de Lawton y Brody para las actividades instrumentales de la vida diaria (AIVD)}

Mide capacidad y tienen un buen coeficiente de reproductibilidad $(0,94)$

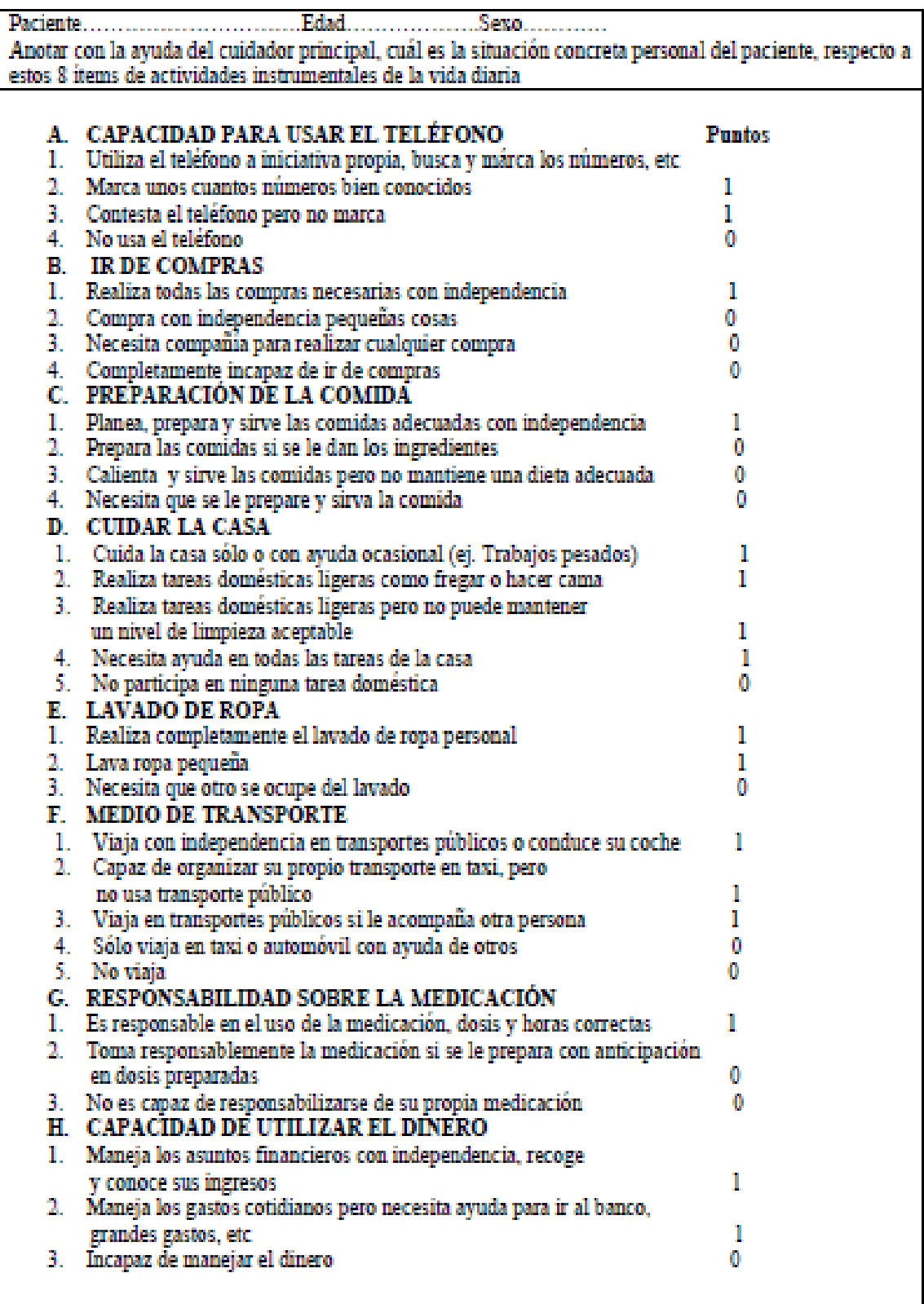

Máxima dependencia: 0 puntos

Independencia total: 8 puntos 


\section{Appendix E}

Attitude Toward Own Aging Scale

English and Spanish Versions 


\section{Polisher Research Institute \\ Abramson Center for Jewish Life \\ (formerly the Philadelphia Geriatric Center) \\ Lawton's \\ PGC MORALE SCALE}

M. Powell Lawton, Ph.D.

(1923-2001) 
THE PHILADELPHIA GERIATRIC CENTER MORALE SCALE

Guide to Users

The 17-item revised version of the PGC Morale Scale (Lawton, 1975) is the one in general use. Although differences have not been formally tested, it has been widely used in two alternative styles:

1. Interview style, where the interviewer reads the questions as phrased in the attached interview form (second-person style, "Do you ... " "Have you ...." etc.).

2. Questionnaire form, where the form is first-person (but note that item \#6 remains second-person). This form is laid out so that it can be directly reproduced by anyone who wishes).

Scoring is straightforward: Each high-morale response receives a score of "1" and each low-morale response a score of " 0 ," so that total score ranges from 0-17. The X's in the interview version show the high-morale responses. Although factors may be used separately for special purposes, the total score is preferred.

\section{Use of the PGC Morale Scale}

M. Powell Lawton, Ph.D., former director of the Polisher Research Institute, died in 2001. It was Dr. Lawton's intent that his scales be made widely available and he wanted them to be in the public domain. Accordingly, permission is granted to use or reproduce his scales, provided that proper attribution is given. Suggested citation:

Lawton, M.P. (2003), Lawton's PGC Morale Scale [Morale Scale created by M. Powell Lawton (1923-2001) while at the Polisher Research Institute of the Philadelphia Geriatric Center (now known as the Abramson Center for Jewish Life)]. Retrieved [insert date], from http://www.abramsoncenter.org/PRI/ (Scales page).

Additionally, authors who wish to reproduce part of an article where a scale first appeared should request permission from journal publishers before doing so.

Lastly, it would be appreciated if a reprint of any resulting articles be forwarded to the Research Librarian, or if a book is published, that purchasing information be provided to the Research Librarian.

\section{Addendum}

In the report on the revised Morale Scale (Lawton, 1975), the total score and factor means and S.D.'s were inadvertently omitted. For the 17 items and the 3 factors, these data are:

$\begin{array}{lccc} & \underline{\mathrm{N}} & \underline{\mathrm{X}} & \underline{\text { S.D. }} \\ \text { Total } & 928 & 11.35 & 3.76 \\ \text { Agitation } & 929 & 4.38 & 1.65 \\ \text { Attitude toward own aging } & 931 & 2.17 & 1.56 \\ \text { Lonely dissatisfaction } & 930 & 4.81 & 1.50\end{array}$


The Philadelphia Geriatric Center (PGC) Morale Scale provides a multidimensional approach to assessing the psychological state of older people. It has been developed by M. Powell Lawton and his staff at the Madlyn and Leonard Abramson Center for Jewish Life (formerly the Philadelphia Geriatric Center) in response to longer, more complicated tools, some of which conceptualize morale as unidimensional. The PGC Morale Scale is designed to provide a measure of morale appropriate for very old or less competent individuals, as it uses simpler wording in its items and less complex response formats.

\section{Description of the Scale}

Seventeen items make up the revised PGC Morale Scale. These items were derived from a slightly larger set of questions (Lawton, 1972) as described in an earlier publication (Lawton, 1975). Factor analysis of responses generated in several studies yielded three factors, and these factors can be thought of as representing the dimensions of morale. They suggest categories of attitudes or feelings which, in combination, make up the more global psychological state. The three factors which emerge from the morale scale are described below.

Agitation Items 4, 7, 12, 13,16 and 17 load on Factor 1. Labeled Agitation, this set of items characterizes the anxiety experienced by the older person. Lawton suggests, in addition, that "there is a driving, restless, agitated quality to the dysphoric mood ... (1972, p. 155)." Clinically neurotic feelings are reflected, and this group of items may serve as a manifest anxiety scale for older people (Lawton, 1975).

Attitude Toward Own Aging Items which relate to the older person's attitude toward the aging process they experience comprise Factor 2. Items 1, 2, 6, 8 and 10 are included in this factor, which captures the individual's perception of the changes taking place in his or her life, and asks for an evaluation of those changes.

Lonely Dissatisfaction Factor 3 represents the older person's acceptance or dissatisfaction with the amount of social interaction they are presently experiencing. The items do not hold expectations for a high level of interpersonal contact, but rather seek to ascertain the individual's reaction to the relationships he or she maintains. Items 3, 5, 9, 11, 14 and 15 are associated with Factor 3.

A detailed discussion of these factors and the process by which they were formed can be found in previous publications (Lawton, 1972; 1975).

Administration

Because of the problems sometimes encountered by the very old in negotiating paper and pencil tasks, it is recommended that the PGC Morale Scale be administered orally. A simple set of instructions, such as those that follow, is sufficient to introduce the scale.

I would like to ask you a few questions. You can just answer yes or no to most of them.

A few of the items on the scale have answers other than yes or no. In those cases, it is recommended that the alternatives be read to the respondent, and he or she be given an opportunity to choose one.

Be aware of any communication problems that the person you are addressing may have. Speak slowly and distinctly, and loudly enough to be heard by the respondent. If the older person does not understand the question, reread the item, making an effort to communicate clearly. NEVER REWORD AN ITEM OR OFFER 
AN EXPLANATION OR ELABORATION. The only admissible clarification is an exact repetition of the item as it appears on the scale.

$\underline{\text { Scoring }}$

Table 2 lists the items on the PGC Morale Scale and the answers for each question which indicate high morale. For each high morale response, a numerical score of 1 is given. Low morale responses and items which are not answered receive no numerical score. Totaling the number of high morale responses gives the individual's score for a particular administration of the scale.

\section{$\underline{\text { Interpretation }}$}

Clinical interpretation of a test goes beyond mere examination of the score. A host of other clinical judgments and test results must be marshaled to provide an integrated picture of the older person's perceived well being. Any score on the PGC Morale Scale, then, should not be taken as an absolute, but should be used in the clinical setting as one assist in helping older persons and their families make decisions.

Taking into account the above issues, several things may be said concerning the interpretation of the scores on the Morale Scale. No norms have been established for performance on the scale, but some summary statistics are available for a study involving 928 respondents. These older people were part of a larger study of housing for the elderly which systematically sampled tenants of age segregated public housing and limited income housing and community resident elderly. Mean age of the respondents was $72.6 ; 72 \%$ were female; $32 \%$ were married and living with a spouse; $76 \%$ were white; $43 \%$ Jewish, $35 \%$ Protestant and $22 \%$ Catholic; and the great majority were functionally independent. Their mean annual income was $\$ 2,100$ in 1966 or 1967 (Lawton \& Cohen, 1974). Other work utilizing the PGC Morale Scale has been done by Morris and Sherwood (1975) and their work has contributed to the development of the scale.

Table 1 gives the means and standard deviations for each factor as well as for the scale as a whole. Looking at the particular score in relationship to the overall mean for this sample allows an individual's performance to be compared with a larger group. As general guidelines, scores at 13 to 17 would be considered high scores on the scale, 10 to 12 high morale responses fall within the mid range, and scores under 9 are at the low end of the scale. They do, however, provide a framework for beginning to assess the individual's psychological disposition.

Agencies, or professionals using the PGC Morale Scale on a frequent basis might consider developing their own norms for the population they regularly serve. This strategy will probably provide for the most accurate interpretation of the score ge nerated by a particular client, although adequate numbers of scores may take some time to collect.

\section{In Conclusion}

Clinical psychologists at the Philadelphia Geriatric Center have used the PGC Morale Scale in treatment settings, as well as the research projects that originally fostered the development of the instrument. They report that one of the major strengths of the Scale lies in its ability to promote communication between clinician and client. The items will often prompt the older person to elaborate upon that aspect of their lives which a particular item addresses, providing valuable insights for the attending professional. This ability to facilitate dialogue is seen as an important feature of the Scale, often more usefully from a clinical perspective than the actual score which has been generated. 
$\underline{\text { References }}$

Lawton, M.P. The dimensions of morale. In D. Kent, R. Kastenbaum, and S. Sherwood (Eds.) Research. planning, and action for the elderly. Behavioral Publications, New York, 1972.

Lawton, M.P. The Philadelphia Geriatric Center Morale Scale: a revision. Journal of Gerontology, 1975, $\underline{30}$, 85-89.

Morris, J.N., and Sherwood, S. A retesting and modification of the Philadelphia Geriatric Center Morale Scale.

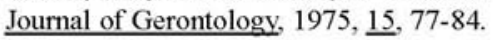

Table 1

Descriptive Statistics for the PGC Morale Scale

\begin{tabular}{llccc}
\hline Factor & & $\mathrm{N}$ & $\overline{\mathrm{X}}$ & S.D. \\
\hline Factor 1: & Agitation & 929 & 4.38 & 1.65 \\
Factor 2: & Attitude toward our aging & 931 & 2.17 & 1.56 \\
Factor 3: & Lonely dissatisfaction & 930 & 4.81 & 1.50 \\
Total & & 928 & 11.35 &
\end{tabular}


Table 2

High Morale Responses for the PGC Morale Scale

Factor 1 - Agitation

4. Do little things bother you more this year? No

7. Do you sometimes worry so much that you can't sleep? No

12. Are you afraid of a lot of things? No

13. Do you get mad more than you used to? No

16. Do you take things hard? No.

17. Do you get upset easily? No

Factor 2 - Attitude Toward Own Aging

1. Do things keep getting worse as you get older? No

2. Do you have as much pep as you had last year? Yes

6. Do you feel that as you get older you are less useful? No

8. As you get older, are things ___ than you thought? Better

10. Are you as happy now as you were when you were younger? Yes

Factor 3 - Lonely Dissatisfaction

3. How much do you feel lonely?

Not much

5. Do you see enough of your friends and relatives?

Yes

9. Do you sometimes feel that life isn't worth living?

No

11. Do you have a lot to be sad about?

No

14. Is life hard much of the time?

No

15. How satisfied are you with your life today?

Satisfied 
Philadelphia Geriatric Center Morale Scale (questionnaire form)

1. Things keep getting worse as I get older.

2. I have as much pep as I had last year.

3. How much do you feel lonely?

4. Little things bother me more this year.

5. I see enough of my friends and relatives.

6. As you get older, you are less useful.

7. I sometimes worry so much that I can't sleep.

8. As I get older, things are (better/worse) than I thought they would be.

9. I sometimes feel that life isn't worth living.

10. I am as happy now as I was when I was younger.

11. I have a lot to be sad about.

12. I am afraid of a lot of things.

13. I get mad more than I used to.

14. Life is hard for me much of the time.

15. How satisfied are you with your life today?

16. I take things hard.

17. I get upset easily.

$$
\text { Yes }
$$

Yes

Not much

Yes

Yes

Yes

Yes

Better

Yes

Yes

Yes

Yes

Yes

Yes

Satisfied

Yes

Yes
.

No

No

A lot

No

No

No

No

Worse

No

No

No

No

No

No

Not satisfied

No

No 
Philadelphia Geriatric Center Morale Scale (interview version)

\section{$\underline{\text { Agitation Sub-Scale }}$}

4. Do little things bother you more this year?

7. Do you sometimes worry so much that you can't sleep?

Yes

Yes

Yes

Yes

Yes

Yes

17. Do you get upset easily?

\section{Attitude Toward Own Aging Sub-Scale}

1. Do things keep getting worse as you get older?

2. Do you have as much pep as you had last year?

6. Do you feel that as you get older you are less useful?

8. As you get older, are things (better/worse) than you thought they would be?

10. Are you as happy now as you were when you were younger?

\section{$\underline{\text { Lonely-Dissatisfaction Sub-Scale }}$}

9. Do you sometimes feel that life isn't worth living?

11. Do you have a lot to be sad about?

14. Is life hard much of the time?

15. How satisfied are you with your life today?

3. How much do you feel lonely?

5. Do you see enough of your friends and relatives?
Yes

Yes

Yes

Better

Yes

Yes

Yes

Yes

Satisfied

Not much

Yes

No
No

No

No

No

No

No

No

No

No

Worse

No

No

No

No

Not satisfied

A lot 
Collette, J. (1984). Sex differences in life satisfaction: Australian data. Journal of Gerontology, $\underline{39}$. 243-245.

Janson, P., \& Mueller, K.F. (1983). Age, ethnicity, and well-being, Research on Aging, $\underline{5}$, 353-367.

Kop, J.L. (1993). The measurement of subjective well-being of elderly. European Review of Psychology, 43, 271-278. (French)

Lawton, M.P. (1972). The dimensions of morale. In Kent, D.P., Kastenbaum, R., \& Sherwood, S. (Eds.). Research, planning and action for the elderly, pp. 144-165. New York: Behavioral Publications, Inc.

Lawton, M.P. (1975). The Philadelphia Geriatric Center Morale Scale: A revision. Journal of Gerontology, 30, 85-89.

Liang, J., Asano, H., Bollen, K.A., Kahana, E.F., \& Maeda, D. (1987). Cross-cultural comparability of the Philadelphia Geriatric Center Morale Scale: An American-Japanese comparison. Journal of Gerontology, 42, 37-43.

Liang, J., Bennett, J., Akiyama, H., \& Maeda, D. (1992). The structure of PGC Morale Scale in American and Japanese aged: A further note. Journal of Cross-Cultural Gerontology, 7, 45-68.

Liang, J., \& Bollen, K.A. (1983). The structure of the Philadelphia Geriatric Center Morale Scale: A reinterpretation. Journal of Gerontology, $\underline{38}, 181-189$.

Liang, J., \& Bollen, K.A. (1985). Sex differences in the structure of the Philadelphia Geriatric Center Morale Scale. . Journal of Gerontology, 40, 468-477.

Liang, J., Lawrence, R.H., \& Bollen, K.A. (1987). Race differences in factorial structures of two measures of subjective well-being. . Journal of Gerontology, 42, 426-428.

Lohmann, N. (1977). Correlations of life satisfaction, morale and adjustment measures. $\underline{\text { Journal of }}$ Gerontology, 32, 73-75.

McCulloch, B.J. (1991). A longitudinal investigation of the factor structure of subjective well-being: The case of the Philadelphia Geriatric Center Morale Scale. Journal of Gerontology, 46, P251P258.

Morris, J.N., \& Sherwood, S. (1975). A retesting and modification of the Philadelphia Geriatric Center Morale Scale. Journal of Gerontology, 30, 77-84.

Pierce, R.C., \& Clark, M. (1973). Measurement of morale in the elderly. International Journal of Aging and Human Development, 4, 83-101.

Smotkin, D., \& Madari, G. (1996). An outlook on subjective well-being in older Israeli adults. International Journal of Aging and Human Development, 42, 271-289.

Stock, W.A., \& Okun, M.A. (1994). Subjective well-being measures: Reliability and validity among Spanish elders. International Journal of Aging and Human Development, 37, 221-235.

Wenger, G.C., Davies, R., \& Shahthmasebi, S. (1995). Morale in old age: Refining the model. International Journal of Geriatric Psychiatry, 10, 933-943.

Thanks are due Alana Iglewicz for the opportunity to use her exhaustive bibliography on the Morale Scale. 


\section{ESCALA DE SATISFACCION FILADELFIA}

\section{(Lawton, 1972 ${ }^{1}$, Universidad Autónoma de Madrid)}

A continuación le vamos a decir unas frases, me gustaría que me dijera si son aplicables a Vd. Si está de acuerdo con ellas me contesta SI, y en el caso de que no sean aplicables a Ud., me contesta NO.

1. ¿A medida que se va haciendo mayor, se ponen las cosas peor para Vd? SI NO

2. ¿Tiene usted tanta energía como el año pasado? ......................... SI NO

3. ¿Se siente usted solo?

SI NO

4. ¿Le molestan ahora más las cosas pequeñas que antes?

SI NO

5. ¿Siente que conforme se va haciendo mayor es menos útil? ........... $\quad$ SI NO

6. ¿A veces está tan preocupado que no puede dormir? ................... SI NO

7. ¿Según se va haciendo mayor, las cosas son $\quad$ MEJOR_ PEOR_ IGUAL_ que lo que usted pensó que sería?

8. ¿A veces siente que la vida no merece la pena ser vivida?

SI NO

9. ¿Ahora es usted tan feliz como cuando era más joven? ..................

SI NO

10. ¿Tiene muchas razones por las que estar triste?

SI NO

11. ¿Tiene miedo de muchas cosas?

SI NO

12. ¿Se siente más irascible que antes?

SI NO

13. ¿La mayor parte del tiempo la vida es dura y difícil?

SI NO

14. ¿Cómo está de satisfecho con su vida ahora?

15. ¿Se toma las cosas a pecho?

SATISFECHO

NO-SATISFECHO

16. ¿Se altera o disgusta fácilmente?

SI NO

SI NO

Attitude toward own aging subscale

Las cosas van peor según me voy hacienda más mayor?

SI NO

Tengo tanta energía como el año pasado?

SI NO

A medida que te haces mayor, eres menos útil?

SI NO

Soy tan feliz ahora como cuando era más joven?

SI NO

A medida que me hago mayor las cosas son?

Mejor__ Igual__ Peor

1 Adaptación de la Philadelphia Geriatric Center Morale Scale I. Montorio Dpto. Psicología Biológica y de la Salud Facultad Psicología 


\section{Appendix F \\ Dyadic Relationship Scale \\ English and Spanish Versions}




\section{Dyadic Relationship Scale}

For use in both research and practice settings, this scale assesses the positive dyadic interactions (caregiver $a=.85$, care recipient $a=.86$ ) and negative dyadic strain (caregiver $a=.89$, care recipient $a$ $=.84$ ) experienced by caregivers (11 items) and care recipients (10 items). ${ }^{1}$

Carol J. Whitlatch, PhD

Assistant Director of Research

The Margaret Blenknet Research Institute

Benjamin Rose Institute

11900 Fairhill Road, Suite 300

Cleveland, OH 44120-1053

Phone 216.373.1629

cwhiclat@bentose.org

www.benrose.org

${ }^{1}$ Sebern, M.D. \& Whitlatch, C.J. (2007). Dyadic

Relationship Scale: $A$ measure of the impact of the

provision and receipt of family care. The Gerontologist, $47(6)$.

$741-751$.

Copyright (C) 2007 Benjamin Rose Institute 


\section{Dyadic Relationship Scale (Caregiver)}

This series of questions address some of the difficulties that people face as they care for a relative. I'd like to talk about how helping you [REL] has affected your relationship with her/him during the past month. [HAND CG CARD]. Please refer to this card for your responses. How much do agree or disagree with the following statements?

Because of helping my [REL]:

Strongly Agree Disagree Strongly

a. I felt closer to her/him than I have in awhile

b. I have learned some good hings about my TREL

c. I felt angry toward her/him

I felt depressed because of my relationship with her/him

e. I felt resentful toward her/him

f. I have had morc paticncc The past g. I have learned some good
things about mysclf h. I felt that my relationship

i. I have learned some nice my life

j. Communication betwecn m RFIl and te has improved

k. I felt thai s/hhe madee requests over and abovc what Agree

Disagree

$\begin{array}{llll}0 & 1 & 2 & 3\end{array}$

$\begin{array}{llll}0 & 1 & 2 & 3\end{array}$

$\begin{array}{llll}3 & 2 & 1 & 0\end{array}$

3

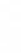

0

$\begin{array}{llll}0 & 1 & 2 & 3\end{array}$

$\begin{array}{llll}3 & 2 & 1 & 0\end{array}$

(1)

$\begin{array}{lll}0 & 1 & 2\end{array}$

\section{Dyadic Relationship Scale (Care Recipient)}

I'd like to talk about how your memory problems have affected your relationship with your [CG] over the past month? [HAND RESP CARD]. Please refer to this card for your responses and again, we are talking about the past month. How much do you agree of disagree with the following statements?

[For Care Recipients who are unabe to distinguish between the four response categories, use only the "Yes" and "No" response options and the reverse of RESP CARD which has the approprinte "Yes"

"No" responses for the entire scale]

Because of helping my [REL]: Strongly Agrec Disagrce Strongly

Agree Disagree

a. I felt closer to her /him than $\quad \begin{array}{lllll}0 & 1 & 2 & 3\end{array}$

$\begin{array}{lllll}\text { I have learned some good } & 0 & 1 & 2\end{array}$

c. I felt angry toward [CG]

d. I felt depressed because of my relationship

e. I felt resentful toward my $[\mathrm{CG}]$

f. I have had more parience than I have had in the past

g. I havc learned somc good
things about my [CG

I felt that my relationship with m [CG] was stmincd

i. I have learned some nice my life j. Communication between my
[REL] and me has improved

$\begin{array}{llll}3 & 2 & 1 & 0\end{array}$

$\begin{array}{llll}3 & 2 & 1 & 0\end{array}$

$\begin{array}{llll}3 & 2 & 1 & 0\end{array}$

$\begin{array}{llll}0 & 1 & 2 & 3\end{array}$

32

$\begin{array}{llll}0 & 1 & 2 & 3\end{array}$

$\begin{array}{llll}0 & 1 & 2 & 3\end{array}$ $\begin{array}{llll}0 & 1 & 2 & 3\end{array}$ 


\section{Escala de Relaciones Diádicas (Aquel que provee asistencia medica)}

Esta serie de preguntas se dirigen hacia algunas de las dificultades que la gente enfrenta al cuidar de un pariente. Quisiera hablar sobre como el cuidar de tu [pariente] ha afectado su relación con el/ella durante el pasado mes. [HAND CG CARD]. Por favor refiérase a esta tarjeta para sus respuestas. ¿Cuánto esta de acuerda o desacuerdo con las siguientes declaraciones?

Por ayudar a mi [relativo]:

a. Me siento más cercano a el/ella después de mucho tiempo

b. He aprendido muchas cosas buenas de mi [pariente]

c. Me sentí enojado hacia él/ella

d. Me sentí deprimido por mí relación con el/ella

e. Sentía resentimiento hacia él/ella

f. He tenido más paciencia que en el pasado

g. He aprendido cosas buenas de mí mismo

h. Sentí que mi relación con él/ella estaba tensa

i. He aprendido algunas cosas buenas

$\begin{array}{lll}\begin{array}{l}\text { Mucho } \\ \text { Acuerdo }\end{array} & \text { De Acuerdo En Desacuerdo } \begin{array}{c}\text { Mucho } \\ \text { Desacuerdo }\end{array}\end{array}$


de otras personas en mi vida

j. Comunicación entre mi [relativo]

y yo ha mejorado

k. Sentí que él/ella pedía favores mas

de lo que necesitaba 
Escala de Relaciones Diádicas [Recipiente de Cuidado]

Quisiera hablar sobre como tus problemas de memoria han afectado tu relación con la persona que cuida de ti durante el último mes. [HAND RESP CARD]. Por favor refiérase a esta tarjeta para sus respuestas and de recuerdo, estamos hablando de este último mes. ¿Cuánto estás de acuerdo o desacuerdo con las siguientes declaraciones?

Por ayudar a mi [relativo]:

a. Me siento más cercano a el/ella

después de mucho tiempo

b. He aprendido muchas cosas

buenas de mi [pariente]

c. Me sentí enojado hacia él/ella

d. Me sentí deprimido por mí

relación con el/ella

e. Sentía resentimiento hacia él/ella

f. He tenido más paciencia que en el pasado

g. He aprendido cosas buenas de mí mismo

h. Sentí que mi relación con él/ella estaba tensa

i. He aprendido algunas cosas buenas

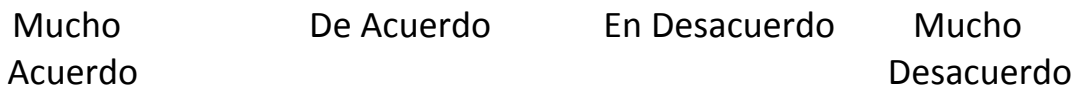

0

1 
de otras personas en mi vida

j. Comunicación entre mi [relativo]

y yo ha mejorado

k. Sentí que él/ella pedía favores mas

de lo que necesitaba 
Appendix G

SF-12 Questionnaire

English and Spanish Versions 


\section{Your Health and Well-Being}

This survey asks for your views about your health. This information will help keep track of how you feel and how well you are able to do your usual activities. Thank you for completing this survey!

For each of the following questions, please mark an $\bigotimes$ in the one box that best describes your answer.

1. In general, would you say your health is:

\begin{tabular}{|lllll|}
\hline Excellent & Very good & Good & Fair & Poor \\
$\square$ & $\square_{2}$ & $\square_{3}$ & $\square_{4}$ & $\square_{3}$
\end{tabular}

2. The following questions are about activities you might do during a typical day. Does your health now limit you in these activities? If so, how much?

\begin{tabular}{|ccc|}
\hline Yes, & Yes, & No, not \\
limited & limited & limited \\
a lot & a little & at all
\end{tabular}

- Moderate activities, such as moving a table, pushing a vacuum cleaner, bowling, or playing golf...

- Climbing several flights of stairs

SF-12v $2^{\circ}$ Health Survey $\odot 1994,2002$ Medical Outcomes Trust and QualityMetric Incorporated. All rights reserved.

$\mathrm{SF}-12^{\circ}$ is a registered trademark of Medical Outcomes Trust.

(SF-12v2 ${ }^{\circ}$ Health Survey Standard, United States (English)) 
3. During the past 4 weeks, how much of the time have you had any of the following problems with your work or other regular daily activities as a result of vour physical health?

- Accomplished less than you would like

\begin{tabular}{ccccc|}
$\begin{array}{c}\text { All of } \\
\text { the time }\end{array}$ & $\begin{array}{c}\text { Most of } \\
\text { the time }\end{array}$ & $\begin{array}{c}\text { Some of } \\
\text { the time }\end{array}$ & $\begin{array}{c}\text { A little of } \\
\text { the time }\end{array}$ & $\begin{array}{c}\text { None of } \\
\text { the time }\end{array}$
\end{tabular}

Were limited in the kind of

work or other activities.

4. During the past 4 weeks, how much of the time have you had any of the following problems with your work or other regular daily activities as a result of anv emotional problems (such as feeling depressed or anxious)?

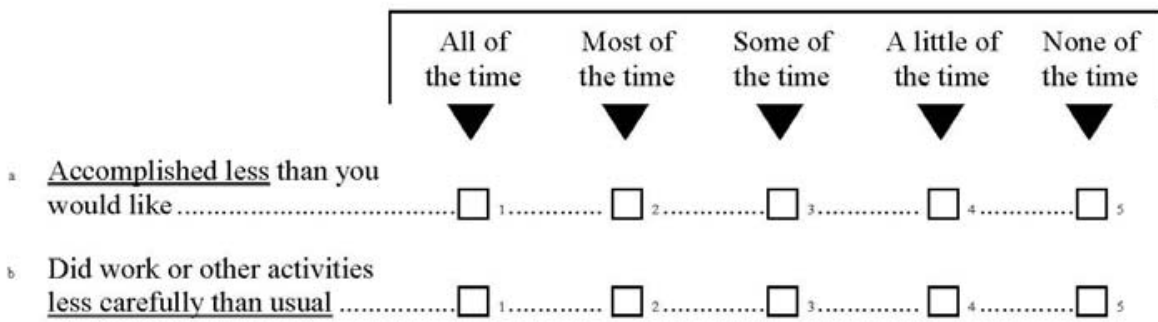

5. During the past 4 weeks, how much did pain interfere with your normal work (including both work outside the home and housework)?

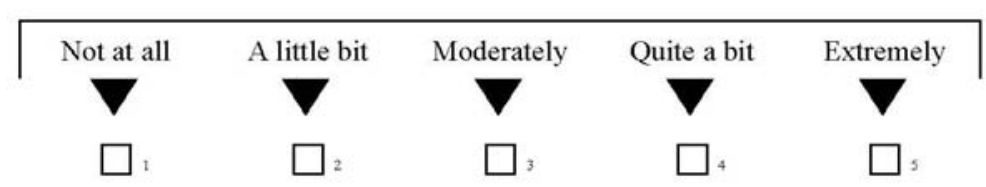

SF $-122^{\circ}$ Health Survey $\odot 1994,2002$ Medical Outcomes Trust and QualityMetric Incorporated. All rights reserved.

$\mathrm{SF}-12^{\circ}$ is a registered trademark of Medical Outcomes Trust.
(SF-12v2 $2^{\circ}$ Health Survey Standard, United States (English)) 
6. These questions are about how you feel and how things have been with you during the past 4 weeks. For each question, please give the one answer that comes closest to the way you have been feeling. How much of the time during the past 4 weeks...

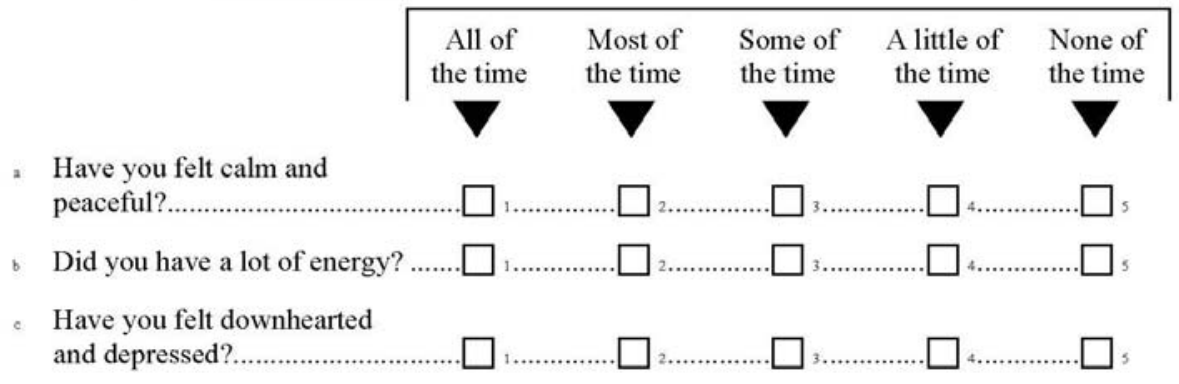

7. During the past 4 weeks, how much of the time has your physical health or emotional problems interfered with your social activities (like visiting with friends, relatives, etc.)?

$\begin{array}{|cccc|}\begin{array}{c}\text { All of } \\ \text { the time }\end{array} & \begin{array}{c}\text { Most of } \\ \text { the time }\end{array} & \begin{array}{c}\text { Some of } \\ \text { the time }\end{array}\end{array}$

Thank you for completing these questions!

SF $-122^{\circ}$ Health Survey $\odot 1994,2002$ Medical Outcomes Trust and QualityMetric Incorporated. All rights reserved.

$\mathrm{SF}-12^{\circ}$ is a registered trademark of Medical Outcomes Trust.

(SF-12 $\mathrm{v}^{\circ}{ }^{\circ}$ Health Survey Standard, United States (English)) 


\section{Su Salud y Bienestar}

Esta encuesta le pide sus opiniones acerca de su salud. Esta información permitirá saber cómo se siente y qué tan bien puede hacer usted sus actividades normales. ¡Gracias por contestar estas preguntas!

Para cada una de las siguientes preguntas, por favor marque con una $\triangle$ la casilla que mejor describa su respuesta.

1. En general, diría que su salud es:

\begin{tabular}{|llll|}
\hline Excelente & Muy buena & Buena & Pasable \\
$\square_{1}$ & $\square_{2}$ & $\square_{3}$ & $\square_{4}$
\end{tabular}

2. Las siguientes preguntas se refieren a actividades que usted podría hacer durante un día típico. ¿Su estado de salud actual lo/la limita para hacer estas actividades? Si es así, ¿cuánto?

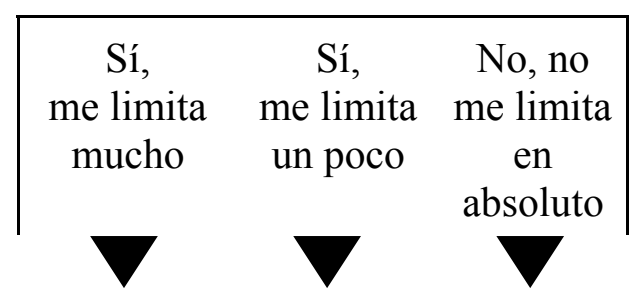

a Actividades moderadas, tales como mover una mesa, empujar una aspiradora, jugar al bowling o al golf o trabajar en el jardín

b Subir varios pisos por la escalera. 
3. Durante las últimas 4 semanas, ¿cuánto tiempo ha tenido usted alguno de los siguientes problemas con el trabajo u otras actividades diarias regulares a causa de su salud física?

\begin{tabular}{|ccccc|}
\hline Siempre & $\begin{array}{c}\text { Casi } \\
\text { siempre }\end{array}$ & $\begin{array}{c}\text { Algunas } \\
\text { veces }\end{array}$ & $\begin{array}{c}\text { Casi } \\
\text { nunca }\end{array}$ & Nunca \\
$\nabla$ & $\nabla$ & $\nabla$ & $\nabla$ & $\nabla$
\end{tabular}

a Ha logrado hacer menos de lo que le hubiera gustado

b Ha tenido limitaciones en cuanto al tipo de trabajo u otras actividades

4. Durante las últimas 4 semanas, ¿cuánto tiempo ha tenido usted alguno de los siguientes problemas con el trabajo u otras actividades diarias regulares a causa de algún problema emocional (como sentirse deprimido/a o ansioso/a)?

\begin{tabular}{|ccccc|}
\hline Siempre & $\begin{array}{c}\text { Casi } \\
\text { siempre }\end{array}$ & $\begin{array}{c}\text { Algunas } \\
\text { veces }\end{array}$ & $\begin{array}{c}\text { Casi } \\
\text { nunca }\end{array}$ & Nunca \\
& $\nabla$ & $\nabla$ & $\nabla$ & $\nabla$
\end{tabular}

a Ha logrado hacer menos de lo que le hubiera gustado

b Ha hecho el trabajo u otras actividades con menos cuidado de lo usual 
5. Durante las últimas 4 semanas, ¿cuánto ha dificultado el dolor su trabajo normal (incluyendo tanto el trabajo fuera de casa como los quehaceres domésticos)?

\begin{tabular}{|c|c|c|c|c|}
\hline $\begin{array}{l}\text { Nada en } \\
\text { absoluto }\end{array}$ & Un poco & $\begin{array}{l}\text { Mediana- } \\
\text { mente }\end{array}$ & Bastante & $\begin{array}{c}\text { Extremada- } \\
\text { mente }\end{array}$ \\
\hline
\end{tabular}

6. Estas preguntas se refieren a cómo se siente usted y a cómo le han ido las cosas durante las últimas 4 semanas. Para cada pregunta, por favor dé la respuesta que más se acerque a la manera cómo se ha sentido usted. ¿Cuánto tiempo durante las últimas 4 semanas...

\begin{tabular}{|lcccc|}
\hline Siempre & $\begin{array}{c}\text { Casi } \\
\text { siempre }\end{array}$ & $\begin{array}{c}\text { Algunas } \\
\text { veces }\end{array}$ & $\begin{array}{c}\text { Casi } \\
\text { nunca }\end{array}$ & Nunca \\
& $V$ & &
\end{tabular}

a se ha sentido tranquilo/a y

sosegado/a?

b ha tenido mucha energía?

se ha sentido desanimado/a y

deprimido/a? 
7. Durante las últimas 4 semanas, ¿cuánto tiempo su salud física o sus problemas emocionales han dificultado sus actividades sociales (como visitar amigos, parientes, etc.)?

\begin{tabular}{|c|c|c|c|c|}
\hline Siempre & $\begin{array}{c}\text { Casi } \\
\text { siempre }\end{array}$ & $\begin{array}{l}\text { Algunas } \\
\text { veces }\end{array}$ & $\begin{array}{l}\text { Casi } \\
\text { nunca }\end{array}$ & Nunca \\
\hline
\end{tabular}

¡Gracias por contestar estas preguntas! 
Appendix $\mathrm{H}$

Contract for SF-12 use from Optuminsight 


\section{NON-COMMERCIAL LICENSE AGREEMENT Office of Grants and Scholarly Research (OGSR)}

License Number: QM019087

\section{Effective Date: $\quad$ 05/15/13}

Licensee Name: Florida International University

Licensee Address: Robert Stempel College of Public Health \& Social Work Miami Beach, FL 33174

Approved Purpose: Non-commercial academic research - Grant funded by government agency or non-profit organization

Study Name: Predictors of independent living outcomes among older women receiving informal care

Study Type: Grant Funded

Therapeutic Area: Wellness \& Lifestyle

Other Definitions: As indicated on Appendix B "License Agreement - Details", including without limitation: Licensed Surveys, Modes, Fees, Administrations, Services, Approved Languages and (if applicable) License Term

Licensee accepts and agrees to the terms of this Non-Commercial License Agreement (the "Agreement") from the Office of Grants and Scholarly Research (OGSR) of Optumlnsight Life Sciences, Inc. (f/k/a QualityMetric Incorporated) ("Optumlnsight") as of the Effective Date.

Subject to the terms of this Agreement, including the Optuminsight Non-Commercial License Terms and Conditions attached as Appendix A: (a) Optuminsight grants to Licensee, and Licensee accepts, a non-exclusive, nontransferable, non-assignable, non-sublicensable worldwide license to use, solely for the Approved Purpose and during the License Term, the Licensed Surveys in the authorized Modes and Approved Languages indicated on Appendix B and to administer the Licensed Surveys only up to the approved number of Administrations (and to make up to such number of exact reproductions of the Licensed Surveys necessary to support such Administrations) in any combination of the specific Licensed Surveys and Approved Languages and Modes and to use any related software provided by Optuminsight and (b) Licensee agrees to pay the Fee and other applicable charges in accordance with the attached invoice.

Capitalized terms used in this Agreement shall have the meanings assigned to them above or in Appendices $\mathrm{A}$ and $\mathrm{B}$ attached hereto. Appendices $\mathrm{A}$ and $\mathrm{B}$ are incorporated into and made a part of this Agreement for all purposes.

EXECUTED, as of the Effective Date, by the duly authorized representatives as set forth below.

Optuminsight Life Sciences, Inc.

[Optuminsight],

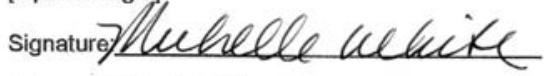

Name: Michelle White

lorida Intemational University

Title: $\quad$ Director of Consulting Science

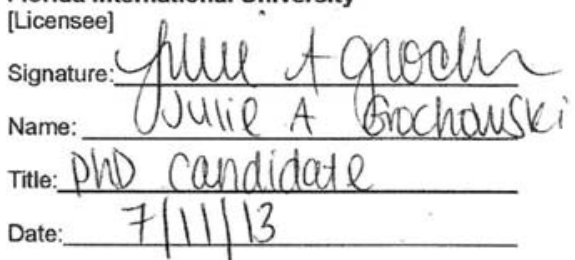

Filename: Florida International University - Julie Grochowski - license agreement - QM019087

M

Template: OGSR Grant Funded SLA - 2012-11-21

an Optuminsight company

Page 1 of 6 


\title{
OPTUMInsight
}

\section{APPENDIX A}

\section{QUALITYMETRIC NON-COMMERCIAL LICENSE TERMS AND CONDITIONS}

\author{
Attached to and Incorporated into License No. QM019087
}

1. No Commercial Use of Data - Licensee agrees to use the data resulting from Licensee's administration of the Licensed Surveys only for the Approved Purpose and related academic or scientific uses. Licensee agrees not to use such data for any other purpose or to provide such data to any commercial entity or to any entity for commercial purposes, including University Hospitals.

2. License Fees and Payment Terms - Licensee agrees to pay the Fee and all other charges indicated on the invoice provided by Optumlnsight, which amounts shall become due upon Licensee's receipt of such invoice. All amounts are stated in, and all payments shall be in, U.S. Dollars. Licensee shall be responsible for all taxes relating to all fees and charges. Such fees and charges are exclusive of any sales tax, value added taxes, duties, or other withholding.

3. License Term and Termination - This Agreement shall be effective until the end of the License Term reflected in Appendix B, after which this Agreement and the licenses granted here under shall terminate. Notwithstanding the foregoing, Optumlnsight may terminate this Agreement at any time upon in the event of a material breach by Licensee or its personnel of this Agreement that is not cured within thirty (30) days following notice to Licensee.

4. Administration by Students and Third Parties - Students of Licensee may use and administer the Licensed Surveys, subject to each such students' execution of Optuminsight's Acknowledgement by Students form, available by request. A third party service provider may administer the Licensed Surveys on behalf of Licensee, subject to such third party's execution of Optumlnsight's Acknowledgement by Agent form, available by request. However, in all such cases, Licensee shall not be relieved of its obligations, and Licensee shall be responsible for any breach hereof by such student or third party.

5. Trademark and Copyright Notices - Licensee agrees to reproduce the copyright and trademark notices included with the Licensed Surveys on all reproductions of the Licensed Surveys permitted hereunder, including electronic reproductions and representations. Licensee shall not alter the wording or order of the items or any other part of the Licensed Surveys. Licensee shall not create any derivative work from the Survey Materials (as defined in Section 7(a)).

6. Records - Licensee shall maintain accurate records, in all material respects, containing information sufficient to verify Licensee's compliance with this Agreement, including as applicable, but not limited to, records of the number of reproductions of the Licensed Survey(s) made, the location of and/or confirmation of the destruction of such reproductions, the number of administrations of the Licensed Surveys performed, and the use(s) made of the data resulting from Licensee's administration of the Licensed Surveys.

\section{Proprietary Rights -}

a. Licensee acknowledges that the Licensed Surveys, manuals, copyright in all publications purchased, Software or other scoring solution, and all intellectual property rights related thereto ("Survey Materials"), shall be and remain at all times the property of Optumlnsight. Licensee shall have no right, title or interest in the Survey Materials except for the limited license described herein. Licensee shall not use, modify, reproduce, or transmit any of the Survey Materials except as expressly provided hereunder in connection with the Approved Purpose. If the Approved Purpose includes administration of the Licensed Surveys in physical form, Licensee is authorized to make exact reproductions of the Licensed Survey(s) sufficient to support such administrations.

Filename: Florida International University - Julie Grochowski - license agreement - QM019087 
b. Licensee acknowledges and agrees that the Mode of survey administration reflected in Appendix $B$ is the only manner in which Licensee may administer the Licensed Surveys. By way of example, it the Mode reflected in Appendix B is "paper", the Licensed Survey(s) shall be used, distributed, and administered via paper only, and shall not be used, distributed, displayed, or administered via any electronic means.

c. Licensee acknowledges and agrees that scoring of Licensed Survey(s) responses must be performed by Optumlnsight or by Licensee through use of an Optuminsight scoring solution. Licensee shall not imbed, input, insert, or transfer the Survey Materials, or any part thereof, into Licensee's systems or applications absent purchase by Licensee of an Optumlnsight scoring solution.

d. Licensee acknowledges and agrees that any translations of the Licensed Surveys into any language must be performed by Optumlnsight, and Optuminsight retains ownership of any and all translations.

8. Ownership of Survey Results Data - Notwithstanding the foregoing, the parties agree that all results of Licensee's administration of the Licensed Survey(s) shall be the property of Licensee.

9. Confidentiality: Iniunctive Relief - Licensee acknowledges that the Survey Materials are valuable assets of Optuminsight and that the value of the Survey Materials would be significantly impaired by the unauthorized distribution or use of them. Licensee shall ensure that the Survey Materials are not used for unauthorized purposes or by unauthorized persons, and shall promptly report any such unauthorized use to Optuminsight. Licensee acknowledges that, in the event of any material breach of this paragraph by the Licensee, money damages would not be a sufficient remedy, and that Optuminsight shall, to the extent permitted by applicable law, be entitled to equitable relief, including injunction. Such relief shall be in addition to all other remedies available at law or in equity.

10. Disclaimer of Warranty - Licensee understands and acknowledges that complex and sophisticated products such as the Survey Materials are inherently subject to undiscovered defects. Optumlnsight cannot and does not represent or warrant to Licensee that the Survey Materials are free from such defects, that operation of the Survey Materials will be uninterrupted or error free, or that its results will be effective or suitable with respect to any particular application. SURVEY MATERIALS PROVIDED HEREUNDER ARE PROVIDED AS-IS, AND OPTUMINSIGHT MAKES NO REPRESENTATIONS OR WARRANTIES, EXPRESS OR IMPLIED, ARISING BY LAW OR OTHERWISE WTH RESPECT TO SUCH SURVEY MATERIALS OR THIS AGREEMENT, AND DISCLAIMS ALI WARRANTIES INCLUDING WITHOUT LIMITATION ANY REPRESENTATIONS OR WARRANTIES AS TO MERCHANTABILITY, FITNESS FOR A PARTICULAR PURPOSE, NON-INFRINGEMENT OR OTHERWISE.

11. Compliance with Law - Optuminsight and Licensee agree that in performing their respective obligations under this Agreement, each shall conduct business in conformance with sound ethical standards of integrity and honesty and in compliance with all applicable laws, rules and regulations.

12. LIMITATION OF LIABILITY - REGARDLESS OF WHETHER ANY REMEDY SET FORTH HEREIN FAILS OF ITS ESSENTIAL PURPOSE, IN NO EVENT SHALL OPTUMINSIGHT'S TOTAL LIABILITY FOR DIRECT DAMAGES ARISING HEREUNDER EXCEED THE AMOUNT OF THE FEES PAID BY LICENSEE TO OPTUMINSIGHT HEREUNDER. IN NO EVENT SHALL OPTUMINSIGHT BE LIABLE TO LICENSEE OR ANY THIRD PARTY FOR ANY SPECIAL, PUNITIVE, INCIDENTAL, INDIRECT, OR CONSEQUENTIAL DAMAGES, ARISING FROM ANY CLAIMED BREACH OF WARRANTY, BREACH OF CONTRACT, NEGLIGENCE, STRICT LIABILITY IN TORT, OR ANY OTHER LEGAL THEORY, EVEN IF OPTUMINSIGHT HAS BEEN ADVISED OF THE POSSIBILITY OF SUCH DAMAGES. SUCH EXCLUDED DAMAGES INCLUDE, BUT ARE NOT LIMITED TO, LOST PROFITS, COST OF ANY SUBSTITUTE GOODS OR SERVICES, LOST BUSINESS INFORMATION AND DATA, AND BUSINESS INTERRUPTION

13. Additional Terms for Use of Optuminsight Software - The following additional terms apply to any software provided by Optumlnsight to Licensee in connection with this Agreement ("Software"). Licensee may install and use one copy of the Software on a single computer, and except for making one back-up copy of the Software, may not otherwise copy the Software. The Software may not be shared or used concurrently on different computers.

Filename: Florida International University - Julie Grochowski - license agreement - QM019087

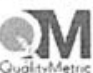

Template: OGSR Grant Funded SLA - 2012-11-21

an Optuminsight company

Page 3 of 6 
Licensee may not reverse engineer, decompile, or disassemble the Software, nor attempt in any other manner to obtain the source code. The Software and the algorithms it contains are proprietary information of Optumlnsight. Licensee shall not attempt to circumvent any function of the Software that limits its use to a certain number of administrations of the Licensed Surveys or to a certain time period. Licensee may not rent or lease the Software to any other person.

14. Form Review - If Licensee will administer the Licensed Surveys on an electronic device Licensee acknowledges that this provision shall be applicable to Licensee's use of the Licensed Surveys. Licensee is required to submit screen shots or a link to the Licensed Surveys for each Approved Language to Optumlnsight. Optumlnsight shall perform an initial form review to determine whether the Licensed Surveys have been appropriately migrated to electronic format (the "Initial Review"). Optumlnsight will complete its Initial Review of the Licensed Surveys for each Approved Language within two (2) weeks from Optumlnsight's receipt of screen shots or website link from Licensee. Upon Optuminsight's completion of the Initial Review, Optumlnsight will provide Licensee with a detailed list of revisions that will need to be made before Optumlnsight can approve the electronic format. Licensee is required to submit subsequent screen shots or a link to the Licensed Surveys for each Approved Language incorporating any changes required by Optuminsight until Optuminsight provides its final approval of the electronic format. The parties acknowledge and agree that multiple rounds of review and revisions may be necessary prior to Optumlnsight being able to provide final approve of the electronic format. Licensee is solely responsible for the electronic creation of the Licensed Surveys. Licensee does not obtain any rights in the Licensed Surveys not otherwise granted in this Agreement due to the administration and/or use of the Licensed Surveys. Nothing in this Agreement prohibits Optuminsight from creating its own electronic forms of Licensed Survey administration. The Licensed Surveys cannot be used in electronic format except as allowed pursuant to the terms and conditions of this Agreement. Licensee acknowledges that there may be response differences due to effects from use of electronic format compared to a static Mode of administration such as paper/pencil. Licensee assumes any and all risk of differential effects resulting from the use of electronic format.

15. Miscellaneous -

a. This Agreement constitutes the entire and exclusive agreement between the parties and supersedes all previous communications or agreements, either oral or written, with respect to the subject matter hereof. This Agreement may not be modified or amended except by an instrument in writing signed by both parties. The Appendices attached hereto are incorporated into and made a part of this Agreement for all purposes.

b. Notices, copies of notices or other communications shall be sent to a party at the address set forth on the first page of this Agreement. All notices shall be effective upon delivery of the notice at such address.

c. Any waiver of any breach or default under this Agreement must be in writing and shall not be deemed a waiver of any other or subsequent breach or waiver. Failure to delay by either party to enforce compliance with any term or condition of this Agreement shall not constitute a waiver of such term or condition.

d. If any provision in this Agreement is determined to be invalid or unenforceable, the remaining provisions of this Agreement shall not be affected thereby and shall be binding upon the parties hereto, and shall be enforceable, as though the invalid or unenforceable provision were not contained herein.

e. In the event a Licensed Survey or associated Optuminsight intellectual property is exported by Licensee outside of the country in which Licensee is located, both parties agree that Licensee is obligated and solely responsible for ensuring compliance with all applicable import and export laws and regulations of the United States of America and/or any applicable foreign jurisdictions. Licensee shall indemnify, defend and hold harmless Optuminsight (including payment of all reasonable costs, fees, settlements and damages) with respect to any suits or proceedings brought against Optumlnsight arising from Licensee's export of a Licensed Survey.

f. This Agreement and performance hereunder shall be governed in accordance with the laws of the State of New York, but excluding New York choice of law principles. With respect to any dispute arising in

Filename: Florida International University - Julie Grochowski - license agreement - QM019087

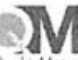

Template: OGSR Grant Funded SLA - 2012-11-21

an Optuminsight company

Page 4 of 6 
connection with this Agreement, Licensee consents to the exclusive jurisdiction and venue in the state and federal courts located in New York City, New York.

g. This Agreement may be executed in multiple counterparts, each of which shall be deemed an original and all of which shall be deemed the same agreement

Filename: Florida International University - Julie Grochowsk - license agreement - QM019087

an Optuminsight company

Template: OGSR Grant Funded SLA - 2012-11-21

Page 5 of 6 


\title{
iopTUMInsight
}

\author{
Very Important - Please Read
}

\section{No formatting or editing changes to the survey}

In order to obtain licensing from Licensor no changes can be made to the survey forms. Any format and/or language changes have the potential to affect the survey data received. Therefore, to maintain the validation and integrity of the SF Health Surveys, no lanquage or formatting changes are allowed. The format of the survey is scientifically engineered to facilitate accurate and unbiased data, as well as keeping the SF Health Survey in a visual format that is comprehensible to the patient/participant, including those who may be impaired and/or elderly. You should administer the survey in the exact format you will receive it in. The only item Licensee may add is a header with patient identification and / or administration information. If you do wish to add a header please ask for a sample copy of the survey to edit and then submit this to your Account Representative for review prior to signing this License Agreement. Once the licensing process is completed, you will receive a clean set of Survey Forms in a word and .pdf.file. These are the forms you will administer. Please do not use any forms vou may already have access to as the ones we send you are the most current versions.

$$
* * *
$$




\section{APPENDIX B}

\section{OPTUMInsight LICENSE AGREEMENT - DETAILS}

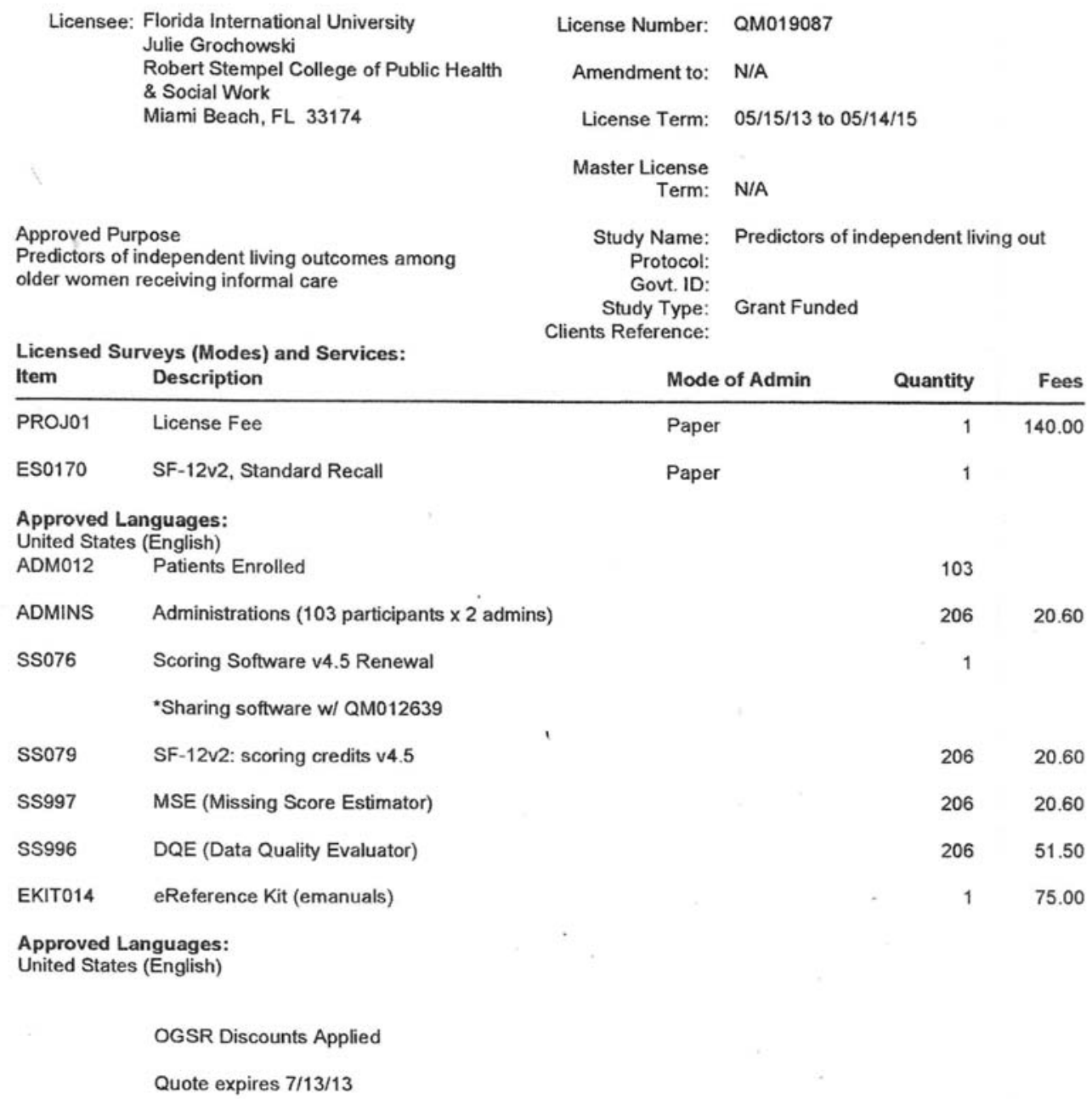




\section{A OPTUMlnsight" \\ NON-COMMERCIAL AMENDMENT TO LICENSE AGREEMENT}

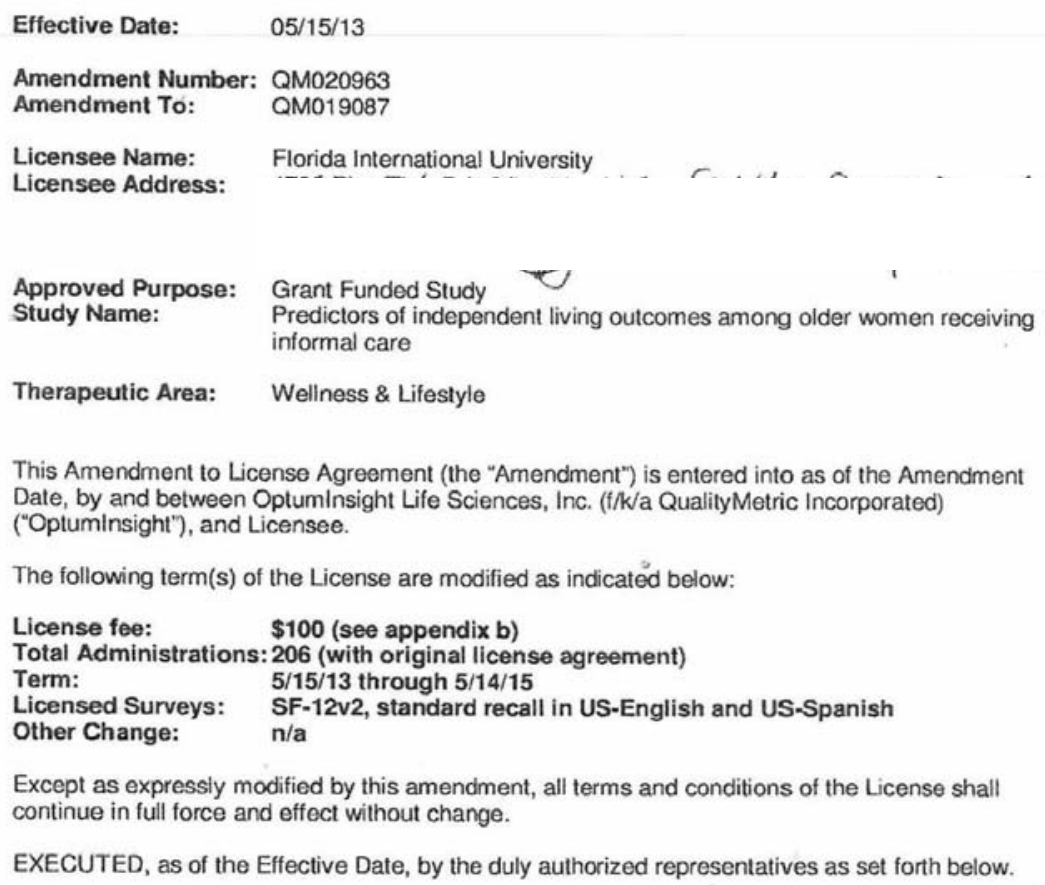

Except as expressly modified by this amendment, all terms and conditions of the License shall continue in full force and effect without change.

EXECUTED, as of the Effective Date, by the duly authorized representatives as set forth below. 


\section{APPENDIX B}

\section{S OPTUMInsight LICENSE AGREEMENT - DETAILS}

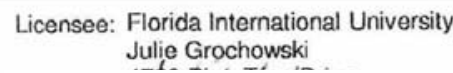

Licensee: Florida International University Julie Grochowski

Approved Purpose older women receiving informal care

$\begin{aligned} & \text { Licensed Surveys (Modes) and Services: } \\ & \text { Item } \\ & \text { Description }\end{aligned}$
See QM019087 for orig license

ES0170
Predictors of independent living outcomes among

\author{
License Number: QM020963 \\ Amendment to: QM019087 \\ License Term: $\quad 05 / 15 / 13$ to 05/14/15 \\ Master License \\ Term: N/A
}

Study Name: Predictors of independent living ou Protocol:

Govt. ID:
Study Type: Grant Funded Study

Clients Reference:

Mode of Admin

Quantity

Fees

Paper

2

Approved Languages:

United States (English)

United States (Spanish)

LANGUAGES Additional Language Fee

\footnotetext{
- OGSR Disounts Applied

Quole expires 10/16/13

-US-Spanish version needed

TOTAL FEES:

100.00 USD

Payment Terms: Due on Receipt
} 
Appendix I

Duke Social Support Inventory

English and Spanish Versions 
Duke Social Support Scale (requires interviewer-administration)

Social Interaction Subscale

1. Other than members of your family, how many persons in this area within one hour's travel (of your home/from here) do you feel you can depend on or feel very close to?

NUMBER

$\overline{\text { None }} \quad 00$

[scoring $0=1,1-2=2,>2=3$ ]

2. (Other than at work) How many times during the past week did you spend some time with someone who does not live with you, that is, you went to see them or they came to visit you, or you went out together?

None $\quad 00$

Once $\quad 01$

Twice 02

Three times $\quad 03$

Four 04

Five 05

Six 06

[scoring $0=1,1-2=2,>2=3$ ]

Seven or more 07

3. (Other than ar work) How many times did you talk to someone - friends, relatives or others - on the telephone in the past week (either they called you, or you called them)?

None $\quad 00$

Once 01

Twice 02

Three times 03

Four 04

Five 05

Six 06

[scoring 0 or $1=1,2-5=2,>5=3$ ] 
4. (Other than at work) About how often did you go to meetings of clubs, religious meetings, or other groups that you belong to in the past week?

[DO NOT INCLUDE ATTENDANCE

AT RELIGIOUS SERVICES OR

None $\quad 00$

Once 01

Twice 02

OTHER RELIGIOUS / SPIRITUAL GROUP MEETINGS]

Three times 03

Four 04

Five 05

Six 06

Seven or more $\quad 07$

[scoring 0 or $1=1,2-5=2,>5=3$ ]

\section{Subjective Social Support}

5. Does it seem that your family and friends (i.e., people who are important to you) understand you most of the time, some of the time, or hardly ever?

Hardly Ever 1

Some 2

Most 3

6. Do you feel useful to your family and friends (i.e., people important to you) most of the time, some of the time, or hardly ever?

Hardly Ever $\quad 1$

Some 2

Most

7. Do you know what is going on with your family and friends most of the time, some of the time, or hardly ever?

Hardly Ever 1

Some 2

Most

8. When you are talking with your family and friends, do you feel you are being listened to most of the time, some of the time, or hardly ever?

Hardly Ever $\quad 1$

Some 2

Most 
9. Do you feel you have a definite role (place) in your family and among your friends most of the time, some of the the time, or hardly ever?

Hardly Ever 1

Some 2

Most 3

10. Can you talk about your deepest problems with at least some of your family and friends most of the time, some of the the time, or hardly ever?

Hardly Ever $\quad 1$

Some 2

Most

11. How satisfied are you with the kinds of relationships you have with your family and friends - very dissatisfied, somewhat dissatisfied, or satisfied?

Very Dissatisfied 1

Somewhat Dissatisf 2

Satisfied 3

If NO FAMILY OR FRIENDS: Would you say

that you are very dissatisfied, somewhat

dissatisfied, or satisfied with not

having any of these relationships?

Now I want to ask you about some of the ways your family and friends help you out. Do your family or friends ever help you in any of the following ways:

[Family includes natural family (parents, brothers, sisters) and acquired family (spouse, children)]

Repeat for each question: "Do they ...

$\underline{\mathrm{NO}} \quad \underline{\mathrm{YES}}$

12. ... help out when you are sick?

12

13. ... shop or run errands for you?

12

14. ... give you gifts (presents)?

12

$15 . .$. help you out with money?

12

16. ... fix things around your house?

12

17. . . keep house for you or do household

12
chores? 
18. . . . give you advice on business or

financial matters?

$19 . .$. provide companionship to you?

20... listen to your problems?

$21 . .$. give you advice on dealing with life's problems?

22. ... provide transportation for you?

23... . prepare or provide meals for you?
12

12

12

12

12

12

[Scoring: Sum up totals for all sections to obtain overall social support score (score range 23-57); best to report totals for each section of the DDSI brief scale [Questions 14 (score range 4-12), Questions 5-11 (score range 7-21), Questions 12-23 (score range 12-24)]. For the 11-item index (not including the instrumental support section), the overall score range is 11-33. Both the11-item and 23-item scales are found in Koenig HG, Westlund RE, George LK, Hughes DC, Hybels C (1993). Abbreviating the Duke Social Support Index for use in chronically ill older adults. Psychosomatics 34:61-69. No information on reliability or validity, other than that work done with full version of DDSI (Landerman R, George LK, Campbell RT, et al 1989. American Journal of Community Psychology 17:625-642.]

Note: Not included here is the Social Network Size subscale of the DSSI (one reason is because it includes questions about religious organizations that may contaminate measure with religious or spiritual content) 


\section{Escala de Apoyo Social de Duke (requiere ser entrevistado)}

Subescala de Interacción Social

1. ¿En cuantas personas usted puede confiar o son cercanas, aparte de los miembros de su familia, en una hora de viaje desde su hogar a su lugar de llegada?

[Resultado $0=1,1-2=2,>2=3$ ]

2. (Excepto en el trabajo) ¿Cuántas veces durante la semana pasada paso algún tiempo con alguien que no vive con usted, es decir, que fue a verlos o ellos vinieron a visitar a usted, o usted salió juntos?

[Resultado $0=1,1-2=2,>2=3$ ]

3. (Excepto en el trabajo) ¿Cuántas veces has hablado con alguien - amigos, familiares u otras personas por el teléfono en la última semana (ya sea que usted llama, o te han llamado)?

[Resultado 0 or $1=1,2-5=2,>5=3$ ]
Ninguno

00

Ninguno $\quad 00$

Una Vez $\quad 01$

Dos 02

Tres 03

Cuatro 04

Cinco 05

Seis 06

Siete o mas 07

Ninguno $\quad 00$

Una Vez 01

Dos 02

Tres 03

Cuatro 04

Cinco 05

Seis 06

Siete o mas 07 
4. (Excepto en el trabajo) ¿Con qué frecuencia has ido a las reuniones de los clubes, reuniones religiosas u otros grupos a los que pertenece en la última semana?

Ninguno $\quad 00$

Una Vez 01

Dos 02

[No incluya asistencia a servicios religiosos $\mathrm{u}$

Tres 03

otras reuniones grupo religioso/espiritual]

Cuatro 04

Cinco 05

Seis 06

[Resulatado 0 or $1=1,2-5=2,>5=3$ ]

Siete o mas

07

\section{Apoyo Social Subjetivo}

5. ¿Le parece que su familia y amigos

(es decir, las personas que son importantes

para usted) te comprenden la mayor parte del

tiempo, algunas veces, o casi nunca?

Casi nunca $\quad 1$

Algunas veces 2

Mayoría de veces 3

6. ¿Se siente útil para su familia y amigos

(es decir, las personas importantes para usted)

la mayoría de las veces, algunas de las veces, o

casi nunca?

Casi nunca $\quad 1$

Algunas veces 2

Mayoría de veces 3

7. ¿Sabes lo que está pasando con su familia y amigos la mayoría de las veces, algunas de las veces, o casi nunca?

Casi nunca $\quad 1$

Algunas veces 2

Mayoría de veces 3

8. ¿Cuando usted está hablando con su familia y amigos, siente que está siendo escuchado en la mayoría de las veces, algunas veces, o casi nunca?

Casi nunca $\quad 1$

Algunas veces 2

Mayoría de veces 3 
9. ¿Usted siente que tiene un papel importante (lugar) en su familia y entre sus amigos la mayoría de las veces, algunas veces, o casi nunca?

Casi nunca $\quad 1$

Algunas veces 2

Mayoría de veces 3

10. ¿Puede hablar de sus problemas más importantes con al menos algunos de sus familiares y amigos la mayoría de las veces, algunas veces, o casi nunca?

$\begin{array}{ll}\text { Casi nunca } & 1 \\ \text { Algunas veces } & 2 \\ \text { Mayoría de veces } & 3\end{array}$

11. ¿Qué tan satisfecho está usted con el tipo de relaciones que tiene con su familia y amigos Muy insatisfecho, algo insatisfecho, o satisfechos?

Muy insatisfecho 1

Algo insatisfecho 2

Satisfecho 3

Si usted NO TIENE FAMILIARES O AMIGOS:

¿Diría usted que está muy satisfecho, algo satisfecho o satisfecho con no tener cualquiera de estas relaciones?

Muy insatisfecho 1 Algo insatisfecho 2 Satisfecho 
Appendix $\mathbf{J}$

Patient Questionnaire - PHQ-9

English and Spanish Versions 
PATIENT QUESTIONNAIRE - PHQ-9

Patient Name:

Physician:
MRN

Date:

Over the last 2 weeks, how often have you been bothered by any of the following problems?

\begin{tabular}{|c|c|c|c|c|}
\hline & $\begin{array}{l}\text { Not at } \\
\text { all } \\
\text { 0 }\end{array}$ & $\begin{array}{c}\text { Several } \\
\text { days }\end{array}$ & $\begin{array}{l}\text { More than } \\
\text { half the } \\
\text { days } \\
2\end{array}$ & $\begin{array}{c}\text { Nearly } \\
\text { every day }\end{array}$ \\
\hline & & & & \\
\hline 1. Little interest or pleasure in doing things. & $\square$ & $\square$ & $\square$ & $\square$ \\
\hline 2. Feeling down, depressed, or hopeless. & $\square$ & $\square$ & $\square$ & $\square$ \\
\hline 3. Trouble falling/staying asleep, sleep too much. & $\square$ & $\square$ & $\square$ & $\square$ \\
\hline 4. Feeling tired or having little energy. & $\square$ & $\square$ & $\square$ & $\square$ \\
\hline 5. Poor appetite or overeating. & $\square$ & $\square$ & $\square$ & $\square$ \\
\hline $\begin{array}{l}\text { 6. Feeling bad about yourself - or that you are a } \\
\text { failure or have let yourself or your family down. }\end{array}$ & $\square$ & $\square$ & $\square$ & $\square$ \\
\hline $\begin{array}{l}\text { 7. Trouble concentrating on things, such as reading } \\
\text { the newspaper or watching television. }\end{array}$ & $\square$ & $\square$ & $\square$ & $\square$ \\
\hline $\begin{array}{l}\text { 8. Moving or speaking so slowly that other people } \\
\text { could have noticed. Or the opposite - being so } \\
\text { fidgety or restless that you have been moving } \\
\text { around a lot more than usual. }\end{array}$ & $\square$ & $\square$ & $\square$ & $\square$ \\
\hline $\begin{array}{l}\text { 9. Thoughts that you would be better off dead or of } \\
\text { hurting yourself in some way. }\end{array}$ & $\square$ & $\square$ & $\square$ & $\square$ \\
\hline
\end{tabular}

A. How difficult have these problems made it for you to do your work, take care of things at home, or get along with other people?

$\square$ Not difficult at all $\square$ Somewhat difficult $\quad \square$ Very difficult $\square$ Extremely difficult

B. In the past two years have you felt depressed or sad most days, even if you felt okay sometimes? $\square$ Yes $\square$ No

Symptoms

Severity Score

IHC DEP-601 / 8-02 
PATIENT HEALTH QUESTIONNAIRE (PHQ-9)

NOMBRE:

FECHA:

Durante las últimas 2 semanas, ¿cuan qué frecuencia le han molestado los siguientes problemas?

\begin{tabular}{|c|c|c|c|c|c|}
\hline 1 & Tener poco interés o placer en hacer las cosas & 0 & 1 & 2 & 3 \\
\hline 2 & Sentirse desanimado/a, deprimido/a, o sin esperanza & 0 & 1 & 2 & 3 \\
\hline 3 & $\begin{array}{l}\text { Con problemas en dormirse o en mantenerse } \\
\text { dormido/a, o en dormir demasiado }\end{array}$ & 0 & 1 & 2 & 3 \\
\hline 4 & Sentirse cansado/a o tener poca energía & 0 & 1 & 2 & 3 \\
\hline 5 & Tener poco apetito o comer en exceso & 0 & 1 & 2 & 3 \\
\hline 6 & $\begin{array}{l}\text { Sentir falta de amor propio - o que sea un fracaso o } \\
\text { que decepcionara a si mismo/a su familia }\end{array}$ & 0 & 1 & 2 & 3 \\
\hline 7 & $\begin{array}{l}\text { Tener dificultad para concentrarse en cosas tales } \\
\text { como leer el periódico o mirar la televisión }\end{array}$ & 0 & 1 & 2 & 3 \\
\hline 8 & $\begin{array}{l}\text { Se mueve o habla tan lentamente que otra gente se } \\
\text { podria dar cuenta - o de lo contrario, esta tan } \\
\text { agitado/a o inquieto/a que se mueve mucho más de lo } \\
\text { acostumbrado }\end{array}$ & 0 & 1 & 2 & 3 \\
\hline 9 & $\begin{array}{l}\text { Se le han ocurrido pensamientos de que sería mejor } \\
\text { estar muerto/a o de que haría daño de alguna manera }\end{array}$ & 0 & 1 & 2 & 3 \\
\hline \multicolumn{3}{|c|}{ add columns: } & \multicolumn{2}{|c|}{+} & \\
\hline
\end{tabular}

Si usted se identificó con cualquier problema en este cuestionario, ¿cuan difícil se le ha hecho cumplir con su trabajo, atender su casa, o relacionarse con otras personas debido a estos problemas?

Nada en absoluto Algo difícil

Muy difíil

Extremadamente difícil 
Appendix K

Demographic Questionnaire

English and Spanish Versions 
Date:

Time:

Interview Code:

Length of Interview:

\title{
Demographic Questions
}

1) Gender

2) Please tell me which one of the following racial groups do you consider yourself to be.

Are you:

\author{
White/Caucasian (not Hispanic) \\ Black/ African-American (not Hispanic) \\ American Indian/Native American \\ Asian or Pacific Islander \\ Hispanic/Latino (Puerto Rican, Mexican, Latin American, Cuban) \\ Other (Specify) \\ Don't know/Refused
}

3) Where were you born?

4) What is your country of origin?

5) What is your primary language?

6) How old are you?

7) What was the last grade or year of school you completed?

8) Have you ever been married?

9) Are you now single, married, widowed, divorced or separated?

10) Do you have any children?

If so, what are their ages \& gender? 
11) What, if any, is your religious preference?

12) How active do you consider yourself in the practice of your religious preference?

13) Which category best describes your household's total income? Please include income from all sources, including wages or salaries, Social Security, pensions, interests and dividends, rental income, government assistance from all people living in the household if you share income.
A. Less than $\$ 10,000$
B. $\$ 10,000$ to $\$ 20,000$
C. $\$ 20,001$ to $\$ 40,000$
D. $\$ 40,001$ to $\$ 60,000$
E. $\$ 60,001$ to $\$ 80,000$
F. $\$ 80,001$ to $\$ 100,000$
G. $\$ 100,000$ to $\$ 150,000$
H. $\$ 150,001$ or more
(I prefer not to answer)
(Don’t know)

14) How many people are supported by that income, including yourself?

$$
\begin{aligned}
& \text { Number of people (specify number) } \\
& \text { Don't know/Refused }
\end{aligned}
$$

15) Do you plan to move in the next few years?

$$
\text { If yes, where? }
$$

16) Who determined whether caregiving should take place? (Were they asked? Did they volunteer? Was it imposed upon them?)

o When is care provided? 
INTERVIEWER NOTES/ CONTEXT 
Appendix L

Qualitative Interview

English and Spanish Versions 
Date:

Time:

Interview Code:

Length of Interview:

\section{Qualitative Interview Questions}

Now I would like to ask you a few questions about you and your caregiver. I want to know about your relationship. There are no right or wrong answers. It should take us 3045 minutes. I am going to record your answers.

I want to talk to you about three different areas: your relationship with (blank), the roles in your relationship, your independence and your attitudes about aging.

1. First, describe your relationship with How long have you known each other? How long have they been helping you?

2. Can you talk to me about what is it like to have a caregiver?

a. Can you tell me about how you feel/think about having a caregiver?

3. Can you give me some examples of a typical day of when [caregiver] is here?

a. Are there things you would want to change? Give me an example.

4. On a scale from 1 to 5, ( 1 being definitely no and 5 being definitely yes) would you like more from your relationship with [caregiver]

a. What kinds of other things would you desire?

5. Do you feel there are any areas or issues that are problems or difficulties within your relationship?

a. Have you discussed this problem? 

b. Was any action taken to deal with the problem?
c. Was the problem resolved or sorted out?

I'm interested in understanding how you and (your caregiver) function. Often one person affects the other person in the relationship.

6. First I am going to ask, in terms of day-to-day activities, I would like to know who is involved in the following jobs and second, how satisfactorily each job is performed.

Grocery; Shopping; Cooking; Laundry; Cleaning; Yard Work; Monthly Bills; Repairs around the house; Large Purchases; Decisions to see Doctor

7. Do you discuss who is to do various jobs?

a. If no: What stops you?

8. Do any of you feel overburdened by your jobs?

a. If yes: Who feels overburdened?

9. Does anyone feel that they or others are doing too much or too little?

a. Is there any arguing or complaining?

10. Have the roles and jobs changed over the years? How so?

I'm now going to ask you some questions about your independence.

Now tell me a little about how you view your independence or ability to manage on your own.

11. What does independence mean to you? 
12. How would you rate your independence on a scale from 1 to 10 with 1 being not independent at all and 10 being very independent?

13. What is the major impairment or health problem that limits your independence and how long has this impacted you?

Now I want to ask you some questions on how you view the aging process.

14. Many people feel older or younger than they actually are. What age do you feel most of the time?

15. At what age do you consider someone to be old?

16. Can you describe your attitude on aging?

a. What do you think are the best things about growing older? What are the worst things?

b. What are your biggest fears about getting older?

17. Tell me about the types of situations you worry about as you get older. I have no more questions.

Is there something I missed or didn't understand?

I've focused on the three areas: your relationship with (blank), your independence and your attitudes about aging. Is there anything that you would like to add?

INTERVIEWER NOTES/ CONTEXT 
Appendix M

IRB Approvals 


\title{
FIU
}

Office of Research Integrity

\section{MEMORANDUM}

\author{
To: \\ Dr. Barbara Tomlinson \\ CC: \\ Maria Melendez-Vargas, MIBA, IRB Coordinator \\ From: \\ Date: \\ October 4, 2013 \\ Protocol Title: "Predictors of Independent Living Outcomes Among Older Women \\ Receiving Informal Care"
}

The Social and Behavioral Institutional Review Board of Florida International University has approved your study for the use of human subjects via the Expedited Review process. Your study was found to be in compliance with this institution's Federal Wide Assurance (00000060).
IRB Protocol Approval \#:
IRB-13-0407
IRB Approval Date:
$10 / 04 / 13$
TOPAZ Reference \#:
101634
IRB Expiration Date: $10 / 04 / 14$

As a requirement of IRB Approval you are required to:

1) Submit an IRB Amendment Form for all proposed additions or changes in the procedures involving human subjects. All additions and changes must be reviewed and approved by the IRB prior to implementation.

2) Promptly submit an IRB Event Report Form for every serious or unusual or unanticipated adverse event, problems with the rights or welfare of the human subjects, and/or deviations from the approved protocol.

3) Utilize copies of the date stamped consent document(s) for the recruitment of subjects.

4) Receive annual review and re-approval of your study prior to your IRB expiration date. Submit the IRB Renewal Form at least 30 days in advance of the study's expiration date.

5) Submit an IRB Project Completion Report Form when the study is finished or discontinued.

Special Conditions: N/A

For further information, you may visit the IRB website at http://research.fiu.edu/irb. 


\section{FIU] UNIVERSITY}

Office of Research Integrity

\section{MEMORANDUM}

To:

$\mathrm{CC}$ :

From:

Date:

Proposal Title:
Dr. Barbara Thomlison

File

Maria Melendez-Vargas, MIBA, Coordinator

January 24,2014

"Predictors of Independent Living Outcomes Among Older Women Receiving Informal Care"

Approval \# IRB-13-0407

Reference \# 101634

The Social and Behavioral Institutional Review Board has approved the following modification(s):

- Addition of one key personnel (Yamely Gonzalez - Spanish translator)

There are no additional requirements in regards to your study. However, if there are further changes in the protocol after you commence your study, then you are required to resubmit your proposal for review. As a reminder, you are still required to receive annual review and reapproval prior to your expiration date of October 4, 2014. For further information, you may visit the FIU IRB website at http//research.fiu.edu/irb 


\section{FIUU |}

Office of Research Integrity

\section{MEMORANDUM}

To:

$\mathrm{CC}$ :

From:

Date:

Proposal Title:
Dr. Barbara Thomlison

File

Maria Melendez-Vargas, MIBA, Coordinator

April 15, 2014

"Predictors of Independent Living Outcomes Among Older Women Receiving Informal Care"

Approval \# IRB-13-0407

Reference \# 101634

The Social and Behavioral Institutional Review Board has approved the following modification(s):

- Added a Spanish speaking population for the qualitative interview data collection process. The current protocol is approved for English speaking population for quantitiatve and qualitiative data collection process. The current protocol is also approved for Spanish speaking population for the quantiatitive data collection process.

- Added consent forms for this population.

There are no additional requirements in regards to your study. However, if there are further changes in the protocol after you commence your study, then you are required to resubmit your proposal for review. As a reminder, you are still required to receive annual review and reapproval prior to your expiration date of October 4, 2014. For further information, you may visit the FIU IRB website at http://research.fiu.edu/irb. 


\section{Appendix N}

IRB Training Certificates for Research Staff 


\section{COLLABORATIVE INSTITUTIONAL TRAINING INITIATIVE (CITI) RESPONSIBLE C ONDUCT OF RESEARCY CURAICULUM COMPLETION REP ORT Finted on 0.082013}

\begin{tabular}{|c|c|}
\hline LEA RNER & Julie Grochowski (ID: 1436723) \\
\hline PHONE & 305-962-8T 18 \\
\hline EMAIL & Igrocoulgnisedi \\
\hline INSTITUTON & Forite in te natoral Un ue rs its \\
\hline
\end{tabular}

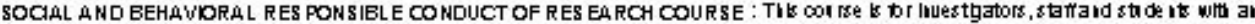

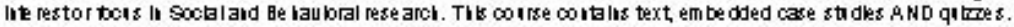

\begin{tabular}{|c|c|}
\hline COURSESTAG E: & $R C R / 1$ \\
\hline PASSEDON: & $11 / 01 / 2009$ \\
\hline REFERENCE ID: & 3613441 \\
\hline
\end{tabular}

REQUIRED MODULES

The Cmiconse it the Resporsble Condictor Research

In trodictor to the Respons ble Conduct or Reseact

In trodictoi b Rese anch usconduct

Rese anch uscoiduct (RCR-SBE)

Case Sthdr-Truth orConsequelces (RCR-P hys lcalscle uces)

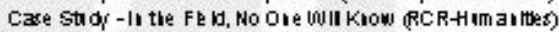

Case stidi Pbglism (RCR-SBE)

Case stod no News s notG ood News (RCR-SB E)

Data Mar agemert (RCR-SiE)

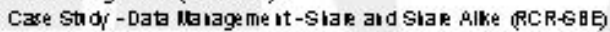

Case stod -Data Uarageme it Who Ows Reseach Dat? (RCR-SBE)

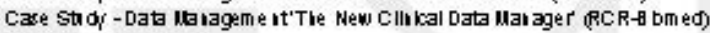

Anthors HP (RCR-SB E)

Resporsble Authorsip - The Chalr as as Anthor (RCREgE)

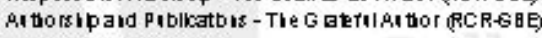

Peer Reulew (RCR-G日E)

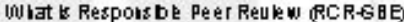

Peer Reulew and Con troue solReseach (RCR-SBE)

Responsble Meitoring $01-1625$

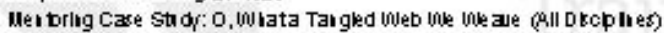

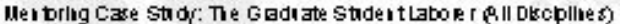

Mei bring Case stadr: She mys Secet (e.ll D scplwes)

Mel bring Case stadr: Ltea a ach' Case (RCR-Blomed)

Meibring Case stodr: The bisitess of Mei bring (RCR-Blomed)

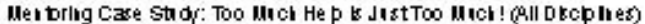

Con nits of lite rest (RCR-GBE)

Col Case Sthd - The Case of the P oming New Techology (RCR-SBE)

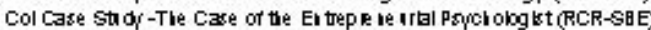

Col Case Stud-Janets S usptions (RCR-SB E)

Colboratue Research (RCR-SB E)

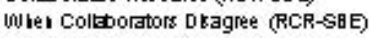

IN Wh Cart ine All JistGe tobig (RCR-S日E)

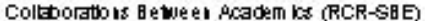

IN hel Coltworators be come Compettors (RCR-SBE)

Maritge Has its aduan bges (RCR-SB

The CII RCR Cou ae Completbu Page

\begin{tabular}{|c|c|}
\hline QMLTE COMPLETED & SCORE \\
\hline 10.0609 & NoO it \\
\hline 10.0609 & NoQ it \\
\hline 10.0609 & NOQIE \\
\hline 10/1609 & $5 \sqrt{6}(8)$ \\
\hline 10/1609 & $55(100 \%)$ \\
\hline 10/1609 & $3 \sqrt{3}$ (100\%) \\
\hline 10/1609 & $33(100 \%)$ \\
\hline $10 / 1609$ & Wh (100 $x)$ \\
\hline $10 / 17.09$ & w5 (ख्य) \\
\hline $10 / 17.09$ & $3 \sqrt{3}(100 x)$ \\
\hline 10/17.09 & $3 \sqrt{3}(100 \%)$ \\
\hline $10 / 17.09$ & NoQIt \\
\hline 10/1809 & 55 (100\%) \\
\hline 10/1809 & $2 / 2(100 \%)$ \\
\hline 10/1809 & 55 (100\%) \\
\hline 10/1809 & $5 / 5(100 \%)$ \\
\hline 10/1809 & w5 (व) \\
\hline 10/1809 & $2 / 2(100 \%)$ \\
\hline 10/1809 & $6 / 6(100 \%)$ \\
\hline 10/1809 & Wh (100\%) \\
\hline 10/1809 & Wh (100\%) \\
\hline 10/4809 & Wh (100's) \\
\hline 10/1809 & $3 \sqrt{3}(100 x)$ \\
\hline 10/1809 & $34(75 \%)$ \\
\hline 10/1809 & $3 \sqrt{3}(100 \%)$ \\
\hline $10 / 2409$ & 56 (83\%) \\
\hline $10 / 2409$ & $88(100 \%)$ \\
\hline $10 / 2409$ & $3 \sqrt{3}(100 x)$ \\
\hline $10 / 2$ 409 & $1 / 1$ (100 $x)$ \\
\hline $10 / 2909$ & $516(3 \%)$ \\
\hline $10 / 2909$ & $3 \sqrt{3}(100 x)$ \\
\hline $10 / 2909$ & $3 \sqrt{3}(100 x)$ \\
\hline 11.01 .09 & Wit (100 $x)$ \\
\hline 11.01 .09 & $3 \sqrt{3}(100 x)$ \\
\hline 11.01 .09 & $2 / 2(100 x)$ \\
\hline 11.01 .09 & NoQIE \\
\hline
\end{tabular}

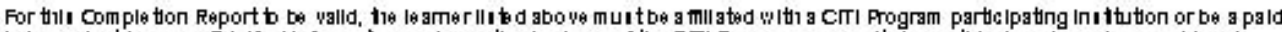

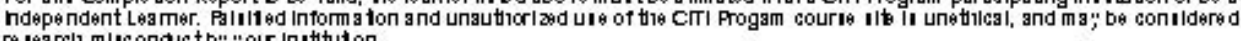
re les reli miconduc tb; ; our Inittition 
For til I Comple tion Report b be valld, the le ame rilled above muit be a millatad with a CrTI Program participating Initution or be a pald

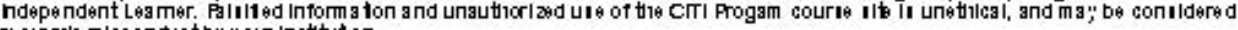
re learcli mliconduc tb; ; our Inittution

Pall Bauschwelge r P I.D.

Protessor, un vershy or Mami

Dlectorotice of Rese anch Edicatb

Crip ogram Cou re Coondiabr 


\section{COLLABORATIVE INSTITUTIONAL TRAINING INITIATIVE (CITI) BAS ICIREFRESHER C OURSE - YUMAN SURJECTS RESEARCH CURRICULUM C OMTLETION REFORT Finted on 0.082013}

\begin{tabular}{|c|c|}
\hline LEA RNER & Julie Grochowski (ID: 1436723) \\
\hline PHONE & $305-962-8118$ \\
\hline EMÁIL & Igrocolo1 Git edı \\
\hline INSTTUTON & Forkte interiatoral Un vers if \\
\hline EX PIRATTON LATE & ㅁ..07.2016 \\
\hline
\end{tabular}

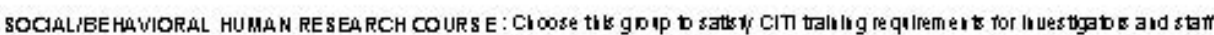

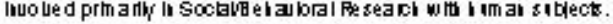

$\begin{array}{ll}\text { COURSESTASE: } & \text { 日askCOIse/1 } \\ \text { PASSEDON: } & \text { [0.082013 } \\ \text { REFERENCE ID: } & 5270254\end{array}$

REFRENCE ID:

\begin{tabular}{|c|c|c|}
\hline REQUIRED MODULES & DMTE COMPLETED & SCORE \\
\hline Be mout Report andcriconrse Intoductor & ㅁ.908/13 & $3 \sqrt{3}$ (100\%) \\
\hline Heby and Eth baI Princples - SBE & 09.0813 & w5 (ख) \\
\hline Dentig Beseacl with HImas Siblect -SBE & $09.08 / 13$ & $3 / 5(\mathbb{1})$ \\
\hline The Regutatbis - S日E & [09.08/13 & $5 / 5$ (100\%) \\
\hline Assesslig Rtsk-SBE & {$[9.08 / 13$} & $35(\mathbb{1})$ \\
\hline It tomed Couse it - SBE & {$[0.08 / 13$} & $45(x)$ \\
\hline Pruagy and Con nde ittehy-SBE & [0.08/13 & $45(2)$ \\
\hline Rese arch with Prtaters - S日E & ㅁ.08/13 & $3 /(15 \%)$ \\
\hline Rese arch with chldre I - S日E & {$[0.08 / 13$} & $W 4(100 \%)$ \\
\hline Rese anch in PIblc Eleme Itay andSecorday schook - SBE & $09.08 / 13$ & $w 4(100 x)$ \\
\hline It E ruatoral Rese anch - SBE & [09.0813 & $3 / 3(100 x)$ \\
\hline It the t Re seanch - SBE & ㅁ.9.0813 & $35(\mathbb{1})$ \\
\hline Cuth alcompe tice it Reseanci & ㅁ.08/13 & $45($ (口) \\
\hline
\end{tabular}

For tili Comple tion Report b be valld, t1e le ame rllited above muitbe a millated with a CrrI Program participating Initution or be a pald

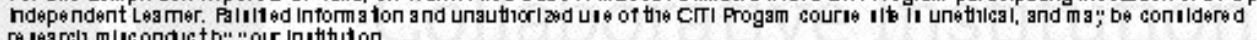
re learcli misconduct to; ; our Inititution

Paul uauschuelge ipr.D.

Protessor, Un teers iny or Mam

DiR cbrotice of Rese arch Edu catb

Cri p ogram coure coordiabr 


\section{COLLABORATIVE INSTITUTIONAL TRAINING INITIATIVE (CITI) RESFONSIBLE C ONDUCT OF RESEARCH CURRICULUM COMFLETION REF ORT Fintei on 0/23/2013}

\begin{tabular}{|c|c|}
\hline LEA RNER & $\begin{array}{l}\text { Barbara Thomlison (ID: } 3762783 \text { ) } \\
11200 \text { SW' ' \&th Street. } \\
\text { Green Librany Foom } 489 \\
\text { Mami } \\
\text { Forida } 33199 \\
\text { US }\end{array}$ \\
\hline DEPARTMENT & Soceluluork \\
\hline PHONE & 303346045 \\
\hline EMAIL & 11200sin sth ste et, MamI, FI, 33199 \\
\hline INSTTUTON & 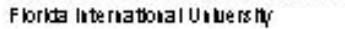 \\
\hline EX PIRATTON DMMTE & \\
\hline
\end{tabular}

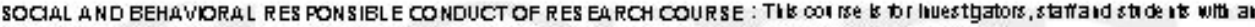

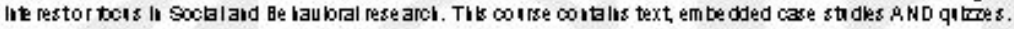

COURSESTAGE: RCR/1

PASSEDON: $\quad$ [O/23/2013

REFERENCE ID: $\quad 11322 \pi 23$

REQUIRED MODULES

The Criconse it the Responsble Conductor Research

In troductor to the Respors ble Conduct of Re seaci

Rese anch Mtscordict (RCR-SBE)

Case Sthd -Truth or Conse que lose (RCR-P hys lcal scle uces)

Case stad - II the Fe id, No Ore (n)lI Kuow (RCR-Humalthes)

Care Sthd Pagantem (RCR-S日E)

Case Sthd no News s notGood News (RCR-SB E)

Dat Mar agemert (RCR-S日E)

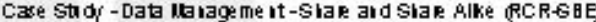

Case stud -Date llabgeme it Who Ows Re seach Data? (RCR-SBE)

Case stu of - Data Uarageme it'The New Cin ical Data Mar ager (RCR-A bmed)

An thors IP (RCR-SBE)

Resporsble A thorstp - The Chalr as al Anthor (RCR-G日E)

An thorsipand Publcatbus - The G atetula thor RCR-GBE

Peer Reukw (RCR-G

UN lat s Respousbe Peer Reulew (RCRe日e)

Peer Reulew and Con troue s alReseach (RCR-SBE)

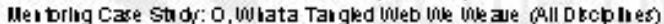

Mer bring Case stod: The Gaduate Stude I Labor r (ell otepilles)

Meibring Case stodr: She mys Secet (s.ll D scpines)

Me t bring Case stadr: Lka 日 ach's Case RCR-Bbme d

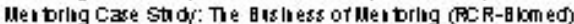

Mei bring Case studr: Too Mich He p s Jist To Mich ! (QIll Dkcphes)

Using aimals ablect in Reseach (RCR-literdscpiliai)

Con nitsts of lite rest (RCREBE)

Col Case stad-The Case of the P omsing New Techology (RCR-SBE)

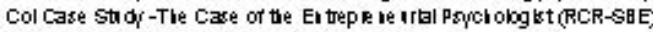

Col Case stod-Janets Sisptions (RCR-SB E)

Coltsorathe Research (RCR-SBE)

Whe coltaorators Dragree (RCR-SBE)

Wurycar tule All JistGe tabig (RCR-SBE)

Coltsoratois betweer academ las (RCR-SBE)

thi hel Collaborators be come Compettors (RC R-SBE)

Marritage Has lts dodual tages (RCR-SB E)

Rese anch I uo ulig Huma sitle ct (RCR-Inte ralscpilıay)

The CTI RCR Coi se Completbi Page

\begin{tabular}{|c|c|}
\hline DATE COMPLETED & SCORE \\
\hline ㅁ/18/13 & NoOIt \\
\hline [0/18/3 & NoQ It \\
\hline [09/1813 & $5 / 5$ (100\%) \\
\hline 며/22/13 & 33 (100 $x)$ \\
\hline$[0 / 22 / 13$ & $3 \sqrt{3}$ (100 $x)$ \\
\hline$[0 / 22 / 13$ & $2 / 2$ (100 $x)$ \\
\hline 며:22/13 & $3 \sqrt{3}$ (100\%) \\
\hline 며:22/13 & $5 / 5$ (100\%) \\
\hline$[0 / 22 / 13$ & $3 \sqrt{3}$ (100 $x)$ \\
\hline 며/22/13 & $3 \sqrt{3}$ (100 $\%)$ \\
\hline 묘:22/13 & NoQitr \\
\hline 묘/2/13 & $5 / 5$ (1002) \\
\hline 묘:22/13 & $2 / 2$ (100 \\
\hline 며/22/13 & $5 / 5$ (100 \\
\hline 묘:22/13 & $5 / 5$ (100\%) \\
\hline 묘:2313 & wh (100s) \\
\hline$[9 / 23 / 13$ & $3 \sqrt{3}(100 \%)$ \\
\hline Da/23/13 & wa (100\%) \\
\hline D9/23/13 & $3 \sqrt{3}$ (100 $x)$ \\
\hline$[9 / 23 / 13$ & wa (100 $x)$ \\
\hline 요2313 & $3 \sqrt{3}$ (100 \\
\hline 며:23/13 & $N 4(100 \%)$ \\
\hline 며:23/13 & $3 / 3$ (100 \\
\hline 며:23/13 & $5 / 5$ (100\%) \\
\hline$[09 / 23 / 13$ & $6 / 6$ (100\%) \\
\hline ㅁ9/23/13 & $w(100 \%)$ \\
\hline ㅁ9/23/13 & $3 / 3(100 \%)$ \\
\hline ㅁ9/23/13 & $w 4(100 x)$ \\
\hline$[09 / 23 / 13$ & $5 / 5$ (100\%) \\
\hline$[09 / 23 / 13$ & $3 \sqrt{3}(100 \%)$ \\
\hline 며/23/13 & $3 / 3(100 \%)$ \\
\hline 며:23/13 & $w 4(100 \%)$ \\
\hline$[0,23 / 13$ & $3 / 3$ (100x) \\
\hline 며:23/13 & $2 / 2$ (100\%) \\
\hline 며:23/13 & 515 (100\%) \\
\hline 며:23/13 & NoQIt \\
\hline
\end{tabular}


For til I Comple tion Report b be valld, the le ame rilled above muit be a millatad with a CrTI Program participating Initution or be a pald

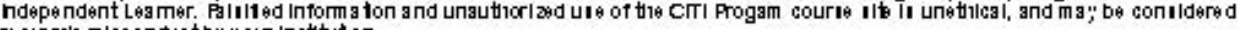
re learcli mliconduc tb; ; our Inittution

Pall Bauschwelge r P I.D.

Protessor, un vershy or Mami

Dlectorotice of Rese anch Edicatb

Crip ogram Cou re Coondiabr 
COLLABORATIVE INSTITUTIONAL TRAINING INITIATIVE (CITT) BAS IC FETRESHER C OURSE - YUMUN SUBJECTS RESEARCH CURRTCULUM C OMTLETION REPORT Buited en 12/3/2013

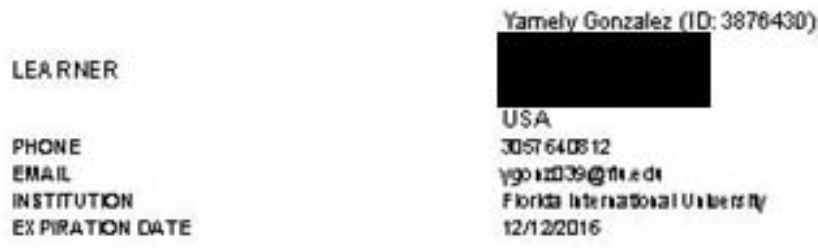

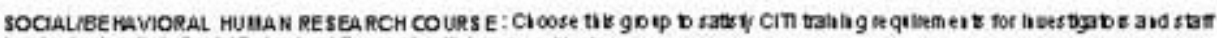
lavobed perm atty h Soctabetiabral Pe reaci wis i ina siblect.

COURSESTAOE: BaskCouse

PASSEDON: $12 / 132013$

REFEREACE ID: 11792971

REQUIRED HODULES

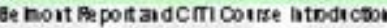

Cin alcompe tice it Retezici

Histopard Es talprichks - SaE

Defing Rereaci win Hinaı Sablect - SHE

The Regtztbus - SAE

Astessing REK - SaE

lo tom ed Coure it - SHE

pruagrand Cou no ittan -SAE

Researci w is Preosess - SaE

Refe arci w in Clidrer - SeE

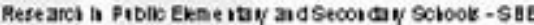

G enatbaal Rase anci - SBE

a ene tre reanch - SBE

\begin{tabular}{|c|c|}
\hline DATE COMPLETED & SCORE \\
\hline $12 \pi 1 / 13$ & $3 \sqrt{3}(100 x)$ \\
\hline $12 / 21 / 13$ & SNS (100x) \\
\hline $12 / 1 / 13$ & s/s (adon) \\
\hline $12 \pi 213$ & SNS (100x) \\
\hline $12 / 2 / 3$ & SNS (1002) \\
\hline $12 / 12 / 3$ & $5 / 5$ (100x) \\
\hline $12 / 1213$ & $5 / 5(000 x)$ \\
\hline $12 \pi 213$ & S/S (atax) \\
\hline $12 \pi 2 / 3$ & w/ (c00x) \\
\hline $12 \pi 313$ & Wi ( \\
\hline $12 / 13 / 13$ & $w /($ (100x) \\
\hline $12 \pi 3 / 3$ & $3 \sqrt{3}$ (100x) \\
\hline $12 \pi 3 / 13$ & $3 / 5(20 \%)$ \\
\hline
\end{tabular}

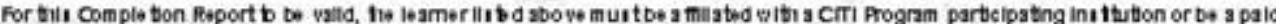

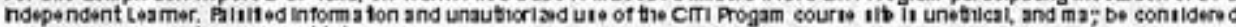
nowe urech misconase tb; ; our inititution

Paula anciwe ber PI. 0 .

Picatbi

crrip bgran coutse Cootolat 


\section{COLLABORATIVE INSTITUTIONAL TRAINING INITIATIVE (CITI) BAS IC REFRESHER C OURSE - KUMAN SUBJECTS RESEARCH CURRICULUM C OMFLETION REPORT Finted on 0.09 /2013}

\begin{tabular}{|c|c|}
\hline LEA RNER & Erica Lara (ID:3729538) \\
\hline PHONE & 乃05-758-m21 \\
\hline EMAIL & e日em4Ggmallom \\
\hline INSTITUTON & 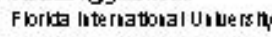 \\
\hline EX PIRATTON DMTE & ㅁ.982016 \\
\hline
\end{tabular}

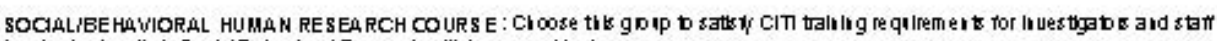

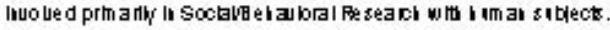

$\begin{array}{ll}\text { COURSES TASE: } & \text { BaskCourse/1 } \\ \text { PASSEDON: } & \text { DQ.092013 } \\ \text { REFERENCE ID: } & 11223649\end{array}$

REQUIRED MODULES

Be mort be port andcriconse Irtodictor

Hebry and Eth bal Priccles - SBE

Deiling Reseaci with Huma Siblect - SBE

The Regitatbis - S日E

assessing Rtsk - SBE

It omed Corse it -SBE

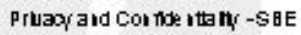

Rese anch with Prtsolers - SBE

Rese arch with Chlldre $-\mathrm{SBE}$

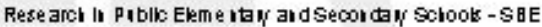

It e ruatou al Rese arch - SAE

It the the search - SBE

Culth alcompe to ice it Reseanct

\begin{tabular}{|c|c|}
\hline DMTE COMPLETED & SCORE \\
\hline ㅁ.9.09/13 & $3 \sqrt{3}(100 \%)$ \\
\hline $09.09: 13$ & $5 / 5$ (100\%) \\
\hline $09.09 / 13$ & $5 / 5$ (100\%) \\
\hline $09.09 / 13$ & $5 / 5$ (100\%) \\
\hline $09.09 / 13$ & $5 / 5$ (100\%) \\
\hline $09.09: 13$ & $5 / 5$ (100\%) \\
\hline $09.09 / 13$ & $5 / 5$ (100\%) \\
\hline Do.09/13 & $w(100 x)$ \\
\hline [0.09813 & $w 4(100 \%)$ \\
\hline [0.0913 & wh (100 $s)$ \\
\hline [0.0913 & 33 (100 \\
\hline [0.0913 & $5 / 5$ (100 $x)$ \\
\hline [9.0913 & $1 / 5(2 x)$ \\
\hline
\end{tabular}

For thil comple tion Report b be valld, the le ame rilıted above muitbe a mil ated with a CrTI Program participating Initution or be a pald ndependent Lesmer. Palil1 ed Inform a ton and unauthorlasd ule of the CrTI Progam courie ile li unetilcal, and ma"; be conildered re leareli milic onduct tb; ; our Inititut on

Pall gurschueber Pr.D.

Protessor, Un the rsity or Maml

DiR cbrothoe of Rese arch Edı catb

CITI p ogram Cou rse Coordiator 
VITA

\section{JULIE ANN GROCHOWSKI}

2008

B.A., Social Work

Camden College of Arts and Sciences

Rutgers, The State University of New Jersey

Camden, New Jersey

2008

Phi Alpha Honor Society

$\mathrm{Nu}$ Omicron Chapter

2009

Dissertation Evidence Acquisition Fellowship

Florida International University

2009

M.S.W., Social Work

School of Social Work

Rutgers, The State University of New Jersey

New Brunswick, New Jersey

2009-present

Doctoral Candidate in Social Welfare

School of Social Work

Florida International University

Miami, Florida

\section{PUBLICATIONS AND PRESENTATIONS}

Gammonley, D. \& Grochowski, J. (in press). Older adults, families and life stressors. In B. Thomlison. Family assessment handbook: An introduction and practical guide to family assessment ( $4^{\text {th }}$ ed). Pp XX-XX. Belmont, CA: Brooks/Cole.

Grochowski, J. \& Thomlison, B. (2014). Interventions to improve physical and psychosocial outcomes among older adults: A critical review. Poster presented at the 2014 Annual Conference of the American Society on Aging: Aging in America. San Diego, CA. March 2014.

Grochowski, J. \& B. Thomlison. (2013). Predictors of independent living outcomes among older women receiving informal care: Results of a pilot study. Poster presented at 
the Exhibit Session at Third Aging and Society: An Interdisciplinary Conference.

Chicago, IL. November 2013.

Ruggiano, N., Shtompel, N., Hristidis, V., Roberts, L., Grochowski, J. \& E. Brown. (2012). Need and potential use of information technology for case manager-physician communication in home care. Home Health Care Management \& Practice, 24(6), 292297. 